TESIS PARA OPTAR AL TÍTULO DE MAGISTER SCIENCIAE EN MANEJO INTEGRAL DE CUENCAS HIDROGRÁFICAS

Facultad de Ciencias Agrarias y Forestales

Universidad Nacional de La Plata

\title{
ESTADO Y PROPUESTA DE MANEJO DE LOS RECURSOS NATURALES DE LA CUENCA DEL ARROYO GRANDE, TIERRA DEL FUEGO.
}

\author{
TESIS PARA OPTAR AL TÍTULO DE MAGISTER SCIENCIAE EN MANEJO \\ INTEGRAL DE CUENCAS HIDROGRÁFICAS
}

Tesista: Ing. Forestal Juan Manuel Cellini

Cátedra de Biometría Forestal - Edificio de Bosques.

Facultad de Ciencias Agrarias y Forestales, Universidad Nacional de La Plata. CC. 31 La Plata (1900) Argentina.

jmc@ceres.agro.unlp.edu.ar

Director: Mg. Sci. Gerardo Denegri, (Universidad Nacional de La Plata, Facultad de Ciencias Agrarias y Forestales)

Codirector: Mg. Sci. Guillermo Martínez Pastur, (Centro Austral de Investigaciones Científicas - CONICET)

Instituciones participantes:

Universidad Nacional de La Plata, Facultad de Ciencias Agrarias y Forestales

Centro Austral de Investigaciones Científicas (CONICET)

La Plata, Buenos Aires

Noviembre de 2005

Argentina 


\section{INDICE}

Prefacio.

Título, resumen, palabras clave y título abreviado.

Título en inglés, summary y key words.

1. Introducción.

1.1. Marco Teórico.

1.2. Hipótesis.

1.2.1 Planteo del problema.

1.2.2. Hipótesis.

1.3. Objetivos.

2. Morfometría y vegetación de la $C A G$.

2.1. Introducción.

2.2. Materiales y métodos.

2.2.1. Caracterización morfométrica de la cuenca.

2.2.1.1. Parámetros de forma

2.2.1.2. Parámetros de relieve

2.2.1.3. Parámetros de la red hidrográfica.

2.2.2. Clima e hidrografía.

2.2.3. Geomorfología y suelos.

2.2.4. Vegetación.

2.3. Resultados.

2.3.1. Caracterización morfométrica de la cuenca.

2.3.1.1. Parámetros de forma.

2.3.1.2. Parámetros de relieve.

2.3.1.3. Parámetros de la red hidrográfica.

2.3.2. Clima e hidrografía.

2.3.3. Geomorfología y suelos.

2.3.4. Vegetación.

2.4. Discusión.

3. Uso de la tierra e impacto.

3.1. Introducción

3.2. Materiales y métodos

3.3. Resultados

3.3.1. Uso pasado de los recursos naturales

3.3.2. Uso actual de los recursos naturales e impactos

3.3.2.1. Ganadería

3.3.2.2. Aprovechamiento forestal

3.3.2.3. Explotación de turba

3.2.4. Turismo

3.2.5. Especies exóticas

3.3. Discusión

4. Zonificación y propuestas de manejo de ganadería, turismo y turberas.

4.1. Introducción

4.2. Materiales y métodos

4.3. Resultados

4.3.1. Zonificación

4.3.2. Producción pecuaria

4.3.3. Turismo

4.3.4. Explotación de turberas

4.3.5. Conservación de áreas protegidas

4.4. Discusión

5. Propuesta de manejo forestal

5.1. Introducción 
5.2. Materiales y métodos

5.2.1 Modelos incluidos en el Modelo de Producción de Nothofagus

5.2.2 Supuestos del Modelo de Producción de Nothofagus

5.2.3. Sistema silvícola seleccionado

5.2.4. Estimación de la pérdida actual y potencial de suelos por erosión

5.3. Resultados

5.3.1. Modelo silvícola

5.3.2. Posibilidad

5.3.3. Alternativas de turno

5.3.4. Riesgo erosivo

5.4. Discusión

6. Conclusiones

7. Agradecimientos

8. Bibliografía

9 Fotos, tablas y gráficos

10 Mapas 


\section{PREFACIO}

Esta Tesis es presentada como requisito para optar al Grado de Magister en Manejo de Cuencas Hidrográficas de la Facultad de Ciencias Agrarias y Forestales de la Universidad Nacional de La Plata, siendo ésta inédita. La misma contiene resultados logrados durante los años 2002 al 2004, bajo la dirección del Mg. Sci. Gerardo Denegri, (FCAyF - UNLP) y co-dirigida por el Mg. Sci. Guillermo Martínez Pastur, (CADIC-CONICET).

Juan Manuel Cellini 


\section{TITULO}

Estado y propuesta de manejo de los recursos naturales de la cuenca del Arroyo Grande, Tierra del Fuego.

\section{RESUMEN}

Los análisis morfométricos realizados en la cuenca del Arroyo Grande indican que la misma tiene forma alargada, oval y oblonga, con pendientes abruptas en las cabeceras y moderadas en la zona de valle y desembocadura, con una superficie de 129,5 km² $^{2}$ La vegetación esta compuesta por pastizales, turberas y bosques de Nothofagus pumilio y $N$. betuloides factibles de ser aprovechados comercialmente. La cuenca presenta una degradación de los ambientes naturales debido al impacto de especies exóticas, el aprovechamiento forestal no planificado y el turismo no regulado. Los principales problemas encontrados son la falta de planificación en el uso del suelo y la falta de manejo en áreas naturales frágiles. A través de una ordenación en la cuenca, se analizaron alternativas de manejo para aumentar la eficiencia de las actividades productivas tradicionales. Es necesaria la exclusión del ganado, debido al impacto sobre la regeneración del bosque y a la introducción de especies exóticas, concentradas en los sitios de pastoreo. Asimismo se propone la utilización del método de retención dispersa y agregada para el manejo forestal, siendo su objetivo principal mantener la biodiversidad del bosque dentro de niveles aceptables, logrando una posibilidad de 1.082,2 $\mathrm{m}^{3} / \mathrm{año}$, siendo suficiente para abastecer un aserradero. Se plantea el ordenamiento de la actividad turística y el restablecimiento de las funciones del ecosistema de turberas explotadas mediante técnicas de recuperación específicas.

\section{PALABRAS CLAVE}

Manejo de cuencas hidrográficas, zonificación, manejo forestal, recuperación de ecosistemas, turismo.

\section{TÍTULO ABREVIADO}

Manejo de los recursos naturales en la cuenca del Arroyo Grande. 


\section{TÍTULO EN INGLÉS}

Present state of Arroyo Grande basin, Tierra del Fuego. A natural resources management proposal

\section{SUMMARY}

The Arroyo Grande catchment is a mountain catchment with an area of 129.513 $\mathrm{km}^{2}$, which unloads its waters in the Beagle channel. The vegetation is composed by grasslands, peat bogs and $N$. pumilio and $N$. betuloides forests. The present land use generates a degradation of natural environments due to the browsing by cattle, the presence of Castor canadensis, and nonregulated forest use and tourism. The main problem in the river catchment is the lack of planning in the land use and in the management of the fragile natural areas. The present state of the vegetation and the impact agents were identified. Management alternatives were analyzed to increase the efficiency of traditional productive activities. The exclusion of cattle is proposed, due to the deterioration of soil, the impact on regeneration and the amount of exotic species detected in grazed grasslands. Also the use of the aggregated and disperse retention cut system was proposed for forest management, since its primary objective is to maintain forest biodiversity within acceptable levels, obtaining a possible yield of $1082.29 \mathrm{~m}^{3} / a n ̃ o$, which is enough to supply a sawmill in the zone. Finally, this project proposes the correct regulation of tourist activity and the reestablishment of the peat bog ecosystem functions through recovery techniques.

\section{KEY WORDS}

watershed management, zonification, ecosystem recovery, tourism, conservation 


\section{INTRODUCCIÓN}

La Provincia de Tierra del Fuego, Antártida e islas del Atlántico Sur corresponde al sector argentino de la isla de Tierra del Fuego, tiene una superficie de $21.500 \mathrm{~km}^{2}$, y fue constituida como tal por Ley $N^{\circ} 23.775$ en 1990. La población de la isla se concentra principalmente en dos núcleos urbanos: la ciudad de Ushuaia, capital de la provincia y con una población de 45.430 habitantes, y la ciudad de Río Grande con 52.681 hab. (INDEC, 2001). La población rural de la provincia presenta una densidad de $0,08 \mathrm{hab} / \mathrm{km}^{2}$. La conformación por edades es particularmente interesante, ya que la mitad de la población de esta provincia son niños y jóvenes, denotando la necesidad de la población de áreas protegidas para esparcimiento (APN, 2003a).

Los recursos naturales en Tierra del Fuego constituyen la base de las actividades económicas de la Isla, siendo la extracción forestal, la pesca, la extracción de turba, la ganadería y el turismo las principales actividades. El sector forestal de la isla de Tierra del Fuego ha alcanzado un desarrollo importante con buenas perspectivas para el futuro. La explotación predominante en Tierra del Fuego hasta el año 1994 era aprovechando sólo los árboles con alto potencial maderero, inconcebible en el contexto del manejo sustentable (Mosqueda, 1995). Para optimizar el manejo del bosque, las autoridades provinciales promovieron sistemas de cortas de protección, dando como resultado un mejoramiento de los índices de aprovechamiento (Martínez Pastur, 1999). Hasta aproximadamente 1960, la ganadería fue la principal actividad de Tierra del Fuego, coexistiendo con una industria maderera incipiente. Las explotaciones ganaderas de la zona son por lo general de carácter extensivo y monoproductor. Se cultivan hortalizas como lechugas (Lactuca sativa L.), remolachas (Beta vulgaris L.), zanahorias (Daucus carota L.), papas (Solanum tuberosum L.) y los frutales como frambuesas (Rubus idaeus L.), grosellas (Ribes sativum (Rchb.) Syme) y frutillas (Fragaria vesca L.), principalmente en la zona periférica de la ciudad de Río Grande y Ushuaia. Las principales extracciones mineras en la provincia son el material para la construcción e infraestructura vial, gas, petróleo y turba. En lo que respecta a la producción de turba en Tierra del Fuego, se extraen un promedio anual de $4.500 \mathrm{~m}^{3}$, siendo la Provincia de Buenos Aires el principal destino, donde es empleada en su mayor parte como componente de sustrato para cultivo.

Tierra del Fuego es un destino turístico por excelencia, principalmente visitado por turistas extranjeros, adquiriendo importancia el ecoturismo, ya que el lugar se destaca por sus bellezas escénicas y ambientes prístinos. El número de personas que visitaron la ciudad entre septiembre de 2004 hasta septiembre de 2005 fue de 153.852, con un incremento del 12,5\% comparando con la temporada 2003 - 2004 
(Secretaría de Turismo de la Municipalidad de Ushuaia, 2005a). El desarrollo de la actividad turística se funda en una actividad productiva que, bien planteada e implementada, puede generar ingresos genuinos y puestos de trabajo, sin dar lugar a conflictos intersectoriales estableciendo una relación armónica con la población local.

La Cuenca del Arroyo Grande (CAG), se encuentra en el Dto. de Ushuaia, al sur de la provincia y está caracterizada por un relieve montañoso y bosques de Nothofagus sp. (Nothofagaceae) muy atractivos para el turismo local, nacional e internacional (Figura 1). Por su posición y relieve, se trata de una cuenca de montaña, descargando sus aguas en el canal de Beagle con un valle de dirección predominante oeste-este. El tamaño de la cuenca es cercano a los $175 \mathrm{~km}^{2}$ con una longitud máxima O-E de $20 \mathrm{~km}$ y N-S de $10 \mathrm{~km}$. Dentro de la CAG se encuentra una gran cantidad de atractivos turísticos por su belleza y por la accesibilidad a los mismos.

Figura 1. Localización general de la Cuenca del Arroyo Grande.

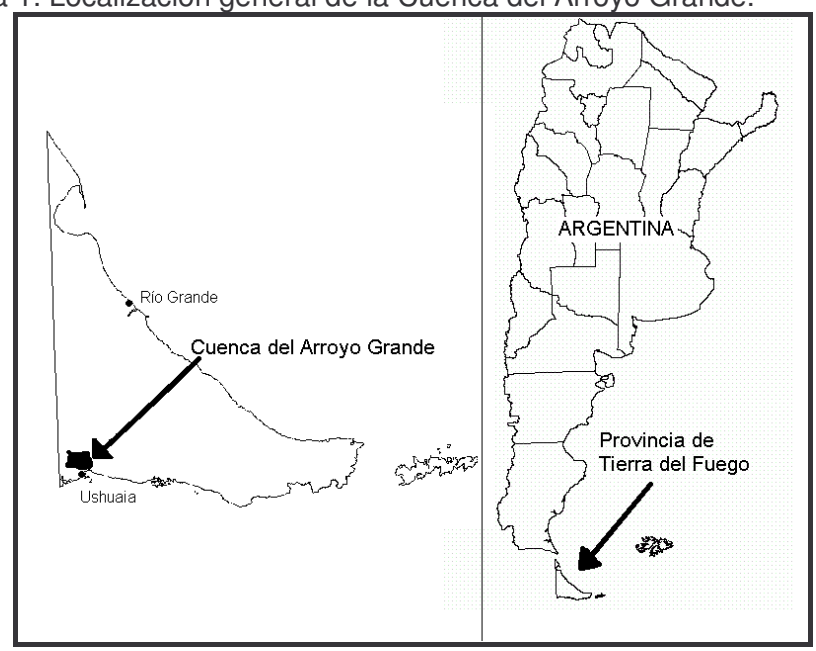

Los principales problemas que se encuentran en la región son la concentración de áreas de uso intensivo, el desarrollo urbano, la falta de planificación en el manejo de las áreas naturales especialmente frágiles, la falta de control en el acceso a determinados sitios y la falta de infraestructura adecuada (Otero, 1997). El bosque de la parte baja de la cuenca presenta la menor cobertura, e incluso partes fueron talados y quemados, lo que originó el desarrollo abundante de calafate (Berberis buxifolia Lam.). También se observa abundante presencia de renovales de Nothofagus pumilio (Poepp. et. Endl.) Krasser (lenga) desarrollados en forma arbustiva debido a la acción del ganado vacuno. El asentamiento poblacional determinó la desaparición parcial de la cobertura vegetal de la zona de la desembocadura del arroyo (Fernández, 1993).

Se presentó ante el Consejo Deliberante de Ushuaia una propuesta para declarar a la zona de tierras municipales del Valle del Arroyo Grande como una zona de manejo análoga a la Reserva Provincial de Usos Múltiples (RUM). Esta zona se 
destinará a usos recreativos controlados siendo un importante paso para detener el avance de la urbanización. La categoría de manejo propuesta admite usos extractivos ya que la Ley Provincial N²72 (Sistema Provincial de Áreas Naturales Protegidas) las define como "áreas de aptitud productiva controladas técnicamente por el Estado".

\subsection{MARCO TEÓRICO}

La cuenca hidrográfica es un sistema natural circunscrito a un área de drenaje en el que todas las aguas que lo atraviesan son recogidas por un colector común (Brooks et al., 1991; Tragsa et al., 1998). Las cuencas hidrográficas son unidades físicas que sirven como marco práctico y objetivo para la planificación y gestión de la conservación y el rendimiento sostenido de los recursos naturales, como demanda su dimensión social, productiva y ambiental (Bruno, 1973). Un enfoque sistémico del concepto de cuenca hidrográfica supera la idea de reducirla a una superficie de convergencia del escurrimiento hídrico superficial y considera a todo el complejo biogeomorfológico, económico y de relaciones sociales como unidad de planificación y gestión para el manejo de los recursos naturales. La comprensión de los procesos que ocurren en una cuenca se pueden obtener a partir de su estudio físico - geográfico, de los eventos meteorológicos que inciden sobre ella, de la información con respecto a suelos y uso del suelo, de los inventarios de la vegetación, del clima presente en la cuenca y de los factores hidrológico y el social (Ferrando,1996). El manejo integral de una cuenca hidrográfica constituye un valioso instrumento del Estado y de la Sociedad para conciliar intereses, conservar la biodiversidad, ordenar sus actividades y permitir un uso sostenido de sus recursos naturales. La cuenca hidrográfica constituye la unidad básica de planeamiento para la ordenación y manejo integrado de sus recursos naturales (Brooks et al., 1991; FAO, 1996). En la actualidad se observan en nuestro país la falta de reconocimiento de la necesidad de un tratamiento integral de la cuenca hidrográfica así como en una dispersión conceptual entre diversas instituciones y organismos acerca del significado de la cuenca hidrográfica (FAO, 1993; Casaza \& Crosio, 1999).

Los pastizales naturales y los bosques se han asociado al bienestar social por su rol en la estabilización del medioambiente a través de su influencia en el ciclo hidrológico (Molchanov, 1963), en el mejoramiento de suelos, en el mantenimiento del equilibrio biológico (Bay \& Blydenstein, 1971), así como por la producción de bienes y servicios resultante de su aprovechamiento forestal, recreacional y paisajístico (Henao, 1988; FAO, 1996; Tragsa et al., 1998). 
El desarrollo turístico involucra variables técnicas y definiciones políticas en un contexto en el que deben conciliarse intereses muchas veces opuestos (Otero, 1997). No obstante debe existir un consenso generalizado sobre las condiciones de conservación de las áreas naturales turísticas (Vergara, 1992). Actualmente se plantean grandes problemas de gestión de éstas debido principalmente a la congestión en áreas de uso intensivo, el desarrollo y la expansión de centros urbanos, la falta de planificación en el manejo de las áreas naturales especialmente frágiles, la falta de control en el acceso a determinados sitios y la falta de infraestructura adecuada (Otero, 1997). El crecimiento del turismo en la región no fue acompañado de una apropiada planificación del acceso y uso de los ambientes y en general, en desmedro de la posibilidad de un uso múltiple de los recursos naturales, marginando el desarrollo de otras potencialidades como la silvicultura. Son escasos los antecedentes relacionados con la planificación del manejo de recursos naturales a escala territorial y los pocos disponibles se orientan mayormente a las áreas protegidas de la provincia. La ausencia del Estado como responsable de la definición de políticas y la planificación y control del uso y conservación de los recursos naturales deja librado a los usuarios y propietarios la gestión del medio natural, hecho que colabora con su rápido deterioro cuando éstos persiguen la maximización de los beneficios derivados del aprovechamiento de bienes y servicios del ambiente. En este contexto se hace necesaria una perspectiva de uso múltiple para alcanzar un manejo integral y sustentable de los recursos naturales a escala de cuenca, compatibilizando uso y conservación, a través de la diversificación del aprovechamiento y la maximización del ingreso local (Brooks et al., 1991).

\subsection{HIPÓTESIS}

\subsubsection{Planteo del problema}

El principal problema en la CAG es la falta de planificación del uso del territorio, que conlleva al desarrollo urbano descontrolado, falta de manejo de las áreas naturales especialmente frágiles, falta de control en el acceso a determinados sitios y falta de infraestructura adecuada. En este marco, la aplicación de estrategias de desarrollo sustentable, como tecnologías de manejo ganadero, la agricultura intensiva y el aprovechamiento del bosque nativo, entre otras posibles, a través de planes de manejo integrado representan una solución al problema.

\subsubsection{Hipótesis}


Los ambientes naturales de la Cuenca del Arroyo Grande están degradados principalmente por el uso ganadero y turístico, y la planificación silvícola constituye un primer paso para su recuperación.

\subsection{OBJETIVOS}

Describir la cuenca mediante parámetros de forma, de relieve y de la red hidrográfica.

Diagnosticar el estado de los ecosistemas en la Cuenca del Arroyo Grande

Determinar los agentes que impactan sobre la vegetación.

Analizar alternativas productivas principalmente forestales aplicables en la cuenca. 


\section{MORFOMETRÍA Y VEGETACIÓN DE LA CAG}

\subsection{INTRODUCCIÓN}

El funcionamiento de una cuenca hidrológica depende, entre diversos factores, de su morfología, de las características del suelo y de la cobertura vegetal (Tragsa et al., 1998). La caracterización y cuantificación de los parámetros involucrados en el funcionamiento de una cuenca es una tarea compleja. Sin embargo, es posible determinar un cierto número de indicadores que sirvan para la clasificación de las diversas unidades hidrológicas que componen una cuenca como para la realización de estudios comparativos relacionados con su comportamiento hidrológico (Henao, 1988; Tragsa et al., 1998). Los procesos de modelización del paisaje guardan una estrecha relación con las características morfométricas de la cuenca. Por ello la descripción del ambiente físico, a través de parámetros morfométricos, resulta de gran interés para identificar y describir procesos morfogenéticos (Ciccacci et al., 1992). El análisis de diversos indicadores del medio físico representa una herramienta fundamental para la caracterización de la cuenca y el ajuste de las propuestas de manejo más apropiadas para las diferentes unidades hidrológicas que la componen. Dada la importancia de la configuración de las cuencas en la planificación del manejo, es necesario cuantificar sus características por medio de índices o coeficientes, los cuales relacionan el movimiento del agua y las respuestas de la cuenca a tal movimiento y su influencia en la vegetación (Llamas, 1993; Aparicio Mijares, 1994). La descripción vegetacional permite conocer el grado de conservación al determinar la cobertura y presencia de especies exóticas, siendo el primer paso para conocer la potencialidad de la zona con respecto a sus recursos naturales.

\subsection{MATERIALES Y MÉTODOS}

\subsubsection{Caracterización morfométrica de la cuenca}

Para determinar los parámetros morfométricos, la evaluación de la unidad hidrológica, el ordenamiento topológico y la descripción de las unidades de vegetación, se llevaron a cabo las siguientes etapas: 1) Interpretación preliminar de la información, 2) Evaluación y verificación a campo y 3) Compilación final. Se utilizaron recortes de imágenes Landsat tomadas en diferentes estaciones (invierno y verano) para poder individualizar los distintos rodales de $N$. betuloides (Mirbel) Oersted (guindo) y $N$. pumilio. Se confeccionaron mosaicos a partir de fotos aéreas y se interpretaron de 
acuerdo a las técnicas descriptas por Gebhard (1978) y Sabins (1987). Las imágenes satelitales se procesaron mediante programas de acceso público (WINBILKO 2.0 (Unesco, 1998) y TITUS 1.03a (Ministère de I'Education Nationale, 1995)). Se generó la cartografía temática mediante un SIG (Sistema de Información Geográfica) utilizando el programa ARCVIEW 2.1 (ESRI, 1998) en el Centro Austral de Investigaciones Científicas (CADIC - CONICET).

Se analizaron y cuantificaron las propiedades lineales, superficiales y de relieve del área sólida de la CAG. Cabe destacar que estas propiedades son dinámicas en el tiempo ya que están afectadas por el modelado producido por la acción erosiva del agua (Strahler, 1979).

\subsubsection{Parámetros de forma}

Se delimitaron los límites de la CAG utilizando el método de la partición de aguas entre sistemas mediante la observación de cartas topográficas: Hoja 5.569-17-1 “Ushuaia” y Hoja 5.569-17-2 "Monte Olivia"; imágenes Landsat tomadas en diferentes estaciones (Invierno y verano). Se digitalizó y georreferenció este material y se desarrolló un sistema de información geográfico para el análisis espacial de información regional así como para el desarrollo posterior de cartografía temática.

El Coeficiente de compacidad $\left(K_{c}\right)$ (Ec. 1) está ligado a la forma de la cuenca. Cuanto más irregular es la cuenca, mayor será su $K_{c}$. Una cuenca circular tendrá un coeficiente de compacidad mínimo, igual a 1, dando así una mayor probabilidad de producir avenidas máximas (Maderey, 1973), ya que los tiempos de concentración para diferentes puntos serán iguales (Benitez Chunga, 1978).

$$
K_{c}=\frac{p}{2 \sqrt{\pi \cdot A}}
$$

Donde: $P=$ perímetro de la cuenca en $\mathrm{km} ; A=$ área de la cuenca en $\mathrm{km}^{2}$.

El factor de forma $\left(R_{f}\right)$ (Ec. 2) tiene relación con las crecidas en la cuenca. Si el factor de forma es bajo, se producirán menos crecidas que en otra cuenca del mismo tamaño pero con un factor de forma mayor (Horton, 1945; Llamas, 1993).

$$
R_{f}=\frac{A}{L_{m}^{2}}
$$


Donde: $A$ = área de la cuenca en $\mathrm{km}^{2} ; L_{m}=$ distancia entre la exudatoria y el punto más alejado de la cuenca siguiendo el curso principal, en km.

El radio de elongación $\left(R_{0}\right)$ (Ec. 3) tiene relación con el tiempo de concentración del sistema. Varía entre 1 para cuencas llanas y menos de 0,6 para cuencas con relieve pronunciado (Llamas, 1993).

$$
R_{o}=\frac{D}{L_{m}}=1.128 \cdot \sqrt{\frac{A}{L_{m}}}
$$

Donde: $D$ = diámetro de un círculo que tenga la misma superficie que la cuenca; $A$ = área de la cuenca en $\mathrm{km}^{2} ; L_{m}=$ distancia entre la exudatoria y el punto más alejado de la cuenca siguiendo el curso principal en $\mathrm{km}$.

\subsubsection{Parámetros de relieve}

La forma de cuantificar el relieve de una cuenca es mediante la curva hipsométrica, definida por la distribución de las elevaciones de la cuenca utilizando curvas de igual altitud. Se caracterizó la proporción de la superficie total de la cuenca comprendida entre 2 curvas adyacentes (Benitez Chunga, 1978). De esta forma se refleja el estado de equilibrio dinámico y el potencial erosivo del sistema. Otro parámetro de relieve es el de la altitud media $\left(H_{h}\right)$ (Ec. 4), mínima y máxima de la Cuenca. La altitud media influye en el escurrimiento, en el tiempo de concentración y en la susceptibilidad al arrastre de sedimentos (Maderey, 1973).

$$
H_{h}=\frac{\sum\left(H_{i} \cdot A_{i}\right)}{A}
$$

Donde: $A$ = área de la cuenca en $\mathrm{km}^{2} ; H_{i} \cdot A_{i}=$ relación de elevación media entre dos curvas de nivel y el área entre ellas.

\subsubsection{Parámetros de la red hidrográfica}

La densidad de Drenaje $\left(D_{d}\right)$ (Ec. 5) es la relación entre la longitud total de los cursos de agua y el área de la cuenca (Aparicio Mijares, 1994), suele utilizarse como 
complemento de los índices de pendiente y compacidad a efectos de escorrentía superficial.

$$
D_{d}=\frac{\sum L_{\mu}}{A}
$$

Donde: $L_{\mu}=$ longitud total de cauces en $\mathrm{km} ; A=$ área de la cuenca en $\mathrm{km}^{2}$.

El tiempo de concentración ( $\left.T_{c}\right)$ (Ec. 6) se puede definir como el tiempo que tarda una gota de agua en llegar de las partes más alejadas de la cuenca al sitio de interés. El tiempo de concentración es uno de los parámetros más importantes en los modelos precipitación - escorrentía, pues se basa en la duración de la tormenta de diseño (Smith \& Vélez, 1997). Además se puede definir como el tiempo que demora una partícula de agua en viajar desde el punto más remoto hasta el punto de interés. Comprende al lapso entre el final de la lluvia y el momento en que cesa el escurrimiento superficial. Es clara, entonces, la dependencia de este parámetro de variables morfométricas, tales como el área, pendiente de la cuenca y longitud del cauce principal. Se utilizó para este cálculo la ecuación de Rowe (Murillo, 2000), de forma:

$$
T_{c}=\frac{0,86 \cdot L^{3}}{H}
$$

Donde: $L=$ longitud del cauce principal en $\mathrm{Km} ; H=$ diferencia entre la mayor y menor altitud de la cuenca en $\mathrm{m}$.

La pendiente media del río $\left(I_{c}\right)$ (Ec. 7) se calcula a partir de la diferencia de la altura máxima y mínima del río principal y su longitud.

$$
I_{c}=\frac{H_{M}-H_{m}}{1000 \cdot L}
$$

Donde: $I_{c}=$ pendiente media del río; $H_{M}=$ altitud máxima del río en m s.n.m.; $H_{m}$ = altitud mínima del río en m s.n.m.; $L=$ longitud media del río en km. 
El coeficiente orográfico de Fourier $\left(C_{f}\right)$ es el producto entre el área de la cuenca en $\mathrm{km}^{2}$ y la $H_{d}$ (altitud media) en m (Maderey, 1973). La $H_{d}$ se calcula promediando las alturas correspondientes a una grilla de puntos distribuida en forma sistemática en toda la superficie de la $C A G$.

\subsubsection{Clima e hidrografía}

Para la descripción climática de la zona se utilizaron los datos de precipitación mensual (en forma pluvial o nival), de temperatura (media mensual, máxima mensual y mínima mensual) y de evapotranspiración, proporcionados por 3 estaciones meteorológicas distribuidas dentro (Valle de Andorra, 54ㄴ 45’ S, 68ำ18' O, 160 m s.n.m.) y fuera de la CAG (Monte Martial, 535 m s.n.m., ubicada al sur de la CAG, en la ladera sur del Monte Martial en las cercanías de la ciudad de Ushuaia; CADIC, 54은 45’ S, 68ํ19' O, 15 m s.n.m., siendo ésta la estación meteorológica del Centro Austral de Investigaciones Científicas, ubicada dentro del ejido urbano de la ciudad de Ushuaia). Las estaciones que se encuentran fuera de la cuenca se utilizaron para extrapolar datos, ya que existe solamente una estación dentro de la cuenca. Es importante destacar que existen escasos antecedentes previos al año 1958, cuando se comenzaron a tomar datos diariamente. Pese a la brevedad de los períodos de mediciones, restringiendo así la variabilidad de los datos, se intentó realizar una descripción climática de la zona.

La estación meteorológica Valle de Andorra se implementó en el año 1984 a raíz de haberse seleccionado la CAG para la realización de estudios hidrológicos, en base a su representatividad respecto de otras cuencas de la Cordillera Fueguina; su proximidad, que permite las mediciones aún en la época invernal y por la importancia socioeconómica del valle (Iturraspe et al., 1989). Paralelamente a las observaciones climáticas, se efectuaron mediciones de caudal en la desembocadura del curso principal en forma continua. La estación dejó de ser funcional en diciembre de 1988.

Se realizó un estudio de escorrentía y precipitación para toda la CAG, relacionando la precipitación total y el caudal en la desembocadura de la cuenca. Los datos utilizados corresponden al período abril de 1985 hasta diciembre de 1988, que es el máximo período en que existen datos reales en mediciones de precipitación para la estación Ushuaia y Andorra y mediciones de caudal en la desembocadura de la CAG (Iturraspe et al. 1989). Se calculó la precipitación total mensual utilizando para ello las superficies ocupadas por cada equidistancia hipsométrica cada 100 m (Tabla 4) y las estimaciones de Barrera et al. (2000) para obtener el valor de la precipitación en un gradiente altitudinal. Para el cálculo del porcentaje de precipitación en forma de 
nieve a lo largo del período estudiado, se utilizaron los datos de la Estación Valle de Andorra, CADIC (Ushuaia) y la Estación Monte Martial. Los porcentajes mensuales se aplicaron al valor de precipitación a lo largo del período.

Cabe resaltar como resultado de este estudio las diferencias encontradas en las variables estudiadas; el aumento de la escorrentía en los meses primaverales se debe al derretimiento de la nieve acumulada en los meses invernales, siendo en los meses de octubre, noviembre, diciembre y enero mayor la escorrentía que la precipitación total, dada por el almacenamiento de agua en forma de hielo o nieve. Este análisis permite conocer el comportamiento hidrológico de la cuenca para la planificación y aprovechamiento de los recursos.

\subsubsection{Geomorfología y suelos}

Se describió la geomorfología de la CAG mediante la utilización de fotografías aéreas, imágenes Landsat y Spot, observaciones a campo y consultando bibliografía regional disponible (Rabassa et al., 1990; Coronato, 1995; Rabassa et al., 2000; APN, 2003a). Para los suelos de la cuenca, existen trabajos para la zona de estudio (Etchevere \& Miaczynski, 1963; Gutierrez y Sebastiá, 1985; Donoso, 1990), además se cuenta con el mapa de suelos del Territorio Nacional de Tierra del Fuego (Godagnone \& Irisarri, 1990) y el mapa de suelos de la República Argentina (SAGyP _ INTA, 1990).

\subsubsection{Vegetación}

Para determinar las características de la vegetación de la cuenca, se dividió la superficie de la CAG mediante interpretación visual en pantalla de los distintos tipos de coberturas de vegetación, utilizando imágenes Landsat, aerofotogramas y software descripto en el punto 2.2.1. Las mismas se utilizaron como capa base sobre las que se digitalizaron las coberturas vegetacionales. La clasificación se realizó en base al tipo de vegetación, lo que permitió separar las coberturas en: a) Guindo (bosque de $N$. betuloides), b) Lenga (bosque de N. pumilio), c) Pastizal y d) Turbera. Dentro de cada uno de los cuatro tipos de cobertura digitalizados, se realizó una nueva separación en unidades de vegetación (UV), las cuales debían presentar una superficie entre 200 y 5 ha. El criterio de separación utilizado para determinar las UV fue mediante interpretación visual en base a diferencias de tono, textura, exposición y altitud. Se 
realizó la digitalización utilizando una escala de 1:10.000, que permite una aproximación de 1/20 de hectárea. El uso de esta escala posibilita utilizar la información así obtenida para aumentar el detalle de análisis a nivel de estructura y realizar cartografía con buen grado de precisión.

Se estableció el punto central de cada UV a fin de establecer la ubicación de las parcelas, las que fueron localizadas mediante GPS durante la conducción de un inventario en enero de 2002. En las parcelas se censó la composición vegetal, su abundancia y cobertura mediante el método de Braun - Blanquet. Se cuantificó la proporción correspondiente a suelo desnudo y residuos leñosos. Se siguió la nomenclatura propuesta por Moore (1983) para las determinaciones sistemáticas. Debido a la dificultad de identificar las especies de hepáticas y los musgos, estos grupos se separaron en Hepáticas y Musgos, discriminando a Sphagnum sp. del resto.

Para determinar las características forestales de la cuenca, se realizó el muestreo en las unidades homogéneas de vegetación (UV) forestales (Guindo y Lenga). Se realizaron tres parcelas de radio variable o de Bitterlich (Bitterlich, 1984; Clutter et al., 1983), siendo su tamaño proporcional al área basal de los árboles incluidos en la parcela (Prodan et al., 1997). Las parcelas se ubicaron en el punto central de la UV y las dos restantes a $30 \mathrm{~m}$ de la central con un rumbo aleatorio. Se utilizaron 3 parcelas de inventario para la realización del muestreo por cada UV con el objetivo de capturar variabilidad dentro de la UV. En cada parcela se caracterizó la estructura del bosque a nivel de rodal a través de la biometría forestal básica: DAP (diámetro normal a 1,30 m del suelo), aptitud maderera del árbol (posibilidad de extracción o no de un fuste maderable), porcentaje de cobertura arbórea por medio de un copímetro de espejo curvo (Lemmon, 1957), área basal, altura dominante, especie dominante y fase de crecimiento del bosque según Schmidt \& Urzúa (1982).

El $D A P$ se determinó con cinta diamétrica. El diámetro cuadrático medio (DCM) de un rodal es el diámetro correspondiente al árbol de área basal media, es utilizado comúnmente para realizar cálculos, extraer conclusiones y efectuar comparaciones sobre estructura, en general cobra mayor importancia en rodales coetáneos donde caracteriza la distribución diamétrica del mismo (Prodan et al., 1997). El DAP se utilizó también para el cálculo del volumen total con corteza (VTCC) y para el cálculo del volumen maderable sin corteza (VVSC).

El área basal se define como el área correspondiente a una sección transversal del fuste a 1,30 m del suelo y a nivel de rodal es la sumatoria de estas secciones en una hectárea (Prodan et al., 1997). Para su determinación a nivel de rodal se utilizó, por medio de conteo angular, un dendrómetro de factor $\mathrm{K}=6$ (Clutter et al., 1983; Bitterlich, 1984). 
En cada parcela se determinó la altura dominante, que se midió con clinómetro y distanciómetro láser, que fue definida por la altura total promedio de los 60 árboles de mayor diámetro por hectárea. La altura dominante fue utilizada para la determinación de la calidad de sitio según Martínez Pastur et al. (1997b), basada en la altura dominante del rodal en fase de envejecimiento o desmoronamiento (Tabla 1). La calidad de sitio es la capacidad de un área determinada para el crecimiento de los árboles en respuesta a la totalidad de condiciones ambientales existentes en ese lugar (Prodan et al., 1997). Se evaluó porque proporciona datos fundamentales para la toma de decisiones silvícolas (Daniel et al., 1982). De acuerdo a la metodología seguida, el Índice de Sitio para $N$. pumilio se expresó como la altura que poseía el rodal a una edad base de 60 años $\left(I S_{60}\right)$.

Tabla 1. Rango de altura media dominante para Clase de Sitio.

Average dominant height intervals for each Site Class.

\begin{tabular}{ll}
\hline $\mathrm{HD}(\mathrm{m})$ & $\mathrm{CS}$ \\
\hline$\geq 27,5$ & $I$ \\
$24-27,49$ & $I I$ \\
$20,5-23,99$ & $I I I$ \\
$17-20,49$ & $\mathrm{IV}$ \\
$10-16,9$ & $V$ \\
$7-9,9$ & VB \\
$<7$ & Krummholz
\end{tabular}

CS: Calidad de sitio, HD: Altura dominante, VB: Calidad de sitio V bajo, Krummholz (Norton \& Schönenberger, 1984)

Las fases de desarrollo son etapas del ciclo de desarrollo natural del bosque de $N$. pumilio de duración variable (Schmidt \& Urzúa, 1982), las cuales se asocian a rangos de edades determinados y a estructuras particulares. Las diferentes fases dominantes del bosque se pueden determinar fácilmente a través de la corteza. El estado de crecimiento óptimo inicial (COI) se caracteriza por presentar corteza lisa, destacándose la presencia de lenticelas. El estado de crecimiento óptimo final (COF) se diferencia por la aparición de grietas verticales. La corteza en etapa de envejecimiento $(E)$ posee grietas verticales muy marcadas y profundas, formando placas. La etapa de desmoronamiento $(D)$ se caracteriza por desprendimiento de la corteza y hendiduras profundas a lo largo del tronco (Schmidt \& Urzúa, 1982). Se consideró como fase dominante a la que presentó mayor área basal en la parcela.

El volumen total con corteza (VTCC) indica la productividad de un rodal, siendo de gran utilidad para definir el potencial maderero de un sitio, analizar el funcionamiento del ecosistema a través del crecimiento (McDill \& Amateis, 1992) y planificar el manejo forestal (Cao, 1993; Schmidt, 1997). El VTCC se refiere al volumen del fuste y de las ramas hasta un diámetro de $5 \mathrm{~cm}$. El volumen maderable sin corteza (VVSC) está compuesto por trozas maderables cuyo destino final es el aserradero. Las trozas 
aserrables tienen una longitud de 3 a $7 \mathrm{~m}$ de largo, no menos de $20 \mathrm{~cm}$ de diámetro en punta fina, pudrición no mayor a un tercio en la peor cara, grano recto y no presentar una flecha excesiva (más de $10 \mathrm{~cm}$ en una troza de dos $\mathrm{m}$ ). Para su cálculo se utilizaron los modelos propuestos por Cellini et al. (2000), Martínez Pastur et al. (2000b, 20012002) y Peri et al. (1997).

$$
\begin{aligned}
& \text { VTCC }=p_{1} \times(6-\text { Sitio })^{p_{2}} \times A B \\
& V V S C=p_{3} \times(6-\text { Sitio })^{p_{4}} \times A B
\end{aligned}
$$

Donde: VTCC: volumen total con corteza $\left(\mathrm{m}^{3}\right), V V S C$ : volumen maderable sin corteza $\left(\mathrm{m}^{3}\right)$, Sitio: Calidad de sitio, $A B$ : área basal $\left(\mathrm{m}^{2}\right), \mathrm{P}_{1}: 6,7619047, \mathrm{P}_{2}: 0,49525143$, $P_{3}: 2,00544727, P_{4}: 0,78548642$

Se realizaron conteos de renovales de Nothofagus sp. para determinar la densidad de la regeneración en parcelas de $1 \mathrm{~m}^{2}$ ubicadas en cada parcela de recuento angular. El tipo de regeneración dominante en cada parcela de muestreo se caracterizó según el criterio utilizado por Pulido et al. (2000) en Inicial (regeneración de un año de edad, con presencia de cotiledones), Avanzada (regeneración mayor a un año de edad con una altura menor a 1,3 m), Instalada (altura mayor a 1,3 m) y Ramoneada (con signos de ramoneo).

\subsection{RESULTADOS}

\subsubsection{Caracterización morfométrica de la cuenca}

\subsubsection{Parámetros de forma}

Por ser una cuenca de montaña, la delimitación de la unidad hidrológica no presentó dificultades, salvo donde existían glaciares o nieves permanentes, consultándose fotos aéreas de la zona en esos casos. La superficie de la CAG es de 129,513 km² con un perímetro de 62,092 km.

El $K_{c}$ de la cuenca en estudio arrojó un resultado de 1,5391, implicando que la forma de la cuenca es de tipo oval-oblonga a rectangular-oblonga, lo que a su vez indicaría que la concentración de gotas de lluvia en el sitio de mayor convergencia dentro de la cuenca tiene baja incidencia. El valor de $L_{m}$ es de $26,77 \mathrm{~km}$, dando un factor de forma $R_{f}$ de 0,1808 . Este valor denota un bajo factor de forma, lo que indica 
que existe una tendencia a las crecidas súbitas. El cálculo del radio de elongación $\left(R_{0}\right)$ arrojó un valor del coeficiente de 0,4984 , lo que indica un relieve pronunciado para esta cuenca.

\subsubsection{Parámetros de relieve}

El relieve es un factor importante en el comportamiento de la cuenca desde el punto de vista hidrológico, y en la planificación del manejo de los recursos naturales. Las curvas hipsométricas se confeccionaron con datos de campo, cartas topográficas y modelos de elevación digital del terreno (MDT). El sistema de curvas hipsométricas se presenta en el Mapa 3. Se pueden observar zonas con alta pendiente y altitudes elevadas en la zona periférica de la cuenca. Las diferencias de altitud entre el fondo de valle y las partes altas de la cuenca rondan los $1.000 \mathrm{~m}$. La $C A G$ tiene una $H_{h}$ de 646,22 m. La altitud mínima es de 0 m s.n.m. en la desembocadura del Arroyo Grande y la máxima de 1.450 m s.n.m. en la cumbre del Monte Vinciguerra.

\subsubsection{Parámetros de la red hidrográfica}

Una densidad alta refleja una cuenca muy bien drenada que debería responder relativamente rápido al influjo de la precipitación, indica generalmente áreas con suelos fácilmente erosionables o relativamente impermeables, con pendientes fuertes y escasa cobertura vegetal; una cuenca con baja densidad refleja un área pobremente drenada con respuesta hidrológica muy lenta y ocurren en sitios donde los materiales del suelo son resistentes a la erosión o muy permeables y donde el relieve es bajo. Es una medida de la textura de la red, y expresa el equilibrio entre el poder erosivo del caudal terrestre y la resistencia del suelo y rocas de la superficie.

La sumatoria de las longitudes de todos los drenes de la cuenca fue de 174,25 $\mathrm{km}$, dando una $D_{d}$ de $1,34 \mathrm{~km} / \mathrm{km}^{2}$, siendo este valor considerado como alto, pudiendo indicar que cuando la $D_{d}$ es alta la cuenca evacua el agua en menos tiempo frente a una tormenta (González \& Sepúlveda Manzor, 2003). En el Mapa 2 se presenta la distribución de los ríos y afluentes de la CAG, clasificados cada uno por el método de Horton (1945). El Río Chico se encuentra caracterizado por tener afluentes de orden 1 y 2, presentando su río colector una variación del orden 1 al 3. El Arroyo Grande (orden 1 a 4) presenta afluentes de orden 1, 2 y 3 . La cantidad de ríos aumenta a medida que disminuye el orden de jerarquía, observándose que la mayoría de los ríos de la CAG pertenece al orden 1, con el 53,11\% del total. El Tiempo de concentración calculado fue de 34,86 horas. La diferencia entre la mayor y menor altitud de la cuenca 
corresponde al Monte Vinciguerra (1.450 m s.n.m.) y la desembocadura del cauce principal en el Canal de Beagle. Se calculó la $I_{c}$ desde el inicio en la alta montaña hasta su desembocadura, siendo la pendiente del cauce principal de 5,62\%. Para el cálculo del coeficiente orográfico de Fourier $\left(C_{f}\right)$, se determinó la $H_{d}$ en $\mathrm{m}$ para la cuenca en estudio, dando un valor de 646,22 m utilizando para el cálculo 26.548 puntos de altitud conocida con $30 \mathrm{~m}$ de resolución espacial en base a los datos de altitud del MDT. El $C_{f}$ hace referencia a la cantidad de suelo que puede perder potencialmente una cuenca. (Fournier, 1960; MARNR-CIDIAT, 1984) Los cálculos de superficie se presentan en la Tabla 2. El $C_{f}$ presenta un valor de 54,0859, correspondiendo a un sistema con relieve acentuado. En la Tabla 3 se presenta un resumen de las características físicas de la $C A G$.

Tabla 2. Área ocupada por cada intervalo de equidistancia hipsométrica cada 100m.

Area occupied by each hypsometric equidistance interval every $100 \mathrm{~m}$.

\begin{tabular}{lll}
\hline Altitud (m s.n.m.) & Superficie. (ha) & $\%$ \\
\hline 0 a 100 & 273,2 & 2,11 \\
100 a 200 & 723,7 & 5,59 \\
200 a 300 & 1251,4 & 9,66 \\
300 a 400 & 966,7 & 7,46 \\
400 a 500 & 983,9 & 7,60 \\
500 a 600 & 1212,3 & 9,36 \\
600 a 700 & 1402,1 & 10,83 \\
700 a 800 & 1523,1 & 11,76 \\
800 a 900 & 1622,7 & 12,53 \\
900 a 1000 & 1471,5 & 11,36 \\
1000 a 1100 & 1022,0 & 7,89 \\
1100 a 1200 & 417,1 & 3,22 \\
1200 a 1300 & 73,5 & 0,57 \\
1300 a 1400 & 4,7 & 0,04 \\
1400 a 1500 & 3,1 & 0,02 \\
\hline
\end{tabular}

Tabla 3. Parámetros de forma, de relieve y de la red hidrográfica de la Cuenca del Arroyo Grande. Shape, relief and hydrographic system parameters of the Arroyo Grande catchment.

\begin{tabular}{lll}
\hline Parámetros & Índice & Valor \\
\hline Parámetros de forma & Superficie & $129,513 \mathrm{~km}^{2}$ \\
& Perímetro & $62,092 \mathrm{~km}$ \\
& $\mathrm{~K}_{\mathrm{c}}$ & 1,5391 \\
& $\mathrm{~L}_{\mathrm{m}}$ & $26,77 \mathrm{~km}$ \\
& $\mathrm{R}_{\mathrm{f}}$ & 0,1808 \\
& $\mathrm{R}_{\mathrm{o}}$ & 0,4984 \\
\hline Parámetro de relieve & $\mathrm{H}_{\mathrm{h}}$ & 646,22 \\
\hline Parámetros de la red hidrográfica & $\mathrm{L}_{\mu}$ & $174,25 \mathrm{~km}$ \\
& $\mathrm{D}_{\mathrm{d}}$ & $1,34 \mathrm{~km}$ \\
& $\mathrm{~T}_{\mathrm{c}}$ & $34,86 \mathrm{~h}$ \\
& $\mathrm{I}_{\mathrm{c}}$ & $5,62 \%$ \\
& $\mathrm{H}_{\mathrm{d}}$ & $646,22 \mathrm{~m}$ \\
& $\mathrm{C}_{\mathrm{f}}$ & 54,0859 \\
\hline
\end{tabular}

$\mathrm{K}_{\mathrm{c}}=$ coeficiente de compacidad; $\mathrm{L}_{\mathrm{m}}=$ distancia entre la exudatoria y el punto mas alejado de la cuenca siguiendo el curso principal; $R_{f}=$ factor de forma; $R_{0}=$ radio de elongación; $H_{h}=$ altitud media; $L_{\mu}=$ longitud total de cauces; $D_{d}=$ densidad de drenaje; $T_{c}=$ tiempo de concentración; $I_{c}=$ pendiente media del río; $\mathrm{H}_{d}=$ altura media; $\mathrm{C}_{\mathrm{f}}=$ coeficiente orográfico de Fourier.

\subsubsection{Clima e hidrografía}

El clima de la región es templado - frío húmedo (Köppen, 1936); las temperaturas presentan variaciones que están determinadas por la latitud, el gradiente altitudinal, el 
gradiente de la insolación a lo largo del año y los cambios estacionales y diarios. Los factores mencionados determinan valores promedios anuales de temperatura de 3,6 C y precipitaciones de $545 \mathrm{~mm}$ aproximadamente (Iturraspe et al., 1989). Las precipitaciones en forma de lluvia, nieve, granizo o agua nieve aumentan en otoño y primavera (Rusch, 1989). La distribución estacional de las precipitaciones para las estaciones se muestra en la Tabla 4. Esta distribución es uniforme para cada estación, sin que se pueda diferenciar una estación seca (Fernández, 1993). Los datos de precipitación, temperatura en valores máximos, mínimos y medios mensuales, se presentan en la Tabla 5.

Tabla 4. Precipitación total y en porcentaje del total por estación Precipitation and in percentage of the total by weather season.

\begin{tabular}{|c|c|c|c|c|c|c|c|c|}
\hline \multirow{2}{*}{ Estación } & \multicolumn{2}{|c|}{ Verano } & \multicolumn{2}{|c|}{ Otoño } & \multicolumn{2}{|c|}{ Invierno } & \multicolumn{2}{|c|}{ Primavera } \\
\hline & $(\mathrm{mm})$ & $(\%)$ & $(\mathrm{mm})$ & $(\%)$ & $(\mathrm{mm})$ & $(\%)$ & $(\mathrm{mm})$ & $(\%)$ \\
\hline CADIC (4 años) & 152,8 & 26,7 & 134,5 & 23,5 & 118,9 & 20,7 & 167,2 & 29,2 \\
\hline Valle de Andorra (3 años) & 164,0 & 27,1 & 180,1 & 29,7 & 114,6 & 18,9 & 147,6 & 24,3 \\
\hline Monte Martial (4 años) & 309,1 & 26,3 & 320,0 & 27,2 & 266,8 & 22,7 & 278,8 & 23,7 \\
\hline
\end{tabular}

Tabla 5. Datos climáticos de la Estación Valle de Andorra y CADIC para el año 1987. Andorra Valley Station and CADIC climate data, 1987.

\begin{tabular}{lllllllll}
\hline & \multicolumn{3}{c}{ Estación Valle de Andorra } & \multicolumn{5}{c}{ Estación CADIC } \\
Meses & $\mathrm{Pp}(\mathrm{mm})$ & $\mathrm{T}$ Med $\left({ }^{\circ} \mathrm{C}\right)$ & $\mathrm{T}$ Máx $\left({ }^{\circ} \mathrm{C}\right)$ & $\mathrm{T}$ Mín $\left({ }^{\circ} \mathrm{C}\right)$ & $\mathrm{Pp}(\mathrm{mm})$ & $\mathrm{T}$ Med $\left({ }^{\circ} \mathrm{C}\right)$ & $\mathrm{T}$ Máx $\left({ }^{\circ} \mathrm{C}\right)$ & T Mín $\left({ }^{\circ} \mathrm{C}\right)$ \\
\hline Ene & 66,7 & 8,0 & 12,9 & 4,8 & 48,2 & 9,9 & 14,5 & 5,4 \\
Feb & 59,1 & 9,5 & 16,9 & 4,3 & 46,7 & 10,0 & 14,7 & 5,3 \\
Mar & 51,4 & 5,1 & 12,7 & $-2,6$ & 56,2 & 7,9 & 12,8 & 3,1 \\
Abr & 57,0 & 3,0 & 11,0 & $-1,4$ & 43,1 & 6,2 & 10,5 & 2,0 \\
May & 39,1 & 1,0 & 5,3 & $-3,0$ & 15,2 & 5,0 & 8,3 & 1,7 \\
Jun & 82,1 & $-1,0$ & 4,3 & $-6,4$ & 46,8 & 2,3 & 5,4 & $-0,7$ \\
Jul & 39,9 & $-2,4$ & 6,8 & $-10,8$ & 59,0 & 0,3 & 3,5 & $-2,9$ \\
Ago & 41,9 & $-0,8$ & 7,4 & $-10,4$ & 8,5 & 2,2 & 6,1 & $-1,7$ \\
Sep & 47,2 & 1,2 & 5,5 & $-3,7$ & 46,3 & 3,7 & 7,4 & 0,0 \\
Oct & 24,9 & 4,6 & 9,8 & 1,1 & 23,0 & 7,0 & 12,3 & 1,8 \\
Nov & 42,7 & 7,2 & 14,5 & 2,6 & 43,8 & 9,0 & 14,4 & 3,7 \\
Dic & 32,4 & 8,4 & 16,7 & 2,5 & 43,4 & 10,2 & 15,5 & 4,9 \\
\hline
\end{tabular}

Pp: precipitación total; T Med: Temperatura media mensual; T Máx: Temperatura máxima mensual;

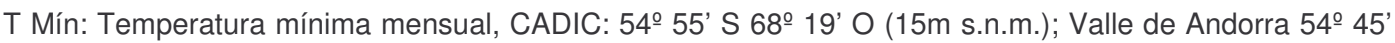
S 68ำ $18^{\prime} \mathrm{O}$ (160 m s.n.m.),

A partir de estos datos, se visualiza que existe una precipitación constante a lo largo de todo el año, siendo de 584,38 mm. La situación de valle intermontano, y un régimen de temperaturas de valores más bajos, motivan una mayor frecuencia de precipitaciones que en Ushuaia. En comparación con los datos pluviométricos de la Estación Monte Martial, se puede observar que la variación altitudinal de 375 m influye notablemente en las precipitaciones ya que el valor promedio anual es de 1.189,7 mm, siendo más de 2 veces el valor de la Estación Valle de Andorra. Los valores de temperatura se registraron durante el año 1987 y a pesar de que el período de 
observación es muy corto, surgen conclusiones muy importantes. El promedio anual de $3,1^{\circ} \mathrm{C}$ es $3 \stackrel{\circ}{\circ} \mathrm{C}$ menor que el promedio en Ushuaia para el mismo período, indicando una variación térmica entre ambos ambientes, superando los márgenes esperables debido a la variación del gradiente altitudinal (con un desnivel de $145 \mathrm{~m}$ entre las estaciones sería una diferencia de temperatura de $-0,8 \stackrel{\circ}{\circ}$ ). Las diferencias térmicas fueron atribuidas por Iturraspe et al. (1989) a a) una insolación prácticamente nula en el mes de junio y muy breve durante el resto del invierno en el fondo del valle ya que el ángulo solar es tan bajo en estas latitudes que no supera la línea de cumbres que limitan la cuenca; b) el enfriamiento por ascensión de las masas de aire que penetran al valle, sobrepasando los límites de la cuenca; c) por la influencia marítima en la estación CADIC (Ushuaia) interviene en la moderación de la amplitud.

El comportamiento de la precipitación a lo largo año no presenta variaciones estacionales, mostrando un promedio mensual de $97,32 \mathrm{~mm}$ y un total de $1.167,85$ $\mathrm{mm}$ anuales (Figura 2). Este valor es el doble del registrado en la Estación Valle de Andorra, a $160 \mathrm{~m}$ s.n.m. Esta uniformidad mensual de las precipitaciones fue observada por Fernández (1993) e Iturraspe et al. (1989), para estaciones meteorológicas. La precipitación nívea presenta un máximo en el período comprendido entre los meses de junio a septiembre, donde se concentran el $80,51 \%$ del total, observándose en los restantes meses valores menores al $6 \%$ del total. El promedio anual de precipitación nívea es de $27,50 \mathrm{~mm}$, y el total de 330,00 mm anuales. La escorrentía presenta los menores valores en los meses de junio, julio y agosto, con valores menores al 5\% del total $(44,4 \mathrm{~mm})$. En los meses de septiembre a diciembre, la escorrentía aumenta hasta su valor máximo de $134,3 \mathrm{~mm}$, disminuyendo en los siguientes meses hasta junio.

Figura 2. Precipitación total, caudal y precipitación nívea en mm en la desembocadura del Arroyo Grande durante el período 1985 a 1988.

Total precipitation, stream flow and snowfall in $\mathrm{mm}$ in the Arroyo Grande mouth from 1985 to 1998.

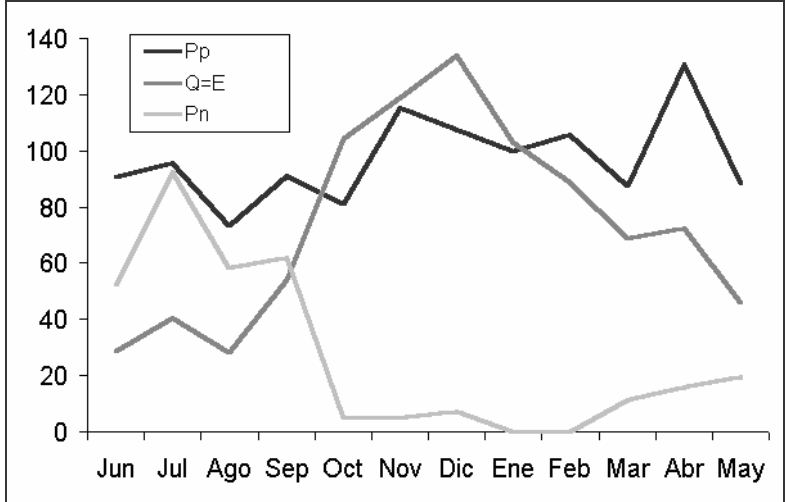

Pp: precipitación total; Q=E: Caudal o escorrentía; Pn: precipitación nívea.

\subsubsection{Geomorfología y suelos}


En toda cuenca de drenaje, el agente erosivo más común es el agua ya sea en forma de precipitación, escurrimiento o glacial. Como consecuencia de la erosión se producen los fenómenos de arrastre y sedimentación, especialmente en laderas con pendientes pronunciadas (Heras, 1976). Sin embargo, el proceso de denudación no sólo puede ser causado por la acción fluvial, también puede estar dado por la interacción de las propiedades bioclimáticas, antrópicas y litológicas del material; por la tectónica y fallas de las formas que influyen en los procesos de meteorización; deslizamientos y reptaciones lentas y rápidas de las geoformas; procesos todos que contribuyen a la erosión y agradación de los materiales (Rice, 1983; Strahler, 1979; Thorbury, 1960). La estructura geológica influye en la hidrología de la cuenca, así como su tipo influye en el movimiento del agua en las capas superiores, controlando en parte pérdidas masivas, así como erosión sub superficial, y en la disolución de ciertos tipos de rocas y el arrastre de los materiales disueltos a los ríos. El hielo y los glaciares pueden influir también en la geomorfología, así como en la colocación del material madre en algunas altas zonas montañosas. El conocimiento de la estructura geológica de la cuenca, ayuda a comprender las posibilidades de almacenamiento y movimiento del agua a través del suelo y las rocas, la realimentación de las capas freáticas, la distribución de los cauces de agua y la erosión (Bay \& Blydenstein, 1971).

En la CAG está presente la formación geológica denominada Yahgan; geológicamente esta formación corresponde al Cretácico, estando formada principalmente por esquistos y turbiditas. Por otro lado, se señala la presencia de pizarras radiolaríticas de color negro, estructura bandeada y clivaje transversal, asociadas con grauvacas y areniscas que contienen fragmentos de rocas volcánicas andesíticas o traquiandesíticas. En los valles cercanos al Monte Martial existen afloramientos de vulcanitas básicas, éstas son rocas hidratadas con respecto a su composición original (Caminos, 1980), denotando una incipiente meteorización. También se pudo observar que los afloramientos en las cercanías de la ciudad de Ushuaia, están constituidos por esquistos filíticos negruzcos con clivaje irregular muy astilloso causado por un intenso diaclasamiento (Méndez, 1978).

Los procesos glaciarios ocurridos durante el Pleistoceno modelaron la formación Yahgan, modificando el paisaje de la CAG. Las geoformas observadas fueron generadas por la depositación y acción erosiva glaciar modificando el terreno formando valles glaciares. Hace aproximadamente 24.000 años, en el Pleistoceno tardío se produce el Último Máximo Glacial, observándose la mayor expansión probablemente hace unos 22.000 años. Durante el tardiglacial, hace 15.000 años aproximadamente, los grandes glaciares comenzaron a retroceder, hasta el comienzo 
del Holoceno (c.a. 10.000 años) (APN, 2003a). Durante el Pleistoceno descendía desde la Cordillera de Darwin el glaciar Beagle que ocupaba el Canal Beagle, presentando la posición terminal en Punta Moat, aproximadamente a $100 \mathrm{~km}$ al este de la CAG (Rabassa et al., 1990). Los glaciares de valle asociados a el Glaciar Beagle modelaron el paisaje del área estudiada (Coronato, 1995). La fase final del Pleistoceno se habría caracterizado por el retroceso y / o calving del Glaciar Beagle y tributarios de este a oeste, la cual fue rápidamente inundada, hace unos 8.000 años (Rabassa et al., 1990).

Las geoformas más importantes se pueden apreciar en las cumbres de los sistemas montañosos de la periferia de la CAG (Mapa 5), las cuales fueron generadas por acción erosiva como los horns, circos y agujas, rocas aborregadas, y formas redondeadas (APN, 2003a). Actualmente existen glaciares de circo y neveros en franco retroceso. Entre las geoformas de depositación glacial se encuentran las colinas de sedimentos glacifluviales y las morenas latero-frontales, así como la presencia de morrenas y rodados glacifluviales, compuestas por sedimentitas debilmente metamorfizadas (Caminos, 1980). En los circos de altura de la CAG existen arcos morénicos más pequeños, generalmente descubiertos de vegetación, depositados por las glaciaciones ocurridas durante el Holoceno Medio a tardío (Rabassa et al., 2000).

El suelo desempeña un importante papel en el funcionamiento de una cuenca hidrográfica, ya que gran parte de la actividad hidrológica básica se produce entre la superficie del suelo y el sistema de aguas freáticas o roca madre. El suelo puede considerarse constituido por partículas minerales, material orgánico y agua, distinguiéndose del material no descompuesto superior y del material madre. Se debe tener un profundo conocimiento de los suelos de una cuenca, ya que las características físicas y biológicas del mismo determinan las funciones hidrológicas. El hombre puede influir en estas características en alguna medida cerca de la superficie y puede controlar la vegetación, influyendo en la capacidad de almacenamiento del suelo (Bay \& Blydenstein, 1971).

En la $C A G$, los suelos presentan gran lixiviación y acidez, con un horizonte orgánico del tipo mor ( $\mathrm{pH} 4,5-5,5)$. Bajo los bosques encontramos suelos del tipo podsol y suelos pardos forestales ácidos y, asociados a estos, litosoles y turbosos. Los suelos se hallan desprovistos de calcáreo libre debido al carácter ácido de la roca madre. Con respecto a los suelos turbosos, se dan por la existencia de sitios de elevada humedad y de mala aireación, donde se concentran mantos de restos vegetales del género Sphagnum (Fernández, 1993). Según Etchevere \& Miaczynski, (1963), la lixiviación de los suelos es mayor de los que indicaría los datos de lluvia, 
posiblemente como consecuencia de la elevada humedad relativa y la elevada nubosidad, que hace disminuir la EVT, tal como se vio en el estudio del comportamiento de la precipitación total y caudal (ver 2.2. Clima e hidrografía). Las pendientes escarpadas presentes en la cuenca han impedido la deposición de los productos de meteorización de las rocas, que se acumulan en los valles. Los someros suelos esqueléticos de las laderas favorecen el escurrimiento de las aguas pluviales (Etchevere \& Miaczynski, 1963).

Los suelos desarrollados en topografía montañosa, con pendientes relativamente fuertes, tienden a ser suelos más delgados que aquellos desarrollados sobre planos o topografía ondulada. La misma mantiene a los suelos en su estado juvenil, muy común en suelos forestales. Por otro lado, se produce un constante deposito de materiales al pie de pendientes o en valles por la erosión de laderas, lo que lleva a que se desarrollen suelos profundos (Donoso, 1990). Los suelos de la región en la que se encuentra el área bajo estudio fueron caracterizados por varios autores (Donoso, 1990; Frederiksen, 1988; Godagnone e Irisarri, 1990; INTA, 1991; Tuhkanen et al., 1989-1990). En general su complejidad es alta, ya que poseen gran variabilidad de geoformas, materiales originarios y vegetación. Los órdenes que pueden encontrarse son Molisoles, Entisoles, Inceptisoles, Espodosoles e Histosoles (Soil Survey Staff, 1999).

En los bosques de $N$. pumilio, el perfil del suelo presenta varios horizontes (Bravo et al., 2002): un O generado por la biomasa aérea aportada por los árboles; un $A$ muy desarrollado, con alto contenido de materia orgánica y bajo porcentaje de saturación en bases; un horizonte $E$, y un $B$, este último formado en un proceso de podzolización (Bh o Bhs) y ocupando gran parte del perfil. Estos se desarrollan sobre un $C$ o un $2 C$, de textura más gruesa y diferente mineralogía que el $C$ suprayacente. El material original sobre el que han evolucionado los suelos forestales está formado en gran parte por sedimentos de rocas metamórficas de origen glacial y geológicamente recientes, morenas y material de arrastre de los glaciares. Estos suelos, con cobertura boscosa, presentan procesos de podsolización que varían según las características del sitio. No llegan a conformar verdaderos podsoles, ya que no presentan un verdadero horizonte spódico (APN, 2003a). La podsolización es un proceso característico de los suelos de la isla, especialmente bajo bosques de $N$. pumilio. La zona de raíces es de menos de $40 \mathrm{~cm}$. de profundidad. En relación con la materia orgánica es destacable que no hay acumulación de hojarasca en el suelo del bosque, sino que ocurre una rápida degradación inicial que origina un horizonte orgánico de 10 cm formado por hojarasca en estados intermedios o avanzados de descomposición 
sobre el suelo mineral. En cambio existe una gran cantidad de residuos gruesos (Bava, 1998).

En las turberas y en los sectores cercanos a ellas o con drenaje deficiente, la napa freática fue subsuperficial y fluctuante, produciendo un marcado hidromorfismo. En las laderas de las montañas en cambio, el suelo fue somero, de escaso desarrollo, con un horizonte superficial de buen contenido de materia orgánica y distintos niveles de pedregosidad, seguido de un $C$ y luego de roca. Estos suelos se desarrollaron a partir de la instalación del bosque de $N$. pumilio y su sotobosque.

Los horizontes de mayor importancia para Nothofagus sp. son los superiores, ya que este género se caracteriza por presentar un sistema radical superficial, pudiendo N. pumilio ocupar también regolitos no edafizados recientemente expuestos como consecuencia de movimientos de remoción en masa. Sin embargo, el crecimiento es mejor en suelos de buen drenaje que puedan retener suficiente humedad, y es seriamente afectado en suelos delgados y de drenaje pobre (Schlatter, 1994). La inestabilidad de los suelos, como las observadas a grandes altitudes, también afecta el crecimiento, y junto con la presión de la nieve genera árboles bajos y deformados, llegando a impedir la expansión de la especie hacia mayores elevaciones. Además, la baja cohesión entre partículas también puede provocar deslizamiento del suelo, que puede incrementarse con la explotación irracional de la masa forestal que sustentan (Asancaic \& Frkovic, 1962). En los bosques de N. pumilio, el suelo presenta variaciones mensuales en la tensión de succión de agua y en su temperatura (Frangi \& Richter, 1992). El agua puede almacenarse por largos períodos de tiempo, principalmente debido a la acumulación de nieve en el invierno. Cuando comienza la estación de crecimiento, el suelo se halla a capacidad de campo, y se va desecando durante el transcurso de la misma (Rusch, 1987). La densidad de las copas y la sombra juegan un papel importante, ya que pueden mantener húmedas las capas superficiales reduciendo la evaporación (Barrera et al., 2000; Donoso, 1990).

En correspondencia al mapa de suelos de la República Argentina (SAGyP INTA, 1990), los suelos de la CAG se ubican en la asociación IVli-2/C Eh. Ésta es una asociación entre 4 subgrupos, pertenecientes a distintos órdenes (Tabla 6).

Tabla 6. Órdenes de suelos de la Cuenca del Arroyo Grande, utilizando la clasificación del Soil Survey Staff (1999).

Soil orders of Arroyo Grande catchment using the Soil Survey Staff (1999) classification.

\begin{tabular}{llll}
\hline ORDEN & SUBORDEN & GRANGRUPO & SUBGRUPO \\
\hline Inceptisoles & Umbreptes & Criumbreptes & ándicos IVan \\
Inceptisoles & Umbreptes & Criumbreptes & líticos IVli \\
Histosoles & Fibristes & Sfagnofibristes & críicos $\mathrm{HEci}$ \\
Spodosoles & Humodes & Criohumodes & típicos SAtc \\
\hline
\end{tabular}


La asociación está descripta como antiguas planicies glaciales, actualmente muy erosionadas, con colinas y cerros. Posee un paisaje de pendientes, valles, planicies turberas y mallines. Sitúan al subgrupo IVli en las pendientes altas, al subgrupo SAtc en las pendientes de hasta un $3 \%$, al IVan al pie de pendientes y en medias lomas y al subgrupo HEci en las depresiones, turberas y sectores aledaños a las vías de drenaje (Foto 2).

Foto 2: Fondo del valle del Arroyo Grande donde se aprecia la turbera en explotación. Bottom of Arroyo Grande Valley where the peat bog in exploitation is observed.

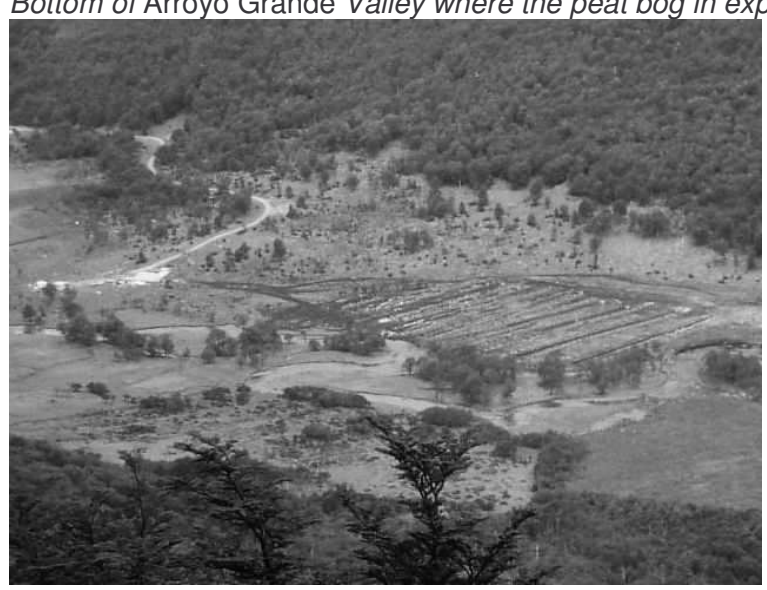

A continuación se presentan las características generales de cada subgrupo:

\section{Subgrupo IVan:}

Suelos poligenéticos, originados a partir de tres materiales distintos. Profundos (alrededor de $110 \mathrm{~cm}$ ) y débilmente desarrollados. Moderadamente bien drenados (grado 3 en la clasificación del INTA), lo que significa que el agua sale con cierta lentitud y existe una capa de permeabilidad moderadamente lenta y/o un nivel relativamente alto y/o cierta infiltración (Etchevere, 1981). Sin rasgos de alcalinidad ni salinidad. Secuencia de horizontes: A, IIC1, IIIB2, IIIC2.

Horizonte $A: 30 \mathrm{~cm}$ de espesor, epipedón úmbrico, bien provisto de materia orgánica (10\%), textura franco arcillosa arenosa.

Horizonte IIC1: $25 \mathrm{~cm}$ de espesor, es un manto de grava sin estructura definida.

Horizonte IIIB2: es de textura arcillosa y bien estructurado.

Horizonte IIIC2: hasta los $110 \mathrm{~cm}$, formado por un manto de gravas y no tiene estructura definida.

\section{Subgrupo IVli:}

Suelos evolucionados a partir de dos materiales diferentes. Son someros (de aproximadamente $40 \mathrm{~cm}$ ) y sin desarrollo. Están excesivamente drenados (grado 5 - 6 en la clasificación del INTA), lo que manifiesta que no retiene la humedad o lo hace 
deficientemente, posee poca diferenciación de horizontes, su permeabilidad es rápida y no tiee moteados ni nivel freático cercano a la superficie (Etchevere, 1981). No tienen rasgos de salinidad ni alcalinidad. La secuencia de horizontes es: A11, A12, IIC, $R$.

Horizontes $A 11$ y $A 12$ : constituyen el epipedón úmbrico de aproximadamente 28 cm, están bien provistos de materia orgánica (16\%) y presentan textura franca.

Horizonte $C$ : con textura franco arcillosa, bien estructurado y abundantes clastos pequeños en su matriz.

\section{Subgrupo SAtC:}

Evolucionaron a partir de dos materiales distintos. La profundidad es mayor a $140 \mathrm{~cm}$ y están muy desarrollados. No son salinos ni alcalinos. El drenaje se clasifica como moderadamente bien o bien drenado (grado 3 - 4 en la clasificación del INTA) y tiene las siguientes características: retiene una cantidad óptima de agua y el exceso se retira con facilidad pero no con rapidez, las texturas no son extremas y no presentan y no presentan rasgos de hidromorfismo. Poseen la siguiente secuencia de horizontes: O2, $A 2$ o $E, C 1,\|C 2\| C$,3 .

Horizonte 02: de aproximadamente $8 \mathrm{~cm}$, es una acumulación de origen orgánico, con un $21 \%$ de materia orgánica.

Horizonte A2: posee $21 \mathrm{~cm}$ de potencia y correspondería al llamado horizonte $E$.

Horizonte $C$ : se diferencian entre si por la presencia o ausencia de gravas y clastos.

\section{Subgrupo HEci:}

Son profundos, evolucionados a partir de manto turboso de Sphagnum sp. No presentan desarrollo y el drenaje se clasifica como malo (grado 0 en la clasificación del INTA) Según Etchevere (1981), esto determina que el agua se elimine tan lentamente como para que la napa freática permanezca cerca o sobre la superficie. No tienen una secuencia definida de horizontes, estando relacionada con el estado de descomposición del material vegetal y su color. Tampoco poseen estructura definida. El espesor de los perfiles depende de la profundidad en la que se encuentra el agua.

En las altitudes, después de la línea de vegetación, se presentan los afloramientos rocosos y las áreas de nieves y hielos permanentes. Asociados a estos afloramientos se dan suelos someros sobre rocas poco meteorizadas. En la Tabla 7 se presentan las características más importantes de los subgrupos de suelos presentes en la cuenca de estudio. En el Mapa 6 de unidades de vegetación, se pueden interpretar la distribución de los distintos tipos de suelos en la CAG mediante la 
cobertura vegetal. El subgrupo IVli se encuentra determinado por pastizales y las zonas de suelo desnudo de altura. El subgrupo SAtc esta representado por los bosques de $N$. pumilio de altura y una parte de los bosque de ladera de $N$. pumilio y $N$. betuloides. El subgrupo IVan se encuentra distribuido en el bosque de $N$. pumilio y $N$. betuloides en los fondos de valle, y el subgrupo HEci en las zonas de turberas.

Tabla 7. Características edáficas de los subgrupos. Sub-groups soil characteristics.

\begin{tabular}{llllll}
\hline Sub Grupo & Drenaje & Profundidad. $(\mathrm{cm})$ & E. Actual & E. Potencial & Pedregosidad \\
\hline IVan & $\mathrm{MB}$ & 110 & $\mathrm{HL}$ & $\mathrm{HS}$ & pocas gravas finas \\
IVli & $\mathrm{B}$ & 40 & - & $\mathrm{HS}$ & pocas gravas finas \\
HEci & $\mathrm{M}$ & 100 & - & - & - \\
SAtc & $\mathrm{MB}$ & 140 & - & - & muchas gravas finas \\
\hline
\end{tabular}

MB: moderadamente bueno, B: bueno, M: malo, E. Actual: erosión actual, E. Potencial: erosión potencial, HL: hídrica leve, HS: hídrica severa.

\subsubsection{Vegetación}

En los bosques de Nothofagus sp. (Foto 3), el estrato de vegetación inferior es dominado por especies arbustivas, subarbustivas y herbáceas. Estas especies desarrollan una altura entre 2 y $80 \mathrm{~cm}$ aproximadamente. La regeneración de Nothofagus sp. es abundante y desarrolla vigorosamente en los sectores abiertos, presentando daños causados por el ramoneo del ganado en lugares intervenidos y cerca de los pastizales (Pulido et al., 2000).

Foto 3: Bosques de N. pumilio y $N$. betuloides.

Forests of $\mathrm{N}$. pumilio and $\mathrm{N}$. betuloides.

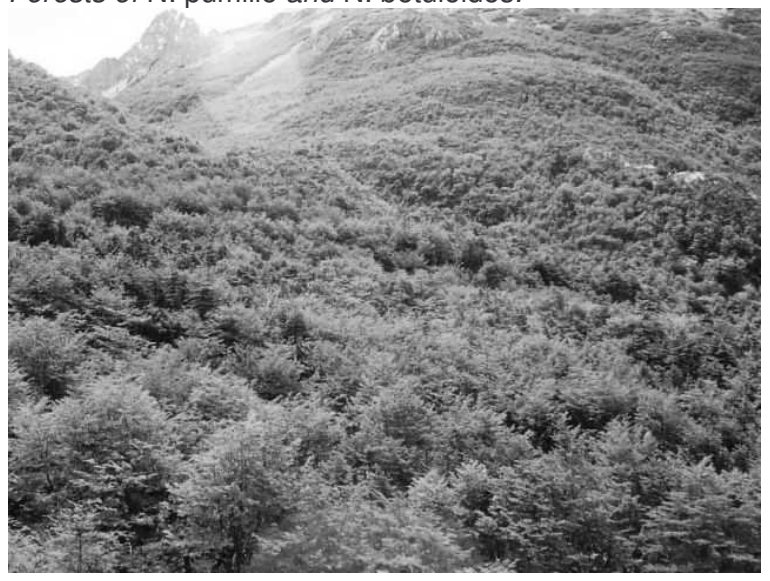

En los turbales y zonas de drenaje deficiente, la condición de hidromorfismo es responsable del desarrollo de una vegetación característica. En los bosques de Tierra del Fuego el sotobosque es específicamente pobre comparado con el de otros ecosistemas forestales templados del mundo (Moore, 1983; Christensen \& Emborg, 1996; Liu et al., 1998; Wigley \& Roberts, 1997). Sus especies características son Blechnum penna-marina (Poiret) Kuhn, Cardamine glacialis (Forster f.) DC, Galium 
aparine L., Dysopsis glechomoides (A. Richard) Müller Arg., Luzula alopecurus Desv., Osmorhiza chilensis Hooker \& Arn, Schizeilema ranunculus (D'Urv.) Domin y Viola magellanica Forster f. (Hildebrand-Vogel et al., 1990; Lencinas et al., 2001b, 2001c Moore, 1983; Pisano, 1997). La composición y distribución de las especies de estos sistemas, dependen de sus características climáticas y edáficas, observándose que un incremento en las precipitaciones permite el desarrollo de musgos y hongos (Matteri \& Schiavone, 1988), mientras que la disponibilidad de agua en el suelo condiciona la riqueza y el crecimiento de las plantas superiores (Moore, 1983; Pisano, 1997; Rivero et al., 2000a, 2000b; Roig, 1998). Un factor importante es la luz incidente dentro del bosque, que varía con la densidad de árboles del sitio (Endlicher \& Santana, 1988) y el grado de cobertura del dosel, que cuando es muy elevado genera un sotobosque ralo y de poca biomasa (Martínez Pastur et al., 2002b). Por otra parte, las propiedades físico-químicas edáficas dependen del tipo de suelo y su drenaje (Pisano, 1997), la altitud sobre el nivel del mar (Hildebrand-Vogel, 1990), la cercanía a las costas y a otras comunidades vegetales, y del grado de intervención antrópica (Martínez Pastur et al., 2002b; Roig, 1998). El suelo en los fondos de valle en comparación con los desarrollados en pendientes relativamente fuertes es más profundo (ver 2.3. Geomorfología y suelos), existiendo diferencias en la composición y estructura vegetacional (Lencinas, et al., 2001d; Mariottini et al., 2002).

Se determinaron 139 unidades de vegetación, con una superficie promedio de 43,73 ha por unidad. Del total de las UV, 24 corresponden al tipo $G$ ( $N$. betuloides) con una superficie promedio de 23,75 ha, $84 U V$ al tipo $L$ (N. pumilio) con 49,43 ha de superficie media. Los tipos Pastizal $(P)$ y Turbera $(T)$ presentaron 27 y 4 UV respectivamente, con superficie promedio de 45,14 y 34 ha. En el relevamiento realizado en la $C A G$ en distintas unidades de vegetación se observó la presencia de 110 entidades (71 dicotiledóneas, 33 monocotiledóneas, tres pteridofitas, las morfoespecies de hepáticas y musgos y Sphagnum sp.) (Tablas 8 y 9). Las unidades de vegetación muestreadas presentaron diferencias en la cobertura dependiendo del tipo de unidad y la calidad de sitio (III, IV, V, V Bajo y Krummholz). Las diferencias se pueden observar en la Tablas 10 y 11 . En el caso de $T$ y $P$ presentan las menores coberturas arbóreas llegando a 0 en el caso de $T$. Para el rango de calidades de sitio, no se encontraron diferencias para las coberturas arbóreas. Se pueden observar diferencias en el sotobosque para las distintas situaciones estudiadas. La densidad de sotobosque es máxima en $T(100 \%)$, reduciéndose en $P$ y a medida que el bosque es más bajo, presentando el límite inferior en Krummholz, con 49,93\%. Para los residuos, $T$ y $P$ presentan valores bajos $(0,00 \%$ y $0,67 \%)$ debido a la ausencia de material leñoso y a la alta cobertura de herbáceas, musgos y hepáticas. Por otra parte, en el 
Juan Manuel Cellini - Manejo de los recursos naturales en la Cuenca del Arroyo Grande.

bosque los residuos aumentan a medida que la calidad de sitio mejora, ya que son bosques con mayor producción (16,43\% sitio III a 9,00\% en Krummholz). 
Tabla 8. Especies de dicotiledóneas presentes en la Cuenca del Arroyo Grande: sistemática (según Moore, 1983), clave de identificación y origen.

Dicotyledoneae species present in Arroyo Grande catchment: systematics (according to Moore, 1983), key of identification and origin.

\begin{tabular}{|c|c|c|c|c|c|c|c|}
\hline Porte & Especie & Familia & Origen & G & $\mathbf{L}$ & $\mathbf{P}$ & $\mathbf{T}$ \\
\hline$\overline{\mathrm{AR}}$ & Nothofagus antarctica (Forster f.) Oersted & Nothofagaceae & Nativa & 0 & 1 & 1 & 1 \\
\hline AR & Nothofagus betuloides (Mirbel) Oersted & Nothofagaceae & Nativa & 1 & 1 & 1 & 0 \\
\hline $\mathrm{AR}$ & Nothofagus pumilio (Poepp. et Endl.) Krasser & Nothofagaceae & Nativa & 1 & 1 & 1 & 0 \\
\hline$\overline{\text { AT }}$ & Berberis buxifolia Lam. & Berberidaceae & Nativa & 1 & 1 & 1 & 0 \\
\hline AT & Chiliotrichum diffusum (Forester f.) O. Kuntze & Compositae & Nativa & 1 & 1 & 1 & 0 \\
\hline AT & Ribes magellanica Poiret & Saxifragaceae & Nativa & 1 & 1 & 1 & 0 \\
\hline$\overline{\mathrm{H}}$ & Cerastium arvense $\mathrm{L}$. & Caryophyllaceae & Nativa & 0 & 1 & 1 & 0 \\
\hline $\mathrm{H}$ & Adenocaulon chilense Less. & Compositae & Nativa & 1 & 1 & 0 & 0 \\
\hline $\mathrm{H}$ & Aster vahlii (Gaudich.) Hooker et Arn. & Compositae & Nativa & 1 & 1 & 1 & 0 \\
\hline $\mathrm{H}$ & Cotula scariosa (Cass.) Franchet & Compositae & Nativa & 0 & 1 & 1 & 0 \\
\hline $\mathrm{H}$ & Erigeron myosotis Pers. & Compositae & Nativa & 0 & 0 & 1 & 0 \\
\hline $\mathrm{H}$ & Gamochaeta spiciformis (Sch. Bip.) Cabrera & Compositae & Nativa & 0 & 1 & 0 & 0 \\
\hline $\mathrm{H}$ & Hypochoeris incana (Hooker et Arn.) Macloskie & Compositae & Nativa & 0 & 0 & 1 & 0 \\
\hline $\mathrm{H}$ & Lagenifera hariotii (Franchet) T. Dudley & Compositae & Nativa & 0 & 1 & 0 & 0 \\
\hline $\mathrm{H}$ & Macrachaenium gracile Hooker $\mathrm{f}$. & Compositae & Nativa & 1 & 1 & 0 & 0 \\
\hline $\mathrm{H}$ & Nassauvia magellanica J. F. Gmelin & Compositae & Nativa & 0 & 0 & 1 & 0 \\
\hline $\mathrm{H}$ & Perezia magellanica (L. f.) Lag. & Compositae & Nativa & 0 & 1 & 1 & 0 \\
\hline $\mathrm{H}$ & Perezia pilifera (D. Don) Hooker et Arn. & Compositae & Nativa & 0 & 0 & 1 & 0 \\
\hline $\mathrm{H}$ & Senecio acanthifolius Hombron et Jacquinot & Compositae & Nativa & 1 & 1 & 1 & 0 \\
\hline $\mathrm{H}$ & Senecio alloeophyllus O. Hoffm. & Compositae & Nativa & 0 & 1 & 1 & 0 \\
\hline $\mathrm{H}$ & Senecio magellanicus Hooker et Arn. & Compositae & Nativa & 0 & 0 & 1 & 0 \\
\hline $\mathrm{H}$ & Senecio sp. 1 & Compositae & Nativa & 0 & 1 & 1 & 0 \\
\hline $\mathrm{H}$ & Senecio sp. 2 & Compositae & Nativa & 0 & 0 & 1 & 0 \\
\hline $\mathrm{H}$ & Senecio tricuspidatus Hooker et Arn. & Compositae & Nativa & 0 & 1 & 1 & 0 \\
\hline $\mathrm{H}$ & Cardamine geraniifolia (Poiret) DC. & Cruciferae & Nativa & 0 & 1 & 0 & 0 \\
\hline $\mathrm{H}$ & Cardamine glacialis (Forster F.) DC. & Cruciferae & Nativa & 1 & 1 & 1 & 0 \\
\hline $\mathrm{H}$ & Draba magellanica Lam. & Cruciferae & Nativa & 0 & 1 & 0 & 0 \\
\hline $\mathrm{H}$ & Empetrum rubrum Vahl ex Willd. & Empetraceae & Nativa & 1 & 1 & 1 & 1 \\
\hline $\mathrm{H}$ & Pernettya mucronata (L. f.) Gaudich & Ericaceae & Nativa & 1 & 1 & 1 & 0 \\
\hline $\mathrm{H}$ & Pernettya pumila (L. f.) Hooker & Ericaceae & Nativa & 1 & 1 & 1 & 1 \\
\hline $\mathrm{H}$ & Dysopsis glechomoides (A. Richard) Müller Arg. & Euphorbiaceae & Nativa & 1 & 1 & 0 & 0 \\
\hline $\mathrm{H}$ & Gunnera magellanica Lam. & Haloragaceae & Nativa & 1 & 1 & 1 & 1 \\
\hline $\mathrm{H}$ & Hippuris vulgaris $\mathrm{L}$. & Hippuridaceae & Nativa & 0 & 0 & 0 & 1 \\
\hline $\mathrm{H}$ & Epilobium australe Poeppig et Hausskn. & Onagraceae & Nativa & 0 & 1 & 1 & 0 \\
\hline $\mathrm{H}$ & Oxalis magellanica Forster $\mathrm{f}$. & Oxalidaceae & Nativa & 0 & 1 & 1 & 0 \\
\hline $\mathrm{H}$ & Armeria maritima (Miller) Willd. & Plumbaginaceae & Nativa & 0 & 0 & 1 & 0 \\
\hline $\mathrm{H}$ & Primula magellanica Lehm. & Primulaceae & Nativa & 0 & 1 & 1 & 0 \\
\hline $\mathrm{H}$ & Caltha saqittata Cav. & Ranunculaceae & Nativa & 0 & 1 & 1 & 0 \\
\hline $\mathrm{H}$ & Caltha sp. L. & Ranunculaceae & Nativa & 1 & 1 & 1 & 0 \\
\hline $\mathrm{H}$ & Hamadryas magellanica Lam. & Ranunculaceae & Nativa & 0 & 0 & 1 & 0 \\
\hline $\mathrm{H}$ & Ranunculus biternatus Sm. & Ranunculaceae & Nativa & 1 & 1 & 1 & 0 \\
\hline $\mathrm{H}$ & Ranunculus fuegianus Speq. & Ranunculaceae & Nativa & 1 & 1 & 0 & 0 \\
\hline $\mathrm{H}$ & Ranunculus maclovianus D'Urv. & Ranunculaceae & Nativa & 0 & 1 & 1 & 0 \\
\hline $\mathrm{H}$ & Ranunculus peduncularis Sm. & Ranunculaceae & Nativa & 0 & 1 & 1 & 0 \\
\hline $\mathrm{H}$ & Acaena magellanica (Lam.) Vahl & Rosaceae & Nativa & 1 & 1 & 1 & 0 \\
\hline $\mathrm{H}$ & Acaena ovalifolia Ruiz et Pavón & Rosaceae & Nativa & 1 & 1 & 1 & 0 \\
\hline $\mathrm{H}$ & Acaena pinnatifida Ruiz et Pavón & Rosaceae & Nativa & 0 & 1 & 1 & 0 \\
\hline $\mathrm{H}$ & Acaena tenera Alboff & Rosaceae & Nativa & 0 & 1 & 1 & 0 \\
\hline $\mathrm{H}$ & Geum parviflorum Comm. ex Sm. & Rosaceae & Nativa & 1 & 1 & 1 & 0 \\
\hline $\mathrm{H}$ & Rubus geoide Sm. & Rosaceae & Nativa & 1 & 1 & 1 & 0 \\
\hline $\mathrm{H}$ & Galium antarcticum Hooker $\mathrm{f}$. & Rubiaceae & Nativa & 0 & 1 & 0 & 0 \\
\hline $\mathrm{H}$ & Galium aparine $\mathrm{L}$. & Rubiaceae & Nativa & 0 & 1 & 0 & 0 \\
\hline $\mathrm{H}$ & Nanodea muscosa Banks ex. C. F. Gaertner & Santalaceae & Nativa & 0 & 1 & 1 & 0 \\
\hline $\mathrm{H}$ & Saxifraga magellanica Poiret & Saxifragaceae & Nativa & 0 & 1 & 1 & 0 \\
\hline $\mathrm{H}$ & Ourisia breviflora Bentham & Scrophulariaceae & Nativa & 0 & 1 & 0 & 0 \\
\hline $\mathrm{H}$ & Drapetes muscosus Banks ex Lam. & Thymelaeaceae & Nativa & 0 & 1 & 1 & 0 \\
\hline $\mathrm{H}$ & Azorella fuegiana Speg. & Umbelliferae & Nativa & 0 & 1 & 1 & 0 \\
\hline $\mathrm{H}$ & Azorella lycopodioides Gaudich. & Umbelliferae & Nativa & 0 & 1 & 1 & 0 \\
\hline $\mathrm{H}$ & Bolax gummifera (Lam.) Sprengel & Umbelliferae & Nativa & 0 & 1 & 0 & 0 \\
\hline $\mathrm{H}$ & Osmorhiza chilensis Hooker et Arn. & Umbelliferae & Nativa & 1 & 1 & 1 & 0 \\
\hline $\mathrm{H}$ & Viola magellanica Forster $\mathrm{f}$. & Violaceae & Nativa & 1 & 1 & 1 & 0 \\
\hline $\mathrm{H}$ & Cerastium fontanum Baumg. & Caryophyllaceae & Exótica & 0 & 1 & 1 & 0 \\
\hline
\end{tabular}




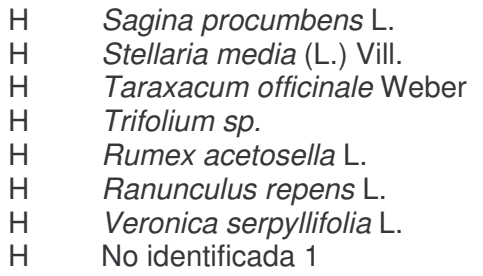

$\begin{array}{llllll}\text { Caryophyllaceae } & \text { Exótica } & 0 & 1 & 0 & 0 \\ \text { Caryophyllaceae } & \text { Exótica } & 0 & 1 & 0 & 0 \\ \text { Compositae } & \text { Exótica } & 0 & 1 & 1 & 0 \\ \text { Leguminosae } & \text { Exótica } & 0 & 1 & 1 & 0 \\ \text { Polygonaceae } & \text { Exótica } & 0 & 1 & 1 & 0 \\ \text { Ranunculaceae } & \text { Exótica } & 0 & 1 & 1 & 0 \\ \text { Scrophulariaceae } & \text { Exótica } & 0 & 1 & 0 & 0 \\ \text { - } & - & 0 & 0 & 1 & 0 \\ \text { - } & - & 0 & 1 & 0 & 0\end{array}$

AR: arbóreo, AT: arbustivo, $H$ : herbáceo, L: tipo de unidad de vegetación N. pumilio, G: tipo de unidad de vegetación $N$. betuloides, $T$ : tipo de unidad de vegetación Turbera, $P$ : tipo de unidad de vegetación Pastizal, 0: ausencia de la especie en el tipo de unidad de vegetación, 1: presencia de la especie en el tipo de unidad de vegetación

Tabla 9. Especies de monocotiledóneas, pteridofitas y briófitas presentes en la Cuenca del Arroyo Grande: sistemática (según Moore, 1983), clave de identificación y origen.

Monocotyledoneae, Bryophyta and Pteridophyta present in Arroyo Grande catchment: systematics (according to Moore, 1983), key of identification and origin.

\begin{tabular}{|c|c|c|c|c|}
\hline Tipo & Nombre científico & Familia & Origen & G L P T \\
\hline$\overline{\mathrm{M}}$ & Carex gayana Desv. & Cyperaceae & Nativa & 0010 \\
\hline M & Carex magellanica Lam. & Cyperaceae & Nativa & 00001 \\
\hline M & Carex sp. L. & Cyperaceae & Nativa & 0010 \\
\hline M & Cartex curta Gooden. & Cyperaceae & Nativa & 0001 \\
\hline M & Schoenus antarctucus (Hooker f.) Dusén & Cyperaceae & Nativa & 0010 \\
\hline M & Uncinia lechleriana Steudel & Cyperaceae & Nativa & 0110 \\
\hline M & Agropyron fuegianum (Speg.) F. Kurtz & Gramineae & Nativa & 0010 \\
\hline M & Alopecurus magellanicus Lam. & Gramineae & Nativa & 0111 \\
\hline M & Bromus unioloides Humb. Bonpl. et Kunth & Gramineae & Nativa & 0010 \\
\hline M & Deschampsia atropurpurea (Wahlenb.) Scheele & Gramineae & Nativa & 0100 \\
\hline M & Deschampsia kingii (Hooker f.) Desv. & Gramineae & Nativa & 0010 \\
\hline M & Festuca magellanica Lam. & Gramineae & Nativa & 0110 \\
\hline M & Hierochloë redolens (Vahl) Roemer et Schultes & Gramineae & Nativa & 1110 \\
\hline M & Phleum alpinum $\mathrm{L}$. & Gramineae & Nativa & 0110 \\
\hline M & Poa alopecurus ssp. fuegiana (Hooker f.) D. M. Moore et Doggett & Gramineae & Nativa & 0010 \\
\hline M & Poa robusta Steudel & Gramineae & Nativa & 0110 \\
\hline M & Stipa rariflora (Hooker f.) Bentham & Gramineae & Nativa & 0010 \\
\hline M & Trisetum cernuum Trin. & Gramineae & Nativa & 0100 \\
\hline M & Trisetum sp. Pers. 1 & Gramineae & Nativa & 0100 \\
\hline M & Trisetum sp. Pers. 2 & Gramineae & Nativa & 0100 \\
\hline M & Trisetum spicatum (L.) K. Richter & Gramineae & Nativa & 0110 \\
\hline M & Luzula alopecurus Desv. & Juncaceae & Nativa & 0110 \\
\hline M & Marsippospermum sp. Desv. & Juncaceae & Nativa & 0111 \\
\hline $\mathrm{M}$ & Rostkovia magellanica (Lam.) Hooker f. & Juncaceae & Nativa & $\begin{array}{llll}1 & 1 & 0 & 1\end{array}$ \\
\hline M & Tetroncium magellanicum Willd. & Juncaginaceae & Nativa & 0001 \\
\hline M & Astelia pumila (Forster f.) Gaudich. & Liliaceae & Nativa & 0110 \\
\hline M & Luzuriaga marginata (Banks et Sol. ex Gaertner) Bentham et Hooker & Liliaceae & Nativa & 1100 \\
\hline M & Codonorchis lessonii (D'Urv.) Lindley & Orchidaceae & Nativa & 1100 \\
\hline M & Gavilea lutea (Pers.) Correa & Orchidaceae & Nativa & 0100 \\
\hline M & Agrostis stolonifera L. & Gramineae & Exótica & 1111 \\
\hline M & Poa nemoralis L. & Gramineae & Exótica & 1110 \\
\hline M & Poa pratensis L. & Gramineae & Exótica & 0110 \\
\hline M & Poa trivialis $\mathrm{L}$. & Gramineae & Exótica & 0100 \\
\hline $\mathrm{Pt}$ & Polystichum andinum Phil. & Aspidiaceae & Nativa & 0010 \\
\hline $\mathrm{Pt}$ & Cystopteris fragilis (L.) Bernh. & Aspleniaceae & Nativa & 1100 \\
\hline $\mathrm{Pt}$ & Blechnum penna-marina (Poiret) Kuhn & Blechnaceae & Nativa & 1110 \\
\hline $\mathrm{B}$ & Briófita & & Nativa & 11111 \\
\hline $\mathrm{B}$ & Sphagnum sp. & & Nativa & 1111 \\
\hline $\mathrm{B}$ & Hepática & & Nativa & 1100 \\
\hline
\end{tabular}

M: Monocotiledóneas, Pt: Pteridofitas, B: Briófitas, L: tipo de unidad de vegetación N. pumilio, G: tipo de unidad de vegetación $N$. betuloides, $T$ : Turbera, $P$ : Pastizal, 0: ausencia de la especie, 1: presencia de la especie.

En el porcentaje de suelo desnudo es nulo en $T$ y en $P$ y en el sitio III toma valores cercanos al 10\%. El mayor valor se observa en Krummholz con un 41,07\% e 
intermedio para las demás calidades de sitio. Se realizó un análisis de coberturas entre los tipos forestales $N$. pumilio y $N$. betuloides para las variables cobertura de copas, sotobosque, residuos y suelo en porcentaje (Tabla 11), donde se puede observar que el bosque de $N$. betuloides presenta la mayor cobertura de copas y porcentaje de suelo desnudo, con mayor porcentaje en $N$. pumilio en sotobosque y residuos.

Tabla 10. Análisis de varianza de cobertura de las copas y coberturas del suelo discriminadas por sitio. Analysis of variance of forest cover and ground cover discriminated by site class.

\begin{tabular}{llllll}
\hline & $\mathrm{n}$ & Cobertura de Copas (\%) & Sotobosque $(\%)$ & Residuos (\%) & Suelo (\%) \\
\hline $\mathrm{F}$ & & 63,17 & 4,91 & 9,23 & 3,55 \\
$\mathrm{P}(95 \%)$ & & $(0,0000)$ & $(0,0002)$ & $(0,0000)$ & $(0,0032)$ \\
\hline$T$ & 4 & - & $100,00 \mathrm{bc}$ & $0,00 \mathrm{ab}$ & $0,00 \mathrm{ab}$ \\
$P$ & 27 & - & $87,20 \mathrm{~b}$ & $0,67 \mathrm{a}$ & $12,13 \mathrm{a}$ \\
$I I I$ & 7 & $72,14 \mathrm{~b}$ & $72,86 \mathrm{abc}$ & $16,43 \mathrm{c}$ & $10,71 \mathrm{ab}$ \\
$V I$ & 17 & $74,53 \mathrm{~b}$ & $52,00 \mathrm{a}$ & $14,29 \mathrm{c}$ & $33,71 \mathrm{ab}$ \\
$V(17-10 \mathrm{~m})$ & 60 & $78,45 \mathrm{~b}$ & $62,89 \mathrm{ac}$ & $14,53 \mathrm{c}$ & $22,58 \mathrm{ab}$ \\
V Bajo $(10-7 \mathrm{~m})$ & 10 & $81,50 \mathrm{~b}$ & $57,70 \mathrm{abc}$ & $10,20 \mathrm{bc}$ & $32,10 \mathrm{ab}$ \\
Krummholz $(<7)$ & 14 & $76,79 \mathrm{~b}$ & $49,93 \mathrm{a}$ & $9,00 \mathrm{bc}$ & $41,07 \mathrm{~b}$ \\
\hline
\end{tabular}

Letras diferentes indican diferencias significativas a $\mathrm{P}<0,05$ según prueba de Tukey, III, IV, V, V Bajo y Krummholz: calidades de sitio, T: tipo de unidad de vegetación Turbera, $P$ : tipo de unidad de vegetación Pastizal, n: número de observaciones, F: Test de Fisher, P (95\%): nivel de probabilidad, valores expresados en medias.

Tabla 11. Análisis de varianza de cobertura de las copas y cobertura del suelo por unidades de vegetación.

Analysis of variance of forest cover and ground cover discriminated by vegetation units.

\begin{tabular}{llllll}
\hline & $\mathrm{n}$ & Cobertura de Copas (\%) & Vegetación (\%) & Residuos (\%) & Suelo (\%) \\
\hline $\mathrm{F}$ & & 115,81 & 8,40 & 14,88 & 4,22 \\
$\mathrm{P}(95 \%)$ & $(0,0000)$ & $(0,0001)$ & $(0,0000)$ & $(0,0076)$ \\
\hline$T$ & 4 & - & $100,00 \mathrm{a}$ & $0,00 \mathrm{ab}$ & $0,00 \mathrm{ab}$ \\
$P$ & 27 & - & $87,20 \mathrm{a}$ & $0,67 \mathrm{a}$ & $12,13 \mathrm{a}$ \\
$L$ & 84 & $76,04 \mathrm{~b}$ & $61,06 \mathrm{~b}$ & $13,63 \mathrm{c}$ & $25,31 \mathrm{ab}$ \\
$\mathrm{G}$ & 24 & $82,58 \mathrm{~b}$ & $50,81 \mathrm{~b}$ & $11,37 \mathrm{bc}$ & $37,81 \mathrm{~b}$ \\
\hline
\end{tabular}

Letras diferentes indican diferencias significativas a $\mathrm{P}<0,05$ según prueba de Tukey, $L$ : tipo de unidad de vegetación $N$. pumilio, G: tipo de unidad de vegetación $N$. betuloides, T: tipo de unidad de vegetación Turbera, $P$ : tipo de unidad de vegetación Pastizal, n: número de observaciones, F: Test de Fisher, $\mathrm{P}$ (95\%): nivel de probabilidad, valores expresados en medias.

Al realizar un análisis de varianza considerando las unidades de vegetación y calidades de sitio estudiadas se observaron diferencias estadísticas en todas las variables estudiadas (Tablas 12 y 13). El porcentaje de plantas de dicotiledóneas en relación al total, varió significativamente en $T(22,89 \%)$ respecto de los otros tratamientos $(41,65 \%$ a $69,08 \%)$. Lo mismo ocurrió con las matas de monocotiledóneas para $P$, presentando valores menores al $15 \%$ en las demás situaciones y del $35,59 \%$ en el pastizal (Foto 1 ). 
Tabla 12. Análisis de varianza de la abundancia de especies detectadas (\%) discriminada por calidad de sitio y unidad de vegetación.

Analysis of variance of abundance of detected species (\%) discriminated by vegetation units and site class.

\begin{tabular}{llllll}
\hline & $\mathrm{n}$ & Dicotiledóneas & Monocotiledóneas & Musgos y hepáticas & Pteridófitas \\
\hline $\mathrm{F}$ & & 2,79 & 7,06 & 6,83 & 4,30 \\
$\mathrm{P}(95 \%)$ & & $(0,0152)$ & $(0,0000)$ & $(0,0000)$ & $(0,0007)$ \\
\hline$T$ & 3 & $22,89 \% \mathrm{a}$ & $13,05 \% \mathrm{a}$ & $64,06 \% \mathrm{c}$ & $0,0 \% \mathrm{ab}$ \\
$P$ & 15 & $59,66 \% \mathrm{bc}$ & $35,59 \% \mathrm{~b}$ & $4,48 \% \mathrm{a}$ & $0,27 \% \mathrm{a}$ \\
$\mathrm{III}$ & 7 & $69,08 \% \mathrm{c}$ & $14,65 \% \mathrm{a}$ & $14,71 \% \mathrm{ab}$ & $1,56 \% \mathrm{bc}$ \\
$V I$ & 14 & $65,47 \% \mathrm{c}$ & $5,88 \% \mathrm{a}$ & $26,76 \% \mathrm{~b}$ & $1,88 \% \mathrm{c}$ \\
$V(17-10 \mathrm{~m})$ & 38 & $61,94 \% \mathrm{c}$ & $10,54 \% \mathrm{a}$ & $27,08 \% \mathrm{~b}$ & $0,43 \% \mathrm{a}$ \\
V Bajo $(10-7 \mathrm{~m})$ & 10 & $48,43 \% \mathrm{abc}$ & $1,63 \% \mathrm{a}$ & $49,78 \% \mathrm{c}$ & $0,16 \% \mathrm{a}$ \\
Krummholz $(<7)$ & 14 & $41,75 \% \mathrm{ab}$ & $4,73 \% \mathrm{a}$ & $53,37 \% \mathrm{c}$ & $0,15 \% \mathrm{a}$ \\
\hline
\end{tabular}

Letras diferentes indican diferencias significativas a $\mathrm{P}<0,05$ según prueba de Tukey; III, IV, V, V Bajo y Krummholz: calidades de sitio; $T$ : tipo de unidad de vegetación Turbera; $P$ : tipo de unidad de vegetación Pastizal, n: número de observaciones, F: Test de Fisher, P (95\%): nivel de probabilidad, valores expresados en medias.

Tabla 13. Análisis de varianza de la abundancia de especies detectadas por unidades de vegetación (\%). Analysis of variance of abundance of species detected by vegetation units (\%).

\begin{tabular}{llllll}
\hline & $\mathrm{n}$ & $\mathrm{D}$ & $\mathrm{M}$ & Musgos y hepáticas & Pteridófitas \\
\hline $\mathrm{F}$ & & 2,26 & 14,06 & 8,14 & 1,12 \\
$\mathrm{P}(95 \%)$ & & $(0,0859)$ & $(0,0000)$ & $(0,0001)$ & $(0,3455)$ \\
\hline$T$ & 3 & $22,89 \% \mathrm{a}$ & $13,05 \% \mathrm{a}$ & $64,06 \% \mathrm{c}$ & $0,0 \% \mathrm{a}$ \\
$P$ & 15 & $59,66 \% \mathrm{~b}$ & $35,59 \% \mathrm{~b}$ & $4,48 \% \mathrm{a}$ & $0,27 \% \mathrm{a}$ \\
$L$ & 67 & $59,69 \% \mathrm{~b}$ & $9,67 \% \mathrm{a}$ & $29,86 \% \mathrm{~b}$ & $0,78 \% \mathrm{a}$ \\
$G$ & 16 & $51,49 \% \mathrm{ab}$ & $1,26 \% \mathrm{a}$ & $46,91 \% \mathrm{c}$ & $0,34 \% \mathrm{a}$ \\
\hline
\end{tabular}

Letras diferentes indican diferencias significativas a $\mathrm{P}<0,05$ según prueba de Tukey, $L$ : tipo de unidad de vegetación $N$. pumilio, G: tipo de unidad de vegetación $N$. betuloides, T: tipo de unidad de vegetación Turbera, $P$ : tipo de unidad de vegetación Pastizal, D: Dicotiledóneas; M: Monocotiledóneas, n: número de observaciones, F: Test de Fisher, P (95\%): nivel de probabilidad, valores expresados en medias.

Foto 1. Pastizal de altura.

Mountain grasslands.

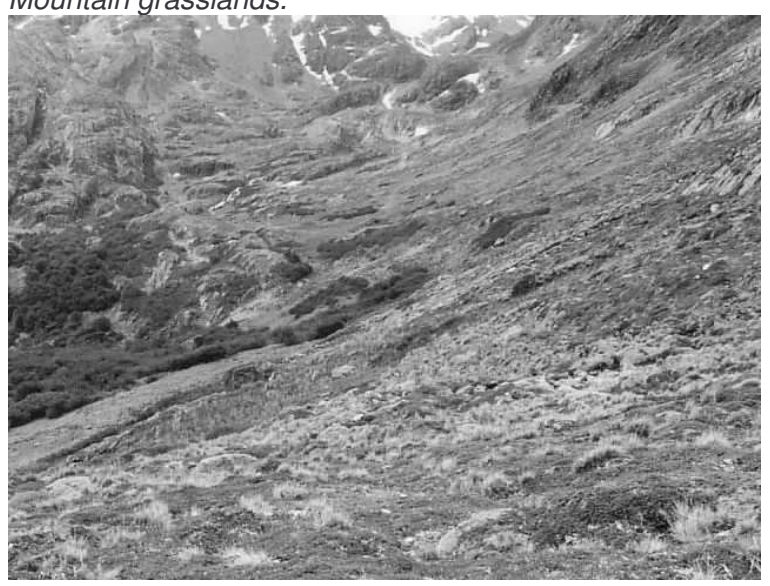

En el caso de las plantas inferiores (musgos y hepáticas), las mismas difirieron significativamente en $P$ y sitio III respecto de los otros tratamientos, presentando valores menores al 15\%, Otro grupo homogéneo fue el de los tratamientos 5B, Krummholz y $T$, con valores mayores al $50 \%$. Con respecto a las pteridófitas, Los sitios III y IV difieren significativamente del resto de las situaciones. Con respecto a las diferencias entre el bosque de $N$. pumilio $(L)$ y el de $N$. betuloides $(G)$ se observa en la 
Tabla 13 que éstas se encuentran en el \% de inferiores, con un 29,86\% para $N$. pumilio y un $46,91 \%$ para $N$. betuloides.

Se realizó un análisis de varianza considerando las diferentes clases de sitio, $T$ y $P$ donde observaron diferencias estadísticas de riqueza (Tabla 14). En el total de especies no se detectaron diferencias significativas, teniendo el valor mínimo en $T$ con 8,67 especies y un máximo en $P$ con 15,53 especies. Para las monocotiledóneas $P$ presentó el mayor valor de 4 especies significativamente superior a las detectadas en el sitio V, V Bajo y Krummholz con valores de 2, 1 y 1,38 especies respectivamente. El número de dicotiledóneas no presentó diferencias significativas siendo sus valores extremos de 3,67 especies $(T)$ a 11 especies $(P)$. Las plantas inferiores (musgos y hepáticas) presentan diferencias significativas en el pastizal presentando el mínimo valor de 0,33 especies en contraposición con los valores máximos del sitio $V$ Bajo y Krummholz con 1,1 y 0,93 especies respectivamente. La pteridófitas presentan la menor riqueza en Krummholz, $T$ y $P$ con valores menores a 0,2 ; diferenciándose del Sitio IV con el valor de 0,86 . Se observaron diferencias en la riqueza de especies exóticas entre los sitios $V$ Bajo y Krummholz (0,30 y 0,36 especies) y el sitio III (3,29 especies).

Tabla 14. Análisis de varianza de riqueza de especies detectadas por discriminadas calidad de sitio. Analysis of variance of species richness discriminated by site class.

\begin{tabular}{llllllll}
\hline & $\mathrm{n}$ & Total & $\mathrm{D}$ & $\mathrm{M}$ & Musgos y hepáticas & Pteridófitas & Exóticas \\
\hline $\mathrm{F}$ & & 2,90 & 2,86 & 4,39 & 3,61 & 3,39 & 2,87 \\
$\mathrm{P}(95 \%)$ & & $(0,0123)$ & $(0,0133)$ & $(0,0006)$ & $(0,0029)$ & $(0,0045)$ & $(0,0129)$ \\
\hline$T$ & 3 & $8,67 \mathrm{a}$ & $3,67 \mathrm{a}$ & $4,00 \mathrm{ab}$ & $1,0 \mathrm{ab}$ & $0,00 \mathrm{ab}$ & $0,33 \mathrm{ab}$ \\
$P$ & 15 & $15,53 \mathrm{a}$ & $11,00 \mathrm{a}$ & $4,00 \mathrm{~b}$ & $0,33 \mathrm{a}$ & $0,20 \mathrm{a}$ & $1,27 \mathrm{ab}$ \\
$\mathrm{III}$ & 7 & $15,43 \mathrm{a}$ & $10,43 \mathrm{a}$ & $3,29 \mathrm{ab}$ & $0,86 \mathrm{ab}$ & $0,86 \mathrm{ab}$ & $3,29 \mathrm{~b}$ \\
$\mathrm{VI}$ & 14 & $15,14 \mathrm{a}$ & $10,57 \mathrm{a}$ & $2,93 \mathrm{ab}$ & $0,78 \mathrm{ab}$ & $0,86 \mathrm{~b}$ & $2,21 \mathrm{ab}$ \\
$V(17-10 \mathrm{~m})$ & 38 & $12,24 \mathrm{a}$ & $9,05 \mathrm{a}$ & $2,00 \mathrm{a}$ & $0,74 \mathrm{ab}$ & $0,45 \mathrm{ab}$ & $1,60 \mathrm{ab}$ \\
V Bajo $(10-7 \mathrm{~m})$ & 10 & $9,10 \mathrm{a}$ & $6,80 \mathrm{a}$ & $1,00 \mathrm{a}$ & $1,1 \mathrm{~b}$ & $0,20 \mathrm{ab}$ & $0,30 \mathrm{a}$ \\
Krummholz $(<7)$ & 14 & $10,43 \mathrm{a}$ & $8,00 \mathrm{a}$ & $1,38 \mathrm{a}$ & $0,93 \mathrm{~b}$ & $0,14 \mathrm{a}$ & $0,36 \mathrm{a}$ \\
\hline
\end{tabular}

Letras diferentes indican diferencias significativas a $\mathrm{P}<0,05$ según prueba de Tukey; III, IV, V, V Bajo y Krummholz: calidades de sitio; T: tipo de unidad de vegetación Turbera; $P$ : tipo de unidad de vegetación Pastizal; D: Dicotiledóneas; M: Monocotiledóneas, n: número de observaciones, F: Test de Fisher, P (95\%): nivel de probabilidad, valores expresados en medias.

Se encontraron diferencias entre el bosque de $N$. pumilio $(L)$ y el de $N$. betuloides (G) en el número de especies total, donde $L$ presenta 13,31 especies y $G 8,12$ (Tabla 15). Para las monocotiledóneas, el bosque de $N$. pumilio posee una riqueza significativamente menor que $P,(4,00$ y 2,34$)$ y mayor que $G$, presentando una riqueza de 0,75 . Para las inferiores (musgos y hepáticas) se observó un gradiente desde $P$ con 0,33 especies, 0,76 especies para el bosque de $N$. pumilio, y 1,12 especies para el bosque de $N$. betuloides. No se observaron diferencias significativas en la riqueza de pteridófitas. Por otro lado, en las especies exóticas $L$ fue significativamente mayor (1,79 especies) que $G(0,19$ especies). Con este análisis se puede observar que en líneas generales el bosque de $N$. pumilio y los pastizales presentan el mayor número 
de especies, dato importante para el posterior análisis de las alternativas productivas a realizar. El número de especies exóticas es in indicador de impacto en las UV estudiadas.

Tabla 15. Análisis de varianza de riqueza de especies discriminadas por unidades de vegetación. Analysis of variance of species richness detected discriminated by units of vegetation.

\begin{tabular}{llllllll}
\hline & $\mathrm{n}$ & Total & $\mathrm{D}$ & $\mathrm{M}$ & Musgos y hepáticas & Pteridófitas & Exóticas \\
\hline $\mathrm{F}$ & & 6,18 & 7,74 & 8,30 & 8,45 & 2,16 & 3,08 \\
$\mathrm{P}(95 \%)$ & & $(0,0007)$ & $(0,0001)$ & $(0,0001)$ & $(0,0000)$ & $(0,0971)$ & $(0,0311)$ \\
\hline$T$ & 3 & $8,67 \mathrm{ab}$ & $3,67 \mathrm{a}$ & $4,00 \mathrm{bc}$ & $1,00 \mathrm{abc}$ & $0,00 \mathrm{a}$ & $0,33 \mathrm{ab}$ \\
$P$ & 16 & $15,53 \mathrm{~b}$ & $11,00 \mathrm{~b}$ & $4,00 \mathrm{c}$ & $0,33 \mathrm{a}$ & $0,20 \mathrm{a}$ & $1,27 \mathrm{ab}$ \\
$L$ & 67 & $13,31 \mathrm{~b}$ & $9,69 \mathrm{~b}$ & $2,34 \mathrm{~b}$ & $0,76 \mathrm{~b}$ & $0,52 \mathrm{a}$ & $1,79 \mathrm{~b}$ \\
$\mathrm{G}$ & 15 & $8,12 \mathrm{a}$ & $6,00 \mathrm{a}$ & $0,75 \mathrm{a}$ & $1,12 \mathrm{c}$ & $0,25 \mathrm{a}$ & $0,19 \mathrm{a}$ \\
\hline
\end{tabular}

Letras diferentes indican diferencias significativas a $\mathrm{P}<0,05$ según prueba de Tukey, $L$ : tipo de unidad de vegetación $N$. pumilio, G: tipo de unidad de vegetación $N$. betuloides, $T$ : tipo de unidad de vegetación Turbera, P: tipo de unidad de vegetación Pastizal; D: Dicotiledóneas; M: Monocotiledóneas, n: número de observaciones, F: Test de Fisher, P (95\%): nivel de probabilidad, valores expresados en medias.

Las semillas no forman un banco de semillas en el suelo ya que no poseen la capacidad de permanecer viables de un año a otro (Cuevas \& Arroyo, 1999) N. pumilio no posee una buena capacidad de dispersión a grandes distancias, siendo generalmente inferior a los cien m (Rusch, 1987). Las semillas de N. pumilio germinan luego de producirse el deshielo, cuando se alcanzan las condiciones ambientales adecuadas para ello. Originan renovales con dos cotiledones epígeos, verdes y reniformes, que crecen muy poco el primer año de vida, alcanzando apenas dos o tres hojas cada planta. A los dos años empiezan a ramificarse, y a los tres ya son más vigorosas, con abundantes ramificaciones (Mutarelli \& Orfila, 1971). En un bosque virgen existe un banco permanente de renovales que sobreviven durante 5-8 años esperando la apertura del dosel y que serán las primeras en desarrollar cuando se produzca el aprovechamiento del bosque (Skrt, et al. 1997). Sin embargo Nothofagus sp. presentan inconvenientes para regenerarse cuando son sometidos a disturbios sistemáticos y permanentes (Calderón, 1993). Rusch (1987) observó regeneración muy abundante en pequeños claros, siendo la intensidad lumínica, en cambio, insuficiente dentro del bosque. En los lugares más expuestos a la luz las hojas presentan color verde oscuro, siendo angostas y algo lustrosas en la cara superior, mientras que en aquellos sitios donde la iluminación es menos intensa las hojas tienen color verde claro y más anchas (Mutarelli \& Orfila, 1971). Pero el factor más crítico es la humedad de suelo, en especial en la zona central de grandes claros (30 m de diámetro). Rusch (1987) señala que la temperatura de la superficie del suelo resulta potencialmente nociva para la supervivencia de los renovales únicamente en sitios expuestos - cuando el diámetro de los claros supera los $50 \mathrm{~m}$ - y días cálidos. También determinó que la remoción del suelo y la eliminación de la vegetación del sotobosque resultaba beneficiosa para la regeneración, aunque no pudo establecer la relación causa - efecto (Rusch, 1987). En el mismo estudio se halló que la 
regeneración en claros no está ligada al tamaño ni a la edad de los mismos, sino al tipo de claro en relación a su origen y así, las mayores densidades y áreas basales se encontraron en los claros producidos por avalanchas, a diferencia de los originados por el viento (Rusch, 1987). Los renovales mayores a $1 \mathrm{~m}$ de altura empiezan a ser capaces de sobrevivir en condiciones de cobertura mínima, y se acentúa la tendencia a disminuir la densidad en altas coberturas. La presencia de regeneración es variable en los puntos de muestreo y no evidencia una relación directa con la oferta de luz en el sotobosque determinada por la cobertura porcentual de copas $\left(R^{2}\right.$ 9,3541\% modelo lineal cobertura de copas - regeneración $\mathrm{m}^{2}$ ), situación esperada para la especie (Loguercio, 1995). No obstante esto, otros factores pueden influenciar sobre la densidad de la regeneración, como exposición (Rechene, 1995), ciclicidad de semillazón (Loguercio, 1995; Schmidt et al., 1994) y la historia e impactos (Martínez Pastur et al., 1999a; Pulido et al., 2000). El tipo de regeneración dominante es la inicial (plantines) representada en el $64,2 \%$ de los bosques. La regeneración avanzada (regeneración menor a 2 m de altura) se encuentra en un 20,9\% y la regeneración instalada ( $>$ de $2 \mathrm{~m}$ de altura) está presente en un 14,9\% de los bosques. En número de plantas por $\mathrm{m}^{2}$ (Tabla 16) se observó que el sitio $V$ presentó el valor mas alto $(38,73$ $\left.\mathrm{pl} / \mathrm{m}^{2}\right)$. En Krummholz se encontró una densidad muy baja de regeneración. Según Richter \& Frangi (1992), la cantidad de renovales de N. pumilio en los sectores achaparrados de mayor altitud es prácticamente nula. En el presente trabajo se incluyó el tipo "regeneración instalada" ( $>$ de $2 \mathrm{~m}$ de altura) como regeneración, resultando valores altos de regeneración en el Krummholz. No se encontraron diferencias significativas en la regeneración para los bosques de $N$. pumilio y de $N$. betuloides (Tabla 17). Estos estudios contrastan con otros en los que se observó una abundante regeneración natural de más de 500.000 plantas por hectárea (Richter \& Frangi, 1992), que probablemente se correspondería con un año de abundante semillazón.

Tabla 16. Análisis de varianza de regeneración de Nothofagus sp. en sitios con diferentes calidades de sitio.

Analysis of variance of Nothofagus sp. regeneration in different site classes.

\begin{tabular}{llll}
\hline & $\mathrm{n}$ & Plantas $/ \mathrm{m}^{2}$ & Error estándar \\
\hline $\mathrm{F}$ & & 1,28 \\
$\mathrm{P}(95 \%)$ & & $(0,2822)$ \\
\hline$I I I$ & 7 & $27,86 \mathrm{a}$ & 20,75 \\
VI & 17 & $31,94 \mathrm{a}$ & 13,32 \\
V $(17-10 \mathrm{~m})$ & 60 & $38,73 \mathrm{a}$ & 7,09 \\
V Bajo $(10-7 \mathrm{~m})$ & 10 & $28,40 \mathrm{a}$ & 17,36 \\
Krummholz $(<7)$ & 14 & 2,07 a & 14,67 \\
\hline
\end{tabular}

Letras diferentes indican diferencias significativas a $\mathrm{P}<0,05$ según prueba de Tukey; III, IV, V, V Bajo y Krummholz: calidades de sitio; n: número de observaciones, F: Test de Fisher, P (95\%): nivel de probabilidad, valores expresados en medias.

Tabla 17. Análisis de varianza de regeneración de Nothofagus sp. en las unidades de vegetación estudiadas.

Analysis of variance of Nothofagus sp. regeneration in the studied units of vegetation.

$$
\mathrm{n} \quad \text { Plantas } / \mathrm{m}^{2} \quad \text { Error estándar }
$$




\begin{tabular}{llll}
$F$ & & 0,79 \\
$P(95 \%)$ & & \\
$(0,3764)$ & \\
\hline$L$ & 84 & $28,73 \mathrm{a}$ & 6,03 \\
$G$ & 24 & $40,08 \mathrm{a}$ & 11,28
\end{tabular}

Letras diferentes indican diferencias significativas a $\mathrm{P}<0,05$ según prueba de Tukey, $L$ : tipo de unidad de vegetación $N$. pumilio, G: tipo de unidad de vegetación $N$. betuloides, n: número de observaciones, F: Test de Fisher, P (95\%): nivel de probabilidad, valores expresados en medias.

Para la caracterización de los bosques, se realizaron tres conteos angulares (Clutter et al., 1983; Bitterlich, 1984) en los 108 rodales marcados (4.722,88 ha), representando en la superficie de los rodales inventariados una intensidad de muestreo de 14,57 hectáreas por parcela. Del total de rodales estudiados, Nothofagus pumilio presentó el mayor numero de unidades ( $\mathrm{n}=84-77,7 \%$ del total) y la mayor superficie $(4.152,66$ ha $-87,93 \%$ del total). Nothofagus betuloides presentó una superficie de 570,2176 ha, resultando el $12,07 \%$ de la superficie forestal. Usualmente N. pumilio se desarrolla en zonas con una mayor variación climática que los bosques de $N$. betuloides (Frangi \& Ritcher 1994) que se desarrollan en la zona de media ladera en la CAG (Figura 3). Los bosques de N. pumilio ocupan zonas más frías y en suelos con mejor drenaje que los preferidos por N. betuloides (Frangi \& Ritcher, 1994; Gutiérrez et al., 1991; Veblen et al., 1996). En zonas marginales (bordes de ríos y pastizales) se encontraron pequeños manchones de Nothofagus antarctica, Esta especie es tolerante a las inundaciones, ocupando áreas con características adversas (Gutiérrez \& Sebastiá, 1985), desarrollándose en sectores inundables y bajos con suelos poco profundos (Roig, 1998).

Figura 3. Localización altitudinal de las unidades de vegetación. Altitude location of the vegetation units.

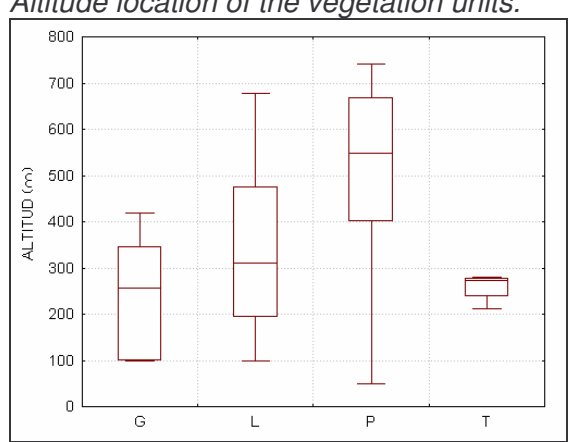

L: tipo de unidad de vegetación $N$. pumilio, G: tipo de unidad de vegetación $N$. betuloides, $T$ : Turbera, $P$ : Pastizal, las lineas representan el valor máximo y mínimo, las cajas representan la ubicación del primer cuartel, el tercer cuartil y la mediana.

El diámetro cuadrático medio $(D C M)$ presentó diferencias significativas en el rango de calidades de sitio estudiadas ( $\alpha=0,05$; Método Tukey HSD; $f=5,39 ; p=0,0007$ ) mostrando una tendencia decreciente de los diámetros a medida que la calidad de sitio baja (18). Los diámetros promedios observados para $N$. pumilio en este estudio $(31,77$ cm) fueron similares al valor promedio informado por Martínez Pastur (1999) para toda la Isla $(39 \mathrm{~cm})$. 
Tabla 18. Diámetro cuadrático medio discriminado por calidad de sitio.

Quadratic mean diameter discriminated by site class.

\begin{tabular}{llll}
\hline Sitio & $\mathrm{n}$ & $D C M(\mathrm{~cm})$ & Error estándar \\
\hline III & 7 & $50,2 \mathrm{c}$ & 7,2 \\
VI & 14 & $38,6 \mathrm{bc}$ & 5,1 \\
V $(17-10 \mathrm{~m})$ & 37 & $34,0 \mathrm{bc}$ & 3,1 \\
V Bajo $(10-7 \mathrm{~m})$ & 10 & $21,7 \mathrm{ab}$ & 6,0 \\
Krummholz $(<7)$ & 12 & $14,5 \mathrm{a}$ & 5,5
\end{tabular}

Sitio: Calidad de sitio, DCM: Diámetro cuadrático medio en $\mathrm{cm}$, Letras diferentes indican diferencias significativas a $\mathrm{P}<0,05$ según prueba de Tukey; III, IV, V, V Bajo y Krummholz: calidades de sitio, n: número de observaciones, valores expresados en medias.

El área basal fue similar entre las calidades de sitio inventariadas $(\alpha=0,05$; Método Tukey HSD; $f=1,27 ; p=0,2867$ ), mostrando un valor promedio de 42,36; y con un mínimo de $36,14 \mathrm{~m}^{2} / \mathrm{Ha}$ para el Krummholz hasta $58,2 \mathrm{~m}^{2} /$ ha en su valor mas elevado en el Sitio $V$ bajo. Se observo una elevada variabilidad interna del área basal en los distintos sitios, la cual se representa en la Tabla 19.

Tabla 19. Área basal discriminada por calidad de sitio.

Basal area discriminated by site class.

\begin{tabular}{llll}
\hline Sitio & $\mathrm{n}$ & $A B$ & Error Estandar \\
\hline III & 7 & 53,28 a & 11,69 \\
VI & 17 & 46,05 a & 7,50 \\
V $(17-10 \mathrm{~m})$ & 60 & 38,85 a & 3,99 \\
V Bajo $(10-7 \mathrm{~m})$ & 10 & 58,20 a & 9,78 \\
Krummholz $(<7)$ & 14 & 36,14 a & 8,26 \\
\hline
\end{tabular}

Sitio: Calidad de sitio, $A B$ : Área basal $\mathrm{m}^{2} / \mathrm{ha}$, letras diferentes indican diferencias significativas a $\mathrm{P}<0,05$ según prueba de Tukey; III, IV, V, V Bajo y Krummholz: calidades de sitio, n: número de observaciones, valores expresados en medias.

La densidad en número de individuos por hectárea no fue significativamente diferente ( $\alpha=0,05$; Método Tukey HSD; $f=1,71 ; p=0,1529$; promedio 1.888,5 ind $/ \mathrm{ha}$ ) entre los sitios, alcanzando valores extremos en el krummholz con 4.667,4 Ind/ha y en la calidad de sitio III con 473,6 ind/ha. Se puede observar también el alto error standard en las determinaciones (Tabla 20). El Índice de Densidad de Rodal (IDR) presentó diferencias entre sitios $(\alpha=0,05$; Método Tukey HSD; $f=3,07 ; p=0,0213$; promedio 84,93\%). Si estos resultados se los compara con los obtenidos para $N$. pumilio por Fernández et al. (1997), se pueden considerar al krummholz como sub ocupado (menos de $70 \%$ de IDR), y a los demás sitios como totalmente ocupados (mayor al $80 \%$ de IDR), según los grados de ocupación considerados por Reineke (1933).

Tabla 20. Densidad e índice de densidad de rodal discriminados por calidad de sitio. Stand density \& stand density index discriminated by site class.

\begin{tabular}{llllll}
\hline Sitio & $\mathrm{n}$ & Densidad & Error Estandar & IDR\% & Error Estandar \% \\
\hline III & 7 & $473,6 \mathrm{a}$ & 2154,9 & $83,34 \mathrm{ab}$ & 11,90 \\
VI & 10 & $3523,1 \mathrm{ab}$ & 1523,4 & $84,06 \mathrm{ab}$ & 8,41 \\
V $(17-10 \mathrm{~m})$ & 38 & $1799,4 \mathrm{ab}$ & 924,6 & $94,49 \mathrm{~b}$ & 5,18 \\
V Bajo $(10-7 \mathrm{~m})$ & 14 & $1760,2 \mathrm{~b}$ & 1802,5 & $84,30 \mathrm{ab}$ & 9,96 \\
Krummholz $(<7)$ & 14 & $4667,4 \mathrm{~b}$ & 1523,1 & $57,91 \mathrm{a}$ & 9,09 \\
\hline
\end{tabular}

Sitio: Calidad de sitio, Densidad: densidad en árboles por hectárea, IDR Índice de Densidad de Rodal, Letras diferentes indican diferencias significativas a $\mathrm{P}<0,05$ según prueba de Tukey; III, IV, V, V Bajo y Krummholz: calidades de sitio, n: número de observaciones, valores expresados en medias. 
Las alturas dominantes promedio de los rodales inventariados fue de $12,12 \mathrm{~m}$, dando así un valor inferior al promedio para el sector argentino de Tierra del Fuego, que ronda entre los 19 y los 20 m (Martínez Pastur, 1999c) como para el chileno donde es aún menor (Schmidt \& Urzúa, 1982). En general, los sitios buenos con árboles que superan los $25 \mathrm{~m}$ de altura son excepcionales, y a diferencia de lo observado en este estudio, suelen presentarse en pocos lugares, tales como cañadones muy protegidos y de suelos profundos (Martínez Pastur et al., 1997b).

La fase de desarrollo predominante en la mayoría de los sitios fue la fase intermedia Envejecimiento - Crecimiento óptimo final (Tabla 21), que se extiende de los 120 a los 200 años (Schmidt \& Urzúa, 1982); esta fase es intermedia entre la fase de envejecimiento con la de crecimiento óptimo, caracterizándose por un mayor número de individuos de copas sanas y mayor volumen total con corteza por hectárea. En la calidad de Sitio III se presentó la mayoría de los rodales en fase de $E$ y $E-D$, muy importante del punto de vista productivo ya que estas fases son las que poseen el mayor volumen maderable (Martínez Pastur et al, 2000a).

Tabla 21. Fase de desarrollo de los rodales inventariados discriminadas por Clase de Sitio. Phase of development discriminated by Site Class.

\begin{tabular}{llllllll}
\hline Sitio & COI $(\%)$ & COF $(\%)$ & COF-E $(\%)$ & $E-C O F(\%)$ & $E(\%)$ & $E-D(\%)$ & $D(\%)$ \\
\hline III & 14,3 & 0,0 & 0,0 & 14,3 & 42,9 & 28,6 & 0,0 \\
VI & 7,1 & 0,0 & 21,4 & 50,0 & 14,3 & 7,1 & 0,0 \\
V $(17-10 \mathrm{~m})$ & 16,2 & 5,4 & 8,1 & 37,8 & 13,5 & 13,5 & 5,4 \\
V Bajo $(10-7 \mathrm{~m})$ & 30,0 & 10,0 & 10,0 & 20,0 & 10,0 & 0,0 & 20,0 \\
Krummholz $(<7)$ & 85,7 & 0,0 & 0,0 & 14,3 & 0,0 & 0,0 & 0,0 \\
Total & 28,0 & 3,7 & 8,5 & 31,7 & 13,4 & 9,8 & 4,9
\end{tabular}

Sitio: Calidad de sitio, FASE: Fase de crecimiento, COI: Crecimiento óptimo inicial, COF: Crecimiento óptimo final, COF-E: Fase intermedia entre Crecimiento óptimo final y Envejecimiento, E-COF: Fase intermedia entre Envejecimiento y Crecimiento óptimo final, $E$ : Envejecimiento, $E-D$ : Fase intermedia entre Envejecimiento y Desmoronamiento, D: Desmoronamiento; III, IV, V, V Bajo y Krummholz: calidades de sitio, valores expresados en medias.

El volumen total con corteza (VTCC) se diferenció significativamente para las distintas calidades de sitio de los rodales estudiados $(\alpha=0,05$; Método Tukey HSD; $f=$ 4,$72 ; p=0,0016$; promedio $361,62 \mathrm{~m}^{3} / \mathrm{ha}$ ). El volumen total con corteza fue menor a medida que disminuía la altura dominante (Tabla 22). Los volúmenes totales con corteza fluctuaron entre 244,714 y $648,28 \mathrm{~m}^{3}$ /ha, correspondiéndose a lo observado en similares rodales (Martínez Pastur et al., 1994; 2000a), y ubicándose dentro de los rangos informados por Schmidt (1997). El volumen maderable sin corteza (VVSC) se diferenció significativamente para las distintas calidades de sitio $(\alpha=0,05$; Método Tukey HSD; $f=$ 10,55; $p=0,0000$; promedio $87,009 \mathrm{~m}^{3} / \mathrm{ha}$ ), dando un resultado lógico a otros estudios (Martínez Pastur et al., 2000a, 2000c). 
Tabla 22. Volumen total con corteza y volumen maderable sin corteza discriminado por distintas calidades de sitio.

Total volume with bark and loggable volume discriminated by different site class.

\begin{tabular}{llllll}
\hline Sitio & $\mathrm{n}$ & VTCC & Error Estandar & VVSC & Error Estandar \\
\hline III & 7 & $648,286 \mathrm{a}$ & 87,412 & $162,771 \mathrm{a}$ & 17,632 \\
VI & 14 & $451,706 \mathrm{ab}$ & 56,091 & $100,164 \mathrm{~b}$ & 11,314 \\
V $(17-10 \mathrm{~m})$ & 38 & $398,981 \mathrm{ab}$ & 32,071 & $49,966 \mathrm{bc}$ & 9,469 \\
V Bajo $(10-7 \mathrm{~m})$ & 10 & $313,200 \mathrm{~b}$ & 73,134 & $18,603 \mathrm{c}$ & 7,752 \\
Krummholz $(<7)$ & 14 & $244,714 \mathrm{~b}$ & 61,810 & $3,542 \mathrm{~d}$ & 1,467
\end{tabular}

Sitio: Calidad de sitio, VTCC: Volumen total con corteza en $\mathrm{m}^{3} / \mathrm{Ha}$, VVSC: Volumen maderable sin corteza en $\mathrm{m}^{3} / \mathrm{Ha}$, Letras diferentes indican diferencias significativas a $\mathrm{P}<0,05$ según prueba de Tukey; III, IV, $V, V$ Bajo y Krummholz: calidades de sitio, valores expresados en medias.

\subsection{DISCUSIÓN}

La CAG tiene una superficie de 12.951,29 ha, de forma oval-oblonga a rectangular-oblonga. Posee un bajo factor de forma y un valor reducido del radio de elongación, denotando una tendencia a las crecidas súbitas. La red hidrográfica presenta una alta densidad de drenaje, siendo factible la rápida evacuación del agua frente a una tormenta.

Las precipitaciones se mantienen constantes estacionalmente, arrojando un promedio mensual de 97,32 $\mathrm{mm}$ y un total de 1.167,85 $\mathrm{mm}$. En los meses de junio, julio y agosto existe una acumulación nívea, resultando en la disminución de la escorrentía, con valores menores al $5 \%$ del total $(44,4 \mathrm{~mm})$. Asimismo, en primavera la escorrentía presenta su valor máximo de $134,3 \mathrm{~mm}$, disminuyendo en los siguientes meses.

Los órdenes de suelos presentes en la CAG son Molisoles, Entisoles, Inceptisoles, Espodosoles e Histosoles, ubicados en distintas situaciones dentro de la cuenca. El mayor crecimiento forestal se presenta en suelos de buen drenaje que puedan retener la suficiente humedad. La CAG posee un paisaje de pendientes, valles, planicies, turberas y mallines, debido a su origen glaciar al encontrarse indicios de antiguas planicies glaciales, actualmente muy erosionadas, con colinas y cerros.

Se relevaron en las distintas unidades de vegetación la presencia de 110 entidades en total (71 dicotiledóneas, 33 monocotiledóneas, tres pteridofitas, las morfoespecies de hepáticas y musgos y Sphagnum sp.). Se determinó la densidad de sotobosque mostrando el máximo valor en la $U V T$, reduciéndose en $P$ y en el bosque de $N$. pumilio y $N$. betuloides, la densidad del sotobosque disminuía con la altitud. La riqueza de especies fue mayor en los pastizales y menor en los turbales. En el análisis de especies exóticas, se observó una mayor presencia en el bosque de N. pumilio que en el bosque de $N$. betuloides.

Se encontró que el tipo de regeneración dominante es la inicial (plantines), en el $64,2 \%$ de los bosques, siguiendo la regeneración avanzada, en un $20,9 \%$. En la 
densidad de la regeneración, la calidad de sitio $V$ presentó el valor más alto con 38,73 $\mathrm{pl} / \mathrm{m}^{2}$, mientras que en Krummholz se encontró la menor densidad de regeneración.

En cuanto a la estructura forestal, el DCM presentó una tendencia a decrecer a medida que la calidad de sitio baja; en la calidad de sitio III el DCM fue de 50,2 cm mientras que en el Krummholz el valor fue de $14,5 \mathrm{~cm}$. Las alturas dominantes arrojaron un promedio de $12,12 \mathrm{~m}$, valor inferior al promedio de los bosques productivos del sector argentino de Tierra del Fuego. El valor de la CAG es llamativamente bajo, ya que incluye todas las UV forestales, incluidas las no productivas. La fase de crecimiento mas frecuente en las UV forestales fue la fase intermedia Envejecimiento - Crecimiento óptimo final, representada por árboles maderables con buena sanidad. El VTCC observado presentó un gradiente dado por la calidad de sitio, entre los valores extremos de 244,71 y $648,28 \mathrm{~m}^{3} /$ ha; el VVSC para las calidades de sitio $V$, VI y III presentaron valores rentables, superiores a los $35 \mathrm{~m}^{3} / \mathrm{ha}$. 


\section{USO DE LA TIERRA E IMPACTO}

\subsection{INTRODUCCIÓN}

El monitoreo de los cambios espaciales en los recursos naturales es un requisito previo para una efectiva planificación de su manejo (Espinoza et al., 1993). La combinación de diferentes técnicas de análisis y procedimientos de la información remota resulta apropiada para efectuar relevamientos múltiples de los recursos naturales (Marcolín et al., 1996). Asimismo los relevamientos a campo permiten corroborar y ampliar la información de la percepción remota. La descripción de los ambientes, la caracterización de su estado de conservación y de los agentes de impacto representan un paso previo fundamental durante la planificación de la ordenación, en especial debido a que constituye una de las principales influencias que el hombre puede manejar a su favor durante el manejo de una cuenca hidrográfica (Gil, 1986). La zona de estudio presenta una falta de ordenamiento en la ocupación del hombre y el aprovechamiento de los recursos naturales (Fernández, 1993), siendo los más importantes la concentración de áreas de uso intensivo, el desarrollo urbano y la falta de planificación en el manejo de las áreas naturales especialmente frágiles. Se identificaron y estudiaron la ocupación actual e histórica de la población, los usos pasados y presentes de los recursos naturales, el grado y la distribución del impacto ganadero, turístico, forestal y de la extracción de turba, para la posterior zonificación.

\subsection{Materiales y métodos}

Se consultó bibliografía regional disponible para determinar el uso pasado de los recursos naturales (Chapman, 1987; Orquera \& Piana, 1999; Borla \& Vereda, 2001). Para determinar los impactos antrópicos en la Cuenca del Arroyo Grande (CAG) se dividió la superficie de la cuenca en las unidades de vegetación (UV) detalladas en 2. Morfometría y vegetación de la CAG. En el punto central de cada UV se relevó una parcela de una hectárea, donde se determinó:

a) El impacto de la ganadería mediante la cuantificación de renovales de Nothofagus sp., gramíneas y dicocotiledóneas con signos de ramoneo, así como otras alteraciones producidas (pisoteo y heces).

b) La existencia de aprovechamientos forestales recientes y antiguos ( $V$ : antiguo; $R$ : reciente). Los aprovechamientos forestales recientes se determinaron por presencia de tocones y trozas olvidadas con signos de haber sido realizados con motosierra. Los 
aprovechamientos antiguos presentaron tocones y trozas olvidadas realizados con hacha (Foto 6).

Foto 6: Aprovechamiento antiguo, donde se observa una troza y el bosque joven.

Old forest harvesting, with a forgotten log and young forest.

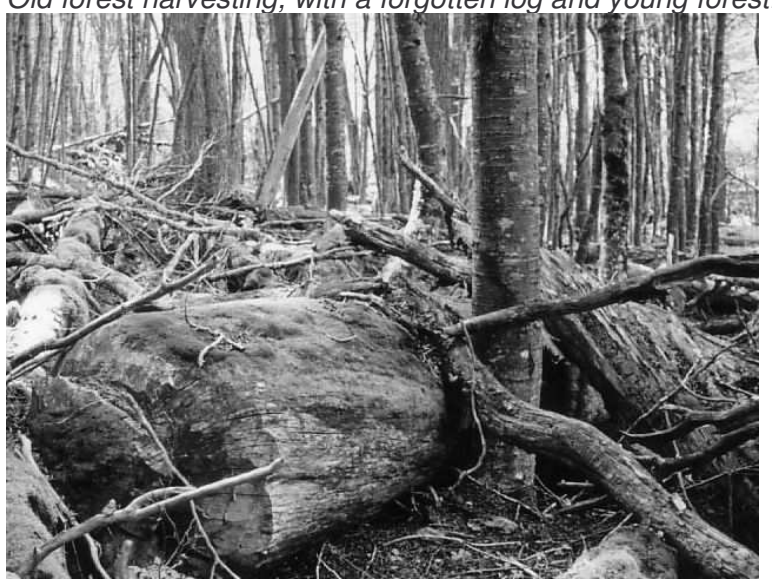

c) El impacto originado por turismo, mediante la observación de senderos, residuos, daños en la vegetación y fogones abandonados.

Se caracterizó la intensidad mediante una escala sencilla de valoración: $(F)$ fuerte intensidad de impacto, con alteración estimada de más de un $40 \%$ de la cobertura vegetal; $(B)$ intensidad moderada a baja, con alteración estimada de menos de un $40 \%$ de la cobertura vegetal. Asimismo se analizó la información de especies exóticas vegetales (ver 2. Morfometría y vegetación de la $C A G$ ). Con la información obtenida se complementó el sistema de información geográfico de la cuenca desarrollado previamente (ver 2. Morfometría y vegetación de la CAG).

\subsection{RESULTADOS}

\subsubsection{Uso pasado de los recursos naturales}

Los indios Yámana vivían en la costa sur de la isla grande de Tierra del Fuego desde hace 6.000 años de antigüedad (Orquera \& Piana, 1999). Eran un grupo nómada canoero, que subsistía de la caza, pesca y recolección. El consumo de alimentos vegetales por parte de las tribus era limitado en cantidad y variedad. Un recurso importante eran los hongos del género Cyttaria. Estos hongos crecen exclusivamente en troncos y ramas de árboles del género Nothofagus. En menor medida consumían murtilla (Empetrum rubrum Vahl ex Willd.), chaura (Pernettya mucronata (Lf) Gaudich ex. G. Don), parrilla (Ribes magellanicum Poir.), calafate (Berberis buxifolia Lam.), michay (Berberis ilicifolia Forst.), frutillas silvestres (Rubus geoides Sm.) y tussac (Poa flabellata (Lam.) Hooker f.) (Chapman, 1987). Para estas 
actividades de subsistencia, utilizaban arpones y "mangos" de madera, con los cuales cazaban aves, peces y Lama guanicoe. Estaban confeccionados con madera de guindo (Nothofagus betuloides), canelo (Drimys winteri JR.Forst. \& G. Forst.) o maitén (Maytenus magellanica (Lam.) Hook. f.), procurando que sean rectos y lisos. Los arcos se fabricaban con madera de $N$. betuloides de 1 a 1,5 m de largo, y las flechas de madera de $M$. magellanica o Berberis buxifolia. Para recoger moluscos usaban palos o espátulas de Berberis ilicifolia o $N$. betuloides ya que es una madera flexible y resistente.

Para el traslado y transporte, el medio más cómodo eran las canoas, ya que por tierra el relieve era abrupto, y los bosques presentaban dificultades para el tránsito. Para la construcción de las canoas eran necesarias cortezas, varillas de madera y ataduras. Los lados y la base de la canoa estaban formados por planchas de corteza de $N$. betuloides, ya que no se resquebraja. Para obtener una corteza de buena calidad, los yámanas se adentraban en el bosque hasta 6 u 8 km, buscando árboles cuyo tronco ofreciera no menos de $5,5 \mathrm{~m}$ de superficie lisa, sin ramas ni protuberancias. Las canoas en promedio median 4,5 m de largo, y se impulsaban con remos de Nothofagus sp. Hacia fines del siglo XIX, las canoas de corteza fueron reemplazadas en la región Yámana por las de tronco excavado o tablas, hechas de Nothofagus betuloides con ayuda de fuego. (Chapman, 1987). Su continua movilidad no justificaba la construcción de alojamientos estables, encontrándose viviendas de dos tipos: en forma de domo o colmena y en forma de cono. Como se puede observar, el grado de modificación de la $C A G$ por parte de los antiguos pobladores fue prácticamente nulo ya que éstos desarrollaban sus actividades en la costa y en el mar principalmente.

Desde fines del siglo XIX se registra una ocupación humana en el área de la desembocadura de la $C A G$, dando como resultado la modificación de amplios sectores de bosques, tanto por la tala de árboles como por el pastoreo. La actividad forestal comenzó sobre la costa del Canal Beagle hacia fines del siglo XIX, siendo los primeros bosques aprovechados en el ejido de Ushuaia (Borla \& Vereda, 2001). La zona del valle inferior del Arroyo Grande y parte del Río Chico fue explotada por el presidio de la ciudad de Ushuaia desde 1910 hasta 1947. Para la extracción de los rollizos se construyó un tren de trocha angosta donde se pueden identificar en la zona vestigios de los terraplenes, planchadas y picadas de extracción de leña. Como resultado de la explotación forestal ocurrida, se puede observar una extensa zona en el bajo valle, de tocones cortados a hacha y el bosque regenerado. En el Río Chico existen pocos datos de actividades forestales, observándose restos antiguos de explotaciones forestales. La actividad ganadera fue de menor magnitud que la forestal, 
desarrollándose también sobre la costa del Canal Beagle y el Lago Roca. La cría de ganado era para consumo propio y abastecimiento de la población de Ushuaia (APN, 2003a).

\subsubsection{Uso actual de los recursos naturales e impactos}

Actualmente no se realizan actividades agrícolas o forestales a gran escala en la cuenca, existiendo una presión en la extracción de leña destinada a la actividad turística y para calefacción de los establecimientos rurales y urbanos de la zona. En la zona de la desembocadura de la CAG se concentran una gran diversidad de actividades productivas, que disminuyen a medida que se entra en el valle. En esas zonas más bajas existe una alta concentración de fábricas y un asentamiento, no planificado urbanísticamente, de precarias casas. Hacia el interior del valle, se evidencia la producción agrícola bajo invernáculos y una zona de aprovechamiento de turba (Fernández, 1993).

En la parte baja de la cuenca (0 a 150 m s.n.m.) el bosque presenta el menor grado de cobertura, e incluso partes del mismo fueron taladas y quemadas, lo que originó un desarrollo abundante de matas de Berberis buxifolia y B. ilicifolia. También se observa abundante presencia de renovales de lenga desarrollados bajo una forma arbustiva debido a la acción del ganado vacuno. El asentamiento poblacional determinó la desaparición parcial de la cobertura vegetal en la zona de la desembocadura de la CAG. Hasta la década del '70 se realizaron extracciones forestales en el Valle de Andorra donde funcionaba un aserradero. Posteriormente dichas actividades extractivas cesaron lo que determinó un aumento en la superficie forestal (Fernández, 1993). Existen cerca de la desembocadura de la CAG algunos invernáculos donde se produce parte de los vegetales que se consumen en la ciudad de Ushuaia, la ganadería se encuentra sub explotada y mal manejada, al encontrarse una muy baja cantidad de ganado y observándose daños en la vegetación (Fernández, 1993). A partir de 1970, las leyes de promoción industrial provocaron una migración de mano de obra, influyendo en la estructura poblacional existente hasta ese momento en la región patagónica. En Tierra del Fuego, este fenómeno produjo una desorganizada ocupación del espacio urbano y una creciente presión y demanda sobre los recursos naturales provocando alteraciones (APN, 2003a). La Provincia de Tierra del Fuego esta desarrollando la actividad turística a partir de fuertes imágenes que reflejan un posicionamiento en sus atractivos naturales y en su ubicación geográfica (Yorio el al., 1998). La ciudad de Ushuaia es el centro urbano más importante vecino a la CAG. Esta ciudad de 49.762 habitantes (INDEC, 2001), cuyo ejido municipal se encuentra 
dentro de la $C A G$, plantea problemas y oportunidades de manejo para el área. Por un lado representa un sitio de interés para las actividades recreativas de la población residente y por otro lado las necesidades de expansión urbana que presionan sobre los ambientes naturales (Silva, 1987).

La mayor parte de las tierras de la CAG son fiscales, ya sea de dominio municipal, provincial o nacional; existiendo en la zona de la desembocadura la existencia de propiedades privadas. Se presentó ante el Consejo Deliberante de Ushuaia una propuesta para declarar a la zona de tierras municipales del valle del Arroyo Grande como una zona de manejo análoga a la Reserva Provincial de Usos Múltiples (RUM). Esta zona se destinará a usos recreativos controlados siendo un importante paso para detener el avance de la urbanización. La categoría de manejo propuesta admite usos extractivos ya que la Ley Provincial $N^{\circ} 272$ las define como "áreas de aptitud productiva controladas técnicamente por el Estado". Un sector de la CAG corresponde al Parque Nacional Tierra del Fuego (PNTdF), ocupando 62,2170 $\mathrm{km}^{2}$ (Mapa 15).

\subsubsection{Ganadería}

En la región, el impacto de la sobre explotación ganadera jugó un papel importante en la historia de las actividades económicas. En los valles cordilleranos, la cría de ganado bovino fue uno de los factores de impacto más importantes para los ecosistemas boscosos de la región, sea por su propia presencia como por las prácticas de quema sistemática utilizadas desde finales del siglo XIX para ganar tierras productoras de pastizales. Un $37,4 \%$ de las UV se encuentran sometidas en algún nivel de pastoreo por parte del ganado, observándose la presencia del ganado en los pastizales de altura cercanos al monte Vinciguerra (Foto 4), en bosques de N. pumilio, en turberas y en pastizales cercanos a la rivera de ríos. Se constató la presencia de equinos en los pastizales cercanos a la confluencia del Arroyo Grande y el Río Chico, tratándose de animales con dueño que provienen de establecimientos ubicados al sur de la confluencia. Además es posible encontrar equinos interior del bosque y en los pastizales de altura.

Foto 4: Ganado y castorera en pastizal de altura cercano al monte Vinciguerra. Cattle and beaver dam in mountain grasslands near Mt. Vinciguerra. 


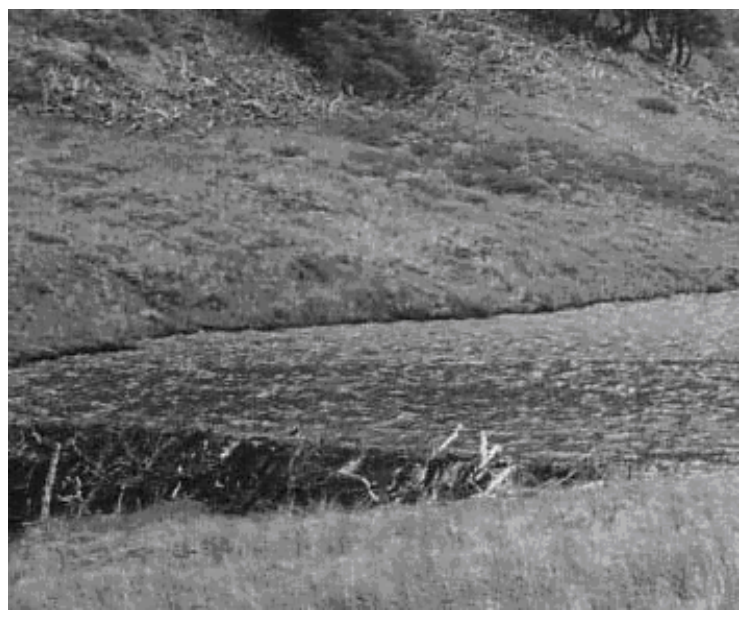

En la superposición de las actividades ganaderas y las forestales, reside la gran limitante para un correcto desarrollo de la regeneración que se instala exitosamente en el bosque. Los Nothofagus presentan inconvenientes para regenerarse cuando son sometidos a disturbios sistemáticos y permanentes (Calderón, 1993), como el sobrepastoreo del ganado ovino y bovino, cérvidos, conejos y guanacos (Alfonso, 1942; Bava \& Puig, 1992; Carabelli, 1991; Ferrando, 1994; Rebertus \& Veblen, 1993; Rothkugel, 1916; Schlichter, 1988; Schmidt et al., 1992; Skrt et al., 1997; Veblen et al., 1989; 1992). En Tierra del Fuego los bosques son fuertemente degradados por el sobrepastoreo vacuno, principalmente en los campos destinados para las veranadas. Por otra parte, la regeneración preinstalada también es afectada por el ramoneo de Lama guanicoe (Rebertus et al., 1997; Schmidt et al., 1992), que usualmente incorpora al Nothofagus en su dieta a lo largo de todo el año (Bonino \& Sbriller, 1991a; 1991b). Sin las debidas consideraciones respecto al ramoneo (por ganado doméstico o las poblaciones naturales de guanacos), no puede asegurarse que se logrará la correcta regeneración del bosque aprovechado. Una alternativa de mitigación es mantener una escollera de troncos en los bordes de los rodales aprovechados o cercarlos con alambrados permanentes o temporarios. Esto impedirá el ingreso del ganado a los sectores ya aprovechados. Existen malos antecedentes al respecto en los sectores cercanos al Lago Yehuin (Lote 79), poniendo como ejemplo, sectores aprovechados con consiguiente volteo, donde posteriormente se introdujo gran cantidad de animales.

Se observó en distintas UV, evidencias de pastoreo, siendo la zona mas afectada los alrededores de la turbera explotada y el área comprendida entre ésta y la desembocadura del Arroyo Grande, donde se pudo comprobar la presencia de ganado produciendo un deterioro de la regeneración de N. pumilio (Foto 5). La alta presión del ganado puede impactar en la baja recuperación de la vegetación nativa. 


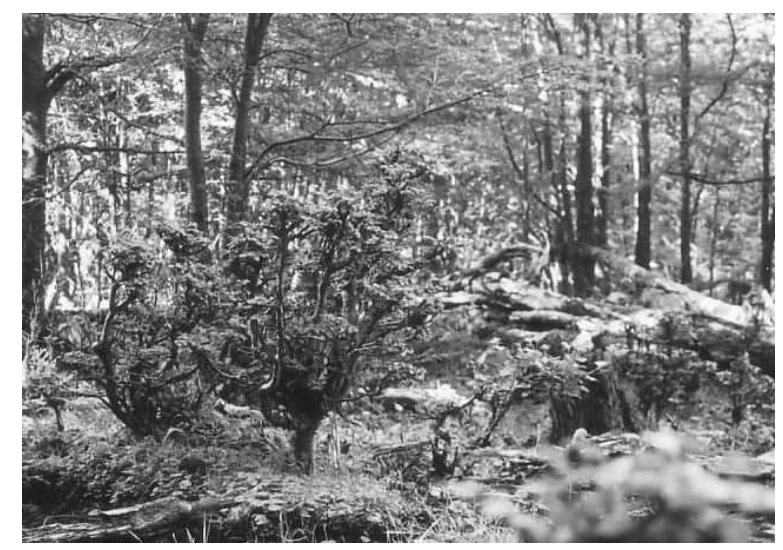

Al realizar el ANOVA se encontraron diferencias significativas entre la cobertura forestal y el impacto ganadero (Tabla 23). En las UV L y G la cobertura arrojó valores promedio de aproximadamente 70 a $80 \%$. El bosque con impacto ganadero fuerte (BGF) presentó un valor de cobertura forestal significativamente menor al bosque sin impacto ganadero $(B)$. En las zonas de BGF se observan claros en el bosque donde la regeneración presenta severos signos de ramoneo, haciendo muy difícil la recuperación del claro. En $B$ el valor de cobertura forestal es similar a los valores encontrados en otros $B$ de la zona (Martínez Pastur et al., 2002b). El bosque con impacto ganadero bajo $(B G B)$ no se diferencia de las situaciones de $B G F$ y $B$, dando un valor promedio de cobertura forestal similar a $B$. En esta zona de bajo impacto se observan indicios de ramoneo pero en menor medida que en $B G F$.

Tabla 23. Análisis de varianza de cobertura forestal y altitud en distintas unidades de vegetación con distinto grado de impacto ganadero.

Analysis of variance of forest cover and altitude in different units of vegetation with different cattle impact.

\begin{tabular}{lllll}
\hline & $\mathrm{n}$ & $\mathrm{COB} \%$ & $\mathrm{~m}$ s.n.m. & $A B$ \\
\hline T GF & 3 & - & $2560 \mathrm{ab}$ & - \\
$T G B$ & 1 & - & $265,0 \mathrm{abc}$ & - \\
$P G F$ & 5 & - & $214,6 \mathrm{a}$ & - \\
$P G B$ & 1 & - & $658,0 \mathrm{bc}$ & - \\
$P S G$ & 21 & - & $564,9 \mathrm{c}$ & - \\
$B G F$ & 29 & $69,90 \mathrm{a}$ & $275,5 \mathrm{a}$ & $49,65 \mathrm{a}$ \\
$B G B$ & 13 & $80,46 \mathrm{ab}$ & $350,2 \mathrm{ab}$ & $70,89 \mathrm{~b}$ \\
$B S G$ & 66 & $80,24 \mathrm{~b}$ & $421,9 \mathrm{~b}$ & $54,80 \mathrm{ab}$ \\
\hline $\mathrm{P}(95 \%)$ & & 0,0000 & 0,0000 & 0,0476 \\
$\mathrm{~F}$ & & 16,50 & 13,36 & 4,79 \\
\hline
\end{tabular}

T: tipo de unidad de vegetación turbera; GF: impacto ganadero fuerte; $G B$ : impacto ganadero bajo; $P$ : tipo de unidad de vegetación pastizal; $B$ : tipo de unidad de vegetación bosque; $S G$ : sin impacto ganadero; Letras diferentes indican diferencias significativas a $\mathrm{P}<0,05$ según prueba de Tukey, $\mathrm{n}$ : número de observaciones, F: Test de Fisher, P (95\%): nivel de probabilidad, valores expresados en medias.

El impacto de la ganadería también presentó una correlación con la altitud, encontrándose los mayores impactos en las zonas bajas dadas por la cercanía a los asentamientos urbanos, estando estas zonas ubicadas entre los 214,6 a 275,5 m s.n.m. Se encontraron diferencias significativas al contrastar $B G F$ con el $B$ presentando un promedio de 275,5 contra 421,9 m s.n.m., concluyendo que los bosques ubicados en zonas mas bajas se encuentran con un alto impacto ganadero, 
mientras que las zonas altas de la cuenca no presentan IG. El $B G B$ se encuentra en una zona intermedia a los 350,2 m s.n.m. caracterizado por un impacto menor que el $B G F$. Con respecto al área basal, se observa que el BGF presenta el menor valor en comparación con $B G B$. El fuerte impacto del ganado impide que el bosque se desarrolle y se instale y cuando el impacto es bajo, el área basal no disminuye en bosques maduros. El caso del $B$, éste es generalmente bosque de altura, y como tal tiene menor área basal en comparación con los bosques ramoneados del fondo de valle (Martínez Pastur et al., 1994), dando por ello menores valores de área basal que $B G B$.

En el Mapa 16 de impacto de la ganadería se puede observar la distribución del impacto a lo largo de la CAG. El impacto en el bosque de Nothofagus presente en el Río Chico se encuentra hasta los $450 \mathrm{~m}$ s.n.m., bordeando los dos pastizales existentes a lo largo del río. Predominan en este valle los impactos fuertes de la ganadería, disminuyendo la intensidad a medida que aumenta la altitud, desapareciendo en los bosques de altura y en los de la cabecera del valle. Además se observa la existencia de una mayor cantidad de UV ubicadas en la margen derecha del río causada por la presencia de un sendero que llega hasta la cabecera del valle. En el Valle del Arroyo Grande, la distribución de los impactos en el bosque de Nothofagus son similares al Valle del Río Chico, en. Estos se encontraron concentrados (mayormente BGF) en la desembocadura y zona periurbana, así como en UV adyacentes a los senderos existentes que llevan a la Laguna del Caminante (Mapa 1) y al Glaciar Vinciguerra. No existe impacto ganadero en un amplio sector de la cabecera del Valle del Arroyo Grande, así como en la mayor parte de la margen izquierda del arroyo, al no existir senderos para facilitar el movimiento del ganado. Los 5 pastizales linderos al Río Chico y al Arroyo Grande presentan un fuerte impacto de la ganadería. Existen sólo dos UV de los 22 pastizales de altura muestreados con impacto ganadero bajo ( $P G B)$, es una zona de veranada cercana al monte Vinciguerra, donde se observan vacunos, siendo poco frecuente encontrar este tipo de práctica en Tierra del Fuego. El $80 \%$ de las turberas presentan impacto ganadero fuerte, distribuyéndose a lo largo del Valle del Arroyo Grande.

\subsubsection{Aprovechamiento forestal}

Los aprovechamientos forestales antiguos (AV) presentaron diferencias significativas en altitud (Tabla 24), observándose que los aprovechamientos viejos fuertes $(A V F)$ y los aprovechamientos viejos bajos $(A V B)$ se diferencian del bosque sin 
aprovechamientos viejos $(B)$. El análisis de la cobertura forestal en relación con el aprovechamiento forestal no dio diferencias en la intensidad de aprovechamiento. Los $A V$ no presentaron diferencias con el $B$, denotando la recuperación de éstos dado por el cerramiento del dosel. Los valores de cobertura de $70,7 \%$ del $A V F$ no difirieron de $B$ y $A V B(80,0$ y $80,5 \%$ respectivamente). En el Mapa 11 se presenta la distribución de los aprovechamientos forestales antiguos, observándose que los aprovechamientos se encuentran en las zonas de bosque de poca pendiente y cercanos a los cursos de agua principales ya que estas zonas son más accesibles y poseen una mejor calidad de sitio. En general los $A V B$ se encuentran en zonas de pendiente moderada y más alejada de la desembocadura que los $A V F$. El $62,7 \%$ de las UV forestales fueron $A V$.

Tabla 24. Análisis de varianza de altitud y cobertura forestal en distintas unidades de vegetación discriminadas por la intensidad del aprovechamiento forestal antiguo.

Analysis of variance of altitude and forest cover in different units of vegetation discriminated by past forest harvest intensity.

\begin{tabular}{llll}
\hline & $\mathrm{n}$ & Altitud (m s.n.m.) & $C O B \%$ \\
\hline$T$ & 4 & $258,25 \mathrm{ab}$ & $0,00 \mathrm{a}$ \\
AVF & 23 & $264,65 \mathrm{a}$ & $70,70 \mathrm{~b}$ \\
AVB & 9 & $289,67 \mathrm{a}$ & $80,50 \mathrm{~b}$ \\
B SV & 51 & $437,51 \mathrm{bc}$ & $80,03 \mathrm{~b}$ \\
$P$ & 27 & $503,48 \mathrm{c}$ & $0,37 \mathrm{a}$ \\
\hline $\mathrm{P}(95 \%)$ & & 0,0000 & 0,0000 \\
$\mathrm{~F}$ & & 14,83 & 99,77
\end{tabular}

m s.n.m.: altitud sobre el nivel del mar en m; $C O B \%$ : cobertura forestal en porcentaje; $T$ : tipo de unidad de vegetación turbera; $A V F$ : aprovechamiento antiguo fuerte; $A V B$ : aprovechamiento antiguo bajo; $B$ : tipo de unidad de vegetación bosque; $P$ : tipo de unidad de vegetación pastizal; $S V$ : sin aprovechamiento antiguo; Letras diferentes indican diferencias significativas a $\mathrm{P}<0,05$ según prueba de Tukey, n: número de observaciones, F: Test de Fisher, P (95\%): nivel de probabilidad, valores expresados en medias.

Los aprovechamientos recientes fuertes $(A R F)$ y los aprovechamientos recientes bajos $(A R B)$ se diferenciaron de $B$ en altitud, siendo el número de $U V$ menor que en los $A V$, marcando que en la $C A G$ existió un aprovechamiento del recurso forestal pasado muy intenso (Tabla 25). Con respecto a la cobertura, sólo en los aprovechamientos recientes fuertes $(A R F)$ marcaron diferencias significativas entre $A R B$ y $B$, mostrando que la reducción de la cobertura es importante (de $80,0 \%$ del $B$ a $37,16 \%$ en $A R F$ ) en los bosques de menor altitud de la CAG. Sólo el 16,1\% de las UV forestales presentan $A R$, estando ubicadas en la zona de la desembocadura y cercanías de la confluencia del Río Chico y Arroyo Grande (Mapa 12). Estos aprovechamientos son utilizados en su mayoría para la fabricación de postes y como combustible.

Tabla 25. Análisis de varianza de altitud y cobertura forestal en distintas unidades de vegetación discriminadas por la intensidad del aprovechamiento forestal reciente.

Analysis of variance of altitude and forest cover in different units of vegetation discriminated by recent forest harvest intensity.

\begin{tabular}{llll}
\hline & $\mathrm{n}$ & Altitud (m s.n.m.) & $C O B \%$ \\
\hline$T$ & 4 & $258,25 \mathrm{ab}$ & $0,00 \mathrm{a}$ \\
$A R F$ & 6 & $206,50 \mathrm{a}$ & $37,17 \mathrm{~b}$ \\
$A R B$ & 9 & $216,33 \mathrm{a}$ & $75,00 \mathrm{c}$ \\
$B S R$ & 93 & $390,61 \mathrm{~b}$ & $80,33 \mathrm{c}$ \\
$P$ & 27 & $503,48 \mathrm{c}$ & $0,37 \mathrm{a}$ \\
\hline
\end{tabular}


$\begin{array}{lll}P(95 \%) & 0,0000 & 0,0000 \\ F & 8,46 & 128,46\end{array}$

m s.n.m.: altitud sobre el nivel del mar en m; $C O B \%$ : cobertura forestal en porcentaje; $T$ : tipo de unidad de vegetación turbera; $A R F$ : aprovechamiento reciente fuerte; $A R B$ : aprovechamiento reciente bajo; $B$ : tipo de unidad de vegetación bosque; $P$ : tipo de unidad de vegetación pastizal; $S R$ : sin aprovechamiento reciente; Letras diferentes indican diferencias significativas a $\mathrm{P}<0,05$ según prueba de Tukey, $\mathrm{n}$ : número de observaciones, F: Test de Fisher, P (95\%): nivel de probabilidad, valores expresados en medias.

\subsubsection{Explotación de turba}

La explotación de la turba en Tierra del Fuego se desarrolla utilizando todavía métodos primitivos. Estas actividades comerciales alteran profundamente el hábitat natural, no sólo por la extracción de la turba, sino también por las actividades derivadas de la explotación, debido al movimiento de equipos, transportes y la degradación del bosque circundante.

La extracción se realiza mediante panes de turba lo cual mejora las cualidades físico - químicas, otorgándole una mayor capacidad para absorber aire y agua y permitiendo una mejor clasificación de los estratos (turba rubia, negra, humus) para su procesamiento industrial. La turba mezclada con tierra negra, guanos animales y/o fertilizantes, es un excelente medio de cultivo en invernaderos y almacigueras. Otros usos de la turba son: en el limpiado de aguas con petróleo, ya que es rápidamente absorbido por este material; como aislante acústico y térmico mediante un proceso de aglomeración; como material para cama de animales; corno materia orgánica en suelos para cultivos de hongos con fines industriales (especialmente en la producción de champiñones); como vehículo para la aplicación de abonos muy solubles y como substratos para el alojamiento de bacterias fijadoras de nitrógeno (Rhizobium) en forma simbiótica en la elaboración industrial de inoculantes comerciales.

Dentro de la CAG existen 4 turberas de Sphagnum sp. (Mapa 6, Unidades de vegetación), ocupando una superficie de 136,29 ha (2,24\% de la superficie del total de las UV). El $96 \%$ de las turberas de Argentina se desarrollan en Tierra del Fuego (Consejo Federal de Inversiones, 1961). Actualmente existe un emprendimiento de explotación de turba realizada por una pequeña empresa ubicada en el turbal más cercano a la desembocadura, la cual utiliza medios precarios para la extracción y secado. La superficie en explotación es de 12 ha, siendo el 8,8\% del total de $T$ presente en la $C A G$.

\subsubsection{Turismo.}

El impacto del turismo es importante, ya que esta actividad produce uno de los mayores impactos en áreas protegidas (Ardura, 1994). Siendo su carácter estacional, 
se observa que el verano es la época de mayor concentración de visitantes. Éstos visitan el área principalmente con fines turísticos, recreativos y contemplativos, y en su gran mayoría realizan visitas de un día o medio día, siendo las actividades más comunes el picnic, asado y paseos cortos. La proximidad a la ciudad de Ushuaia, determina que esta área sea un área propicia para pasar el día, especialmente los fines de semana y feriados. Los principales atractivos turísticos y recreativos del área son el Circuito Valle de Andorra - Cañadón de la Oveja, la Laguna de los Témpanos y el Glaciar Vinciguerra, siendo las principales actividades de estos recorridos el trekking, el campamentismo, la observación de la fauna y flora, la bicicleta de montaña y el safari fotográfico. La cantidad de turistas anuales para la temporada $2004-2005$ (Secretaría de Turismo de la Municipalidad de Ushuaia, 2005b) discriminados por recorrido (información tomada mediante registro voluntario de turistas, por lo cual las cifras no pueden considerarse como cifras totales) fueron: circuito Valle de Andorra Cañadón de la Oveja con 274 visitantes y el sector de la Laguna de los Témpanos y el Glaciar Vinciguerra con 48 turistas.

El circuito Valle de Andorra - Cañadón de la Oveja consiste en unir los valles cruzando por un paso de altura sin vegetación. El circuito incluye pernoctar en la Laguna del Caminante, y la opción de ascender al Cerro Falso Tonelli. Es una opción recomendada para aquellos turistas que deseen pernoctar una o dos noches en la montaña. El circuito puede iniciarse en cualquiera de los dos sentidos, pero debido a que en el Cañadón de la Oveja una buena parte del sendero se encuentra por encima del límite vegetacional, es aconsejable comenzar por éste valle con buen tiempo. La ascensión al cerro Falso Tonelli demanda un día completo desde la Laguna del Caminante, siendo necesario subir paralelo al arroyo de la Laguna Superior, atravesar el glaciar plano que nos separa su pared norte y ascender por un pedrero. Desde la cumbre se puede observar el canal Beagle, el Cabo de Hornos y la Cordillera Darwin. Desde la Laguna del Caminante se desciende por el Valle de Andorra por el sendero hasta la zona de quintas donde se puede llamar a un taxi. Este circuito ingresa en el Parque Nacional Tierra del Fuego, por lo que no está permitido hacer fuego y es necesario avisar en la intendencia antes de realizar la travesía.

La senda para llegar a la Laguna de los Témpanos y el Glaciar Vinciguerra comienza en el Valle de Andorra, luego se desvía hacia el norte para cruzar el puente colgante. El sendero penetra en el bosque, iniciando el ascenso de la montaña. Al salir del bosque se continúa ascendiendo por el pastizal de altura hacia el oeste por la senda. Ésta se desvía por la ladera oeste del cerro en dirección norte, descendiendo al valle del arroyo que proviene de la Laguna de los Témpanos. Se cruza el arroyo y se 
inicia otro ascenso que culmina en la laguna, desde donde se puede observar el Glaciar Vinciguerra.

No existen zonas de campamento organizado, existiendo sectores de acampe agreste, donde se pueden ver restos de fogones y de cobertura forestal reducida. Los senderos relevados son los utilizados para la realización del circuito Valle de Andorra Cañadón de la Oveja, la Laguna de los Témpanos y el Glaciar Vinciguerra, existiendo otro sendero menos utilizado a lo largo del Río Chico. Estos senderos, se hallan en mal estado de mantenimiento. Los impactos derivados del uso público se producen principalmente en senderos y áreas de acampe. Los impactos en los senderos están vinculados a la intensidad de uso, pendientes y tipo de suelo. La presencia de agua sobre el sendero, producida por la falta de drenaje o por el bajo drenaje del suelo donde se encuentra, son comunes los ensanchamientos con muerte de la vegetación arbustiva y herbácea lateral por pisoteo. Estos impactos se observaron a lo largo de los senderos del circuito Valle de Andorra - Cañadón de la Oveja, la Laguna de los Témpanos y el Glaciar Vinciguerra, y en menor medida en el sendero del Río Chico. También en esos senderos se observa la formación de senderos múltiples. Los problemas de erosión dependen de la pendiente, observándose exposición de raíces (APN, 2003a). En las zonas de campamento agreste se puede observar la perdida de la cubierta vegetal por la realización de fogones con la consecuente erosión por la circulación desordenada de personas; y la dispersión de excrementos y papel higiénico por falta de sanitarios. Además se observan los daños a los árboles para utilizarlos como leña. Esta práctica hace que la escasa disponibilidad de material seco y caído en los alrededores de las áreas de acampe provoque el corte de árboles vivos por parte de los acampantes (APN, 2003a). Existe también en las áreas de acampe agreste la acumulación y dispersión de residuos.

\subsubsection{Especies exóticas}

El número de especies, abundancia y biomasa se modifican significativamente a lo largo del ciclo forestal, siendo el mayor impacto por el ingreso de especies exóticas al ecosistema que no estaban presentes en el bosque virgen (Fernández et al., 1999).

Se comparó la riqueza y abundancia de las especies vegetales exóticas en las UV inventariadas con parámetros de la estructura forestal y la topografía, sin encontrar

relaciones que puedan explicar su distribución. Al contrastar la riqueza y la abundancia de estas especies discriminando por la presencia de aprovechamientos forestales antiguos, se encontraron diferencias significativas (Tabla 26) entre el bosque sin 
signos de aprovechamiento antiguo (BSV) y el bosque con aprovechamiento antiguo fuerte $(A V F)$. Se encontraron valores bajos del porcentaje del número de especies exóticas relacionado con el número total de especies de la unidad de vegetación (NXT), en las turberas, el BSV y el pastizal, con valores de entre $2,78 \%$ y $7,79 \%$. Los valores de NXT aumentan en los bosques con aprovechamiento antiguo, siendo el de mayor intensidad, el que posee el mayor porcentaje de $N X T$, alcanzando el 17,19\%. En el caso de la abundancia, dada por el porcentaje de la abundancia de especies exóticas relacionado con la abundancia total de la unidad de vegetación ( $A T X)$, el menor valor se encontró en la turbera, con un 0,04\%.

Tabla 26. Análisis de varianza del número de especies exóticas relacionado con el número total de especies de la unidad de vegetación y abundancia de especies exóticas relacionado con la abundancia total en distintas unidades de vegetación discriminadas por la intensidad del aprovechamiento forestal antiguo.

Analysis of variance of number of exotic species related to the total number of species in each vegetation unit and abundance of exotic species related to the total abundance in different units of vegetation discriminated by past forest harvest intensity.

\begin{tabular}{lllll}
\hline & $\mathrm{n}$ & NXT & AXT & $N$ \\
\hline TSV & 3 & $2,78 \mathrm{ab}$ & $0,04 \mathrm{ab}$ & $0,33 \mathrm{ab}$ \\
B SV & 51 & $4,17 \mathrm{a}$ & $2,60 \mathrm{a}$ & $0,53 \mathrm{a}$ \\
P SV & 15 & $7,79 \mathrm{ab}$ & $7,09 \mathrm{ab}$ & $1,27 \mathrm{a}$ \\
AVB & 9 & $13,81 \mathrm{ab}$ & $2,82 \mathrm{ab}$ & $2,22 \mathrm{ab}$ \\
AVF & 23 & $17,19 \mathrm{~b}$ & $16,02 \mathrm{~b}$ & $3,30 \mathrm{~b}$ \\
\hline $\mathrm{F}$ & & 6,48 & 3,31 & 10,59 \\
$\mathrm{P}(95 \%)$ & 0,0001 & 0,0139 & 0,0000 \\
\hline
\end{tabular}

NXT: número de especies exóticas relacionado con el número total de especies de la unidad de vegetación; $A X T$ : abundancia de especies exóticas relacionado con la abundancia total de la unidad de vegetación; $N$ : número de especies exóticas; $T$ : tipo de unidad de vegetación turbera; $A V F$ : aprovechamiento antiguo fuerte; $A V B$ : aprovechamiento antiguo bajo; $B$ : tipo de unidad de vegetación bosque; $P$ : tipo de unidad de vegetación pastizal; $S V$ : sin aprovechamiento antiguo; Letras diferentes indican diferencias significativas a $\mathrm{P}<0,05$ según prueba de Tukey; $\mathrm{n}$ : número de observaciones, $\mathrm{F}$ : Test de Fisher, P (95\%): nivel de probabilidad, valores expresados en medias.

Al realizar el análisis de varianza contrastando la riqueza como NTX y la abundancia como $A T X$, con el aprovechamiento forestal reciente $(A R)$, se encontró (Tabla 27) que el aprovechamiento reciente fuerte ( $A R F)$ mostraba diferencias significativas con $T, P$ y el bosque sin aprovechamiento reciente $(B S R)$. Los valores de NTX y ATX para ARF fueron los más elevados, con 36,67 y 72,96 \% respectivamente. Al comparar el número de especies exóticas en cada situación, se arribaron a resultados similares a los análisis de riqueza y abundancia. ARF presentó 6 especies exóticas diferenciándose de $P, T$ y $B S R$, siendo el aprovechamiento reciente bajo un valor intermedio entre las situaciones mencionadas, con un valor de 3,17 especies exóticas. 
Tabla 27. Análisis de varianza de número de especies exóticas relacionado con el número total de especies de la unidad de vegetación y abundancia de especies exóticas relacionado con la abundancia total en distintas unidades de vegetación discriminadas por la intensidad del aprovechamiento forestal reciente.

Analysis of variance of number of exotic species related to the total number of species in each vegetation unit and abundance of exotic species related to the total abundance in different units of vegetation discriminated by recent forest harvest intensity.

\begin{tabular}{lllll}
\hline & $\mathrm{n}$ & $N X T$ & $A X T$ & $N$ \\
\hline$T$ & 3 & $2,78 \mathrm{a}$ & $0,05 \mathrm{a}$ & $0,33 \mathrm{a}$ \\
$B S R$ & 75 & $7,3 \mathrm{a}$ & $3,95 \mathrm{a}$ & $1,22 \mathrm{a}$ \\
$P$ & 15 & $7,78 \mathrm{a}$ & $7,09 \mathrm{a}$ & $1,27 \mathrm{a}$ \\
$A R B$ & 6 & $18,55 \mathrm{ab}$ & $14,02 \mathrm{a}$ & $3,17 \mathrm{ab}$ \\
$A R F$ & 2 & $36,67 \mathrm{~b}$ & $72,96 \mathrm{~b}$ & $6,00 \mathrm{~b}$ \\
\hline $\mathrm{F}$ & & 4,83 & 14,8 & 4,42 \\
$\mathrm{P}(95 \%)$ & 0,0014 & 0,0000 & 0,0025
\end{tabular}

NXT: número de especies exóticas relacionado con el número total de especies de la unidad de vegetación; AXT: abundancia de especies exóticas relacionado con la abundancia total de la unidad de vegetación; $N$ : número de especies exóticas; $T$ : tipo de unidad de vegetación turbera; $A R F$ : aprovechamiento reciente fuerte; $A R B$ : aprovechamiento reciente bajo; $B$ : tipo de unidad de vegetación bosque; $P$ : tipo de unidad de vegetación pastizal; $S R$ : sin aprovechamiento reciente; Letras diferentes indican diferencias significativas a $\mathrm{P}<0,05$ según prueba de Tukey, n: número de observaciones, F: Test de Fisher, P (95\%): nivel de probabilidad, valores expresados en medias.

Se encontraron diferencias entre las unidades de bosque y pastizal con distinto grado de impacto ganadero al analizar el NXT. El bosque sin impacto ganadero (BSG) y el pastizal sin impacto ganadero (PSG) presentaron bajos (alrededor de $3 \%$ ) valores de $N X T$, siendo diferentes al bosque con impacto ganadero fuerte y el pastizal con impacto ganadero fuerte, los que tomaron valores cercanos al 20\% (Tabla 28), indicando que el impacto ganadero fuerte tiene implicancias con la inclusión de especies exóticas en la UV.

Tabla 28. Análisis de varianza del número de especies exóticas relacionado con el número total de especies de la unidad de vegetación y abundancia de especies exóticas relacionado con la abundancia total en distintas unidades de vegetación con distinto grado de impacto ganadero.

Analysis of variance of number of exotic species related to the total number of species in each vegetation unit and abundance of exotic species related to the total abundance in different units of vegetation discriminated by different cattle impact.

\begin{tabular}{|c|c|c|c|c|}
\hline & $\mathrm{n}$ & $N X T$ & $A X T$ & $N$ \\
\hline$T G F$ & 3 & $2,78 a b$ & $0,05 a b c$ & $0,33 a b$ \\
\hline$B S G$ & 51 & $3,49 a$ & $0,90 \mathrm{a}$ & $0,43 a$ \\
\hline$P S G$ & 11 & $3,57 \mathrm{a}$ & $1,36 \mathrm{a}$ & $0,64 a b$ \\
\hline$P G B$ & 1 & $6,67 \mathrm{ab}$ & $0,24 a b c$ & $1,00 \mathrm{abc}$ \\
\hline$B G B$ & 9 & $12,25 a b$ & 2,99 ac & $2,22 \mathrm{bc}$ \\
\hline$B G F$ & 23 & $19,31 \mathrm{~b}$ & $19,74 \mathrm{~b}$ & $3,52 \mathrm{c}$ \\
\hline$P G F$ & 3 & $23,61 \mathrm{~b}$ & $30,39 \mathrm{bc}$ & $3,67 \mathrm{bc}$ \\
\hline $\mathrm{F}$ & & 8,75 & 6,98 & 11,57 \\
\hline P (95\% & & 0,0000 & 0,0000 & 0,0000 \\
\hline
\end{tabular}

NXT: número de especies exóticas relacionado con el número total de especies de la unidad de vegetación; AXT: abundancia de especies exóticas relacionado con la abundancia total de la unidad de vegetación; $N$ : número de especies exóticas $T$ : tipo de unidad de vegetación turbera; GF: impacto ganadero fuerte; $G B$ : impacto ganadero bajo; $P$ : tipo de unidad de vegetación pastizal; $B$ : tipo de unidad de vegetación bosque; $S G$ : sin impacto ganadero; Letras diferentes indican diferencias significativas a $\mathrm{P}<0,05$ según prueba de Tukey, n: número de observaciones, F: Test de Fisher, $\mathrm{P}(95 \%)$ : nivel de probabilidad, valores expresados en medias. 
Los valores intermedios (pastizal con impacto ganadero bajo $(P G B)$ y bosque con impacto ganadero bajo $(B G B)$ ) presentaron porcentajes de 6,67 y $12,25 \%$ respectivamente, siendo intermedio entre las situaciones sin ganadería y con fuerte impacto ganadero. Para el $A X T$, se observan similares resultados que en $N X T$, pero con valores bajos en $B S G, P S G, P G B$ y $B G B$, siendo $B G F$ y $P G F$ los valores más altos, llegando al 30,39\% de cobertura.

La especie exótica más frecuente de la CAG es Taraxacum officinale Weber (Compositae) encontrándose en el $29,70 \%$ de las UV. Ésta especie se encuentra ampliamente distribuida en toda la isla de Tierra del Fuego (Moore, 1983). Otras especies exóticas con alta frecuencia fueron: Poa nemoralis L. (Gramineae) 21,78\%. Poa pratensis L. (Gramineae) 21,78\%, Cerastium fontanum Baumg. (Caryophyllaceae) 20,79\%, Ranunculus repens L. (Ranunculaceae) 16,83\%, Stellaria media (L.) Vill. (Caryophyllaceae) 10,98\% y Agrostis stolonifera L. (Gramineae) 5,94\%. En el Mapa 13, donde se observa la distribución de las especies exóticas en la CAG, existe una mayor presencia de estas especies en la zona baja del Valle del Río Chico y la zona correspondida entre la turbera de mayor superficie y la desembocadura del Arroyo Grande. Asimismo se observan en la margen derecha del Arroyo Grande la presencia de una a dos especies exóticas. La distribución de estas especies es similar a la distribución de los impactos ganaderos presentados en el Mapa 16.

En la CAG existen 2 especies de animales de alto impacto, el castor (Castor canadensis Kuhl.) y la rata almizclera (Ondatra zibethica L.) (Jaksic et al., 2002; Vázquez, 2002). El castor es de particular importancia ya que modifica el ambiente para hacerlo propicio a sus necesidades (Lizarralde et al., 1989). Si bien no tiene gran influencia en los bosques productivos (ya que ellos cortan mayormente árboles dentro de la zona buffer que hay que dejar como protección de bordes de ribera), pueden causar grandes inconvenientes al producir embalses al borde de los caminos que cruzan cursos de agua, o inundando grandes zonas por donde eventualmente puedan pasar picadas de madereo.

El Castor canadensis es una especie originaria de América del Norte, introducida en Tierra del Fuego en 1946 para el aprovechamiento de su piel (Lizarraide, 1993, Lizarralde et al., 1989). Las 25 parejas liberadas, se expandieron notablemente en corto tiempo, favorecidas por la ausencia de predadores y competidores naturales. En el año 1964, la especie se extiende hasta el Valle del Río Carbajal y actualmente está presente en el $90 \%$ de las cuencas de la Isla (Lizarralde et al., 2004). Esta especie ocasiona una importante y visible modificación del paisaje ya que el corte de árboles y la construcción de diques modifican la morfología y la hidrología de los cursos de agua en los que desarrolla su actividad, creando y manteniendo sitios inundados (Foto 7). 
Foto 7: Castorera y madriguera de Castor canadiensis. Castor canadiensis dam and burrow.

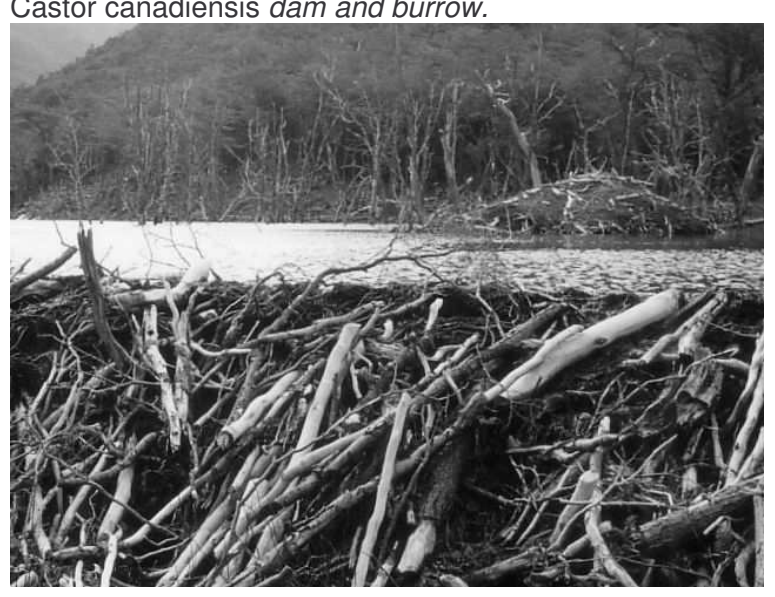

Esto produce la retención de sedimentos y materia orgánica en las zonas endicadas, se modifica el ciclo de nutrientes y la dinámica de la descomposición, se modifica la estructura y dinámica de las zonas riparias y se influencian las características del agua, los materiales transportados, la comunidad biótica y la riqueza, modificando las comunidades vegetales originales (Lizarralde, 1993). Castor canadensis es considerado una especie clave en el ecosistema, por su condición de agente natural de perturbación ya que dadas sus actividades de volteo de árboles y arbustos para alimento, construcción de diques y madrigueras (Foto 8), modifica el ambiente y la dinámica de los nutrientes dentro del bosque (Lizarralde et al., 2004).

Foto 8. Impacto de Castor canadiensis en el bosque de N. pumilio.

Impact of Castor canadiensis on N. pumilio forest.

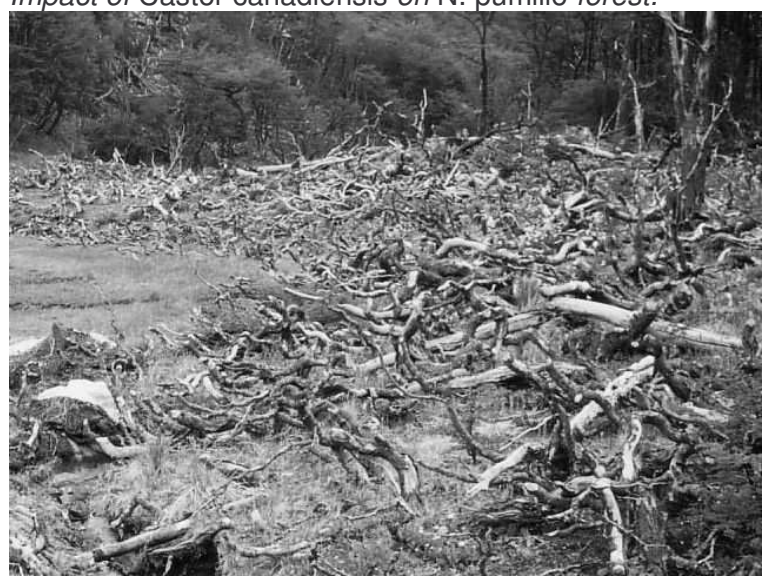

Castor canadensis se encuentra distribuido ampliamente en toda la superficie de la $C A G$, donde se observaron colonias en el Río Chico, Arroyo grande y afluentes de éstos. No se tienen datos de la superficie total de bosque impactada por los mismos. En estudios realizados sobre los efectos de los endicamientos producidos por el castor sobre la dinámica de nutrientes del bosque se ha encontrado que las concentraciones de carbono, nitrógeno orgánico e inorgánico y fósforo son significativamente mayores 
en los estanques de castor (Lizarralde et al., 1996), asimismo, la vegetación que coloniza las castoreras recientemente abandonadas presenta una baja riqueza de especies, recuperándose en años posteriores pero incorporando exóticas. Se observó una escasa regeneración forestal, contrastando con el bosque original, debido a la competencia de especies más agresivas, como exóticas y monocotiledóneas. (Lencinas et al., 2001a). A partir de 1994 se comenzaron a utilizar trampas Conibear $330 \mathrm{Tm}$. Estas trampas permiten capturar a los animales sin modificar el embalse, y sólo se produce el drenaje lento de los mismos una vez asegurada la captura de todos los individuos de la colonia, minimizando la pérdida de sedimentos y nutrientes y favoreciendo la recolonización vegetal. Sin embargo el uso de estas trampas de captura muerta implica riesgos para la fauna nativa.

Ondatra zibethicus fue introducida junto con Castor canadensis y con la misma finalidad. Actualmente se encuentra en la CAG (Escobar, com. pers. 2002), asociada a los ambientes acuáticos y colonizados por Castor canadensis. (Lizarralde \& Escobar, 2000; Jaksic et al., 2002)

EI Conejo europeo (Oryctolagus cuniculus L.) fue introducida a fines del siglo XIX en la islas del Canal Beagle. En 1953 era considerado una plaga. Este mamífero es más abundante en las áreas montañosas y boscosas. Construyen madrigueras en suelos con buen drenaje y en huecos en las rocas. Con el propósito de controlar la población fueron introducidos en 1951 el zorro gris (Dusicyon griseus Gray) y posteriormente en 1954 fue introducido desde Brasil el virus de la mixomatosis, gracias a este último las poblaciones se vieron drásticamente disminuidas (Jaksic et al., 2002). En la actualidad el área de distribución de Oryctolagus cuniculus se restringe a la zona sur de la isla, circunscripta a las zonas costeras del Canal Beagle, directamente relacionada con sectores abiertos con cobertura herbácea, y/o arbustiva o bien sectores con cobertura boscosa pero con signos de impacto como las áreas de acampe.

\subsection{DISCUSIÓN}

El grado de modificación de la $C A G$ dado por los indios Yámanas fue prácticamente nulo, debido a que desarrollaban sus actividades en la costa y en el mar principalmente, ingresando esporádicamente en el interior de la CAG. Desde principios del siglo XX y hasta la década del 70 , se realizaron actividades forestales a gran escala en la cuenca, destinada a la actividad turística y para calefacción de los establecimientos rurales y urbanos de la zona. Actualmente en la parte baja de la 
cuenca (0 a 150 m s.n.m.) el bosque presenta un aspecto ralo debido al ingreso del ganado que impide la correcta regeneración, originando el desarrollo.

El $48,1 \%$ de la CAG pertenece al PNTdF, siendo el resto perteneciente a la Provincia de Tierra del Fuego, al Municipio de Ushuaia y en la zona de la desembocadura, propiedades privadas. Los daños causados en la vegetación por las actividades humanas evidencian impactos fuertes en la zona central y de la desembocadura del Arroyo Grande y Río Chico, dado por el ingreso de bovinos y equinos Se observa un Impacto en algunos sectores por actividad ganadera, con la consecuente degradación de pastizales naturales. Se encontró que el bosque con impacto ganadero fuerte presenta claros donde la regeneración presenta severos signos de ramoneo, haciendo muy difícil su recuperación, al impedir que el bosque se desarrolle y se instale. Los mayores impactos debidos al ganado se encontraron en las zonas bajas dadas por la cercanía a los asentamientos urbanos, estando estas zonas ubicadas entre los 214,6 a 275,5 m s.n.m. En el Valle del Río Chico, el bosque de Nothofagus presenta impactos fuertes de la ganadería, siendo menos intensos a medida que aumenta la altitud, causado por la presencia de un antiguo camino forestal utilizado por el ganado. En el Valle del Arroyo Grande los impactos se encuentran concentrados en la desembocadura y zona periurbana, así como en las cercanías del sendero existentes que llevan a la Laguna del Caminante (Mapa 4) y al Glaciar Vinciguerra.

Una extensa zona de la CAG presenta impactos dados por los aprovechamientos forestales antiguos; éstos se encuentran en la zona central, con baja pendiente, accesibles y con una mejor calidad de sitio. Los aprovechamientos recientes se presentan en el $16,1 \%$ de las $U V$, en la zona de la desembocadura y cercanías de la confluencia del Río Chico y Arroyo Grande.

Existe un emprendimiento de extracción de turba, utilizando medios precarios para la extracción y secado. Estas actividades alteran el hábitat natural ya que producen el desecamiento del ecosistema y la consecuente mortalidad de las especies vegetales que lo integran.

Se observa una acumulación de basura en algunos sectores puntuales y dispersión de basura básicamente por la actividad turística, en el Circuito Valle de Andorra - Cañadón de la Oveja, la Laguna de los Témpanos y el Glaciar Vinciguerra. El impacto se manifiesta en los residuos generados, senderos con signos de erosión, áreas de camping agreste con perdida de la cubierta vegetal, dispersión de excrementos y papel higiénico por falta de sanitarios, daños en los árboles para su utilización como leña y la acumulación y dispersión de residuos. 
Existe una marcada presencia de especies exóticas, distribuidas en la zona baja del Valle del Río Chico y la zona central del Valle de Andorra, siendo similar a la distribución de los impactos ganaderos. Las especies de animales de alto impacto son, principalmente Castor canadensis y menos importante Ondatra zibethica. C. canadensis se encuentra distribuido a lo largo del Arroyo Grande y el Río Chico, constituyendo un serio problema debido a su amplia dispersión. 


\section{ZONIFICACIÓN Y PROPUESTAS DE MANEJO DE GANADERÍA, TURISMO Y TURBERAS.}

\subsection{INTRODUCCIÓN}

Las distintas clasificaciones de los paisajes naturales se desarrollan para determinar las distintas actividades que se pueden realizar en una zona dada. Las actividades permiten distintos grados de uso, expresados por los efectos negativos que pueden producir a la naturaleza (CFI, 2001b). En general se tiende a mantener y conservan la biodiversidad, a la vez que se interviene en el ecosistema en las zonas específicas para ello. El aprovechamiento forestal puede ser incluido en extracciones programadas formando parte de un plan de aprovechamiento que asegure la sustentabilidad del recurso mientras se seleccione un método de regeneración con bajo impacto en el medio. Cuando el área del bosque exhibe menos restricciones al uso, es posible utilizar el planteo del manejo sustentable del mismo, aunque de todas formas este manejo se manifestará en un cierto impacto sobre el sistema, por lo cual si bien se mantiene la biodiversidad probablemente cambiará la intensidad de alguna especie (CFI, 2001b). Además se debe tener en cuenta la calidad del paisaje como elemento educativo y formativo del visitante, apuntando a desarrollar una relación

armónica con la naturaleza (Bessera et al., 1996). Según Martín (1994), las definiciones de las categorías de manejo deberán tener coherencia con los objetivos, las actividades a desarrollar en las mismas, y las restricciones que impone su categoría. Los límites del área deben englobar los sistemas o rasgos naturales que motivan su existencia.

La zonificación del área consiste en un ordenamiento del uso del espacio, estableciendo zonas sometidas a diferentes restricciones y regímenes de manejo, a través de las cuales se espera alcanzar los objetivos de la unidad (Martín, 1994). La zonificación deberá ajustarse a los siguientes lineamientos básicos: a) Las zonas de manejo deben guardar estrecha relación con los objetivos y la categoría del área; b) No deberán contemplarse zonas que impliquen actividades o aprovechamientos no admitidos en la categoría respectiva; c) En áreas pertenecientes a las categorías más permisivas en materia de usos y aprovechamientos, deberán establecerse algunas zonas de alta restricción al uso, destinadas a lograr determinados objetivos de protección.

El análisis integral para planificar del uso de un territorio proporciona un eficaz aprovechamiento de los recursos naturales, permitiendo mejorar los beneficios 
resultantes y su sostenibilidad (Fitzgerald et al., 1972). Las prácticas de manejo deben orientarse a la satisfacción de las necesidades presentes y futuras minimizando los impactos ambientales (McNulty \& Sun, 1998). La ausencia de manejo integrado de recursos naturales es una característica común en países latinoamericanos, como también la degradación de los ecosistemas en extensas áreas (FAO, 1993).

\subsection{MATERIALES Y MÉTODOS}

Se realizó una zonificación de uso en la superficie de la cuenca basada en las exigencias de conservación por los regímenes de áreas protegidas, por la ocupación actual de asentamientos y por la importancia de las actividades económicas consideradas prioritarias en la región. Dentro de la superficie de la $C A G$ se encuentra una parte perteneciente al Parque Nacional Tierra del Fuego $(P N T d F)$, donde ya existe una zonificación establecida por el Decreto del PEN N453/94. la clasificación de las áreas en las categorías de manejo se fijaron por el Decreto PEN N².148/90 de Creación de las Categorías de Reservas Naturales Silvestres y Educativas. La zona no perteneciente al $P N T d F$ se dividió en tres categorías de manejo según la clasificación propuesta en el Inventario y zonificación de la Reserva Corazón de la Isla (CFI 2001b).

Para la elaboración de una propuesta de objetivos de manejo y desarrollo del proceso de zonificación se tuvo en cuenta la información tomada a campo en las distintas Unidades de Vegetación (UV) y analizada en 2. Morfometría y vegetación de la $C A G$ y 3 . Uso de la tierra e impacto. Para la zonificación se contó con los mapas generados de la CAG con dicha información. Para elaborar la zonificación, se trabajó teniendo en cuenta los objetivos específicos planteados en cada una de las categorías de manejo presentadas. Se determinó el grado de compatibilidad entre los objetivos planteado y el área a zonificar, así como la prioridad de los usos de cada categoría de manejo. Teniendo en cuenta la Ley № 272 (Sistema Provincial de Áreas Naturales Protegidas), donde en su artículo 24ํㅡㄹ clasifica las áreas en las categorías de manejo Reserva de Uso Múltiple (RUM) y Reserva Recreativa Natural $(R R M)$ y el decreto del PEN N ${ }^{\circ} 453 / 94$ para la zona del $P N T d F$, así como el Proyecto de Ordenanza Municipal Co.P.U. 40/2004 para la Zona de Uso Especial (ZUE). De esta forma se sugieren las condiciones y limitaciones para el manejo y aprovechamiento racional de los recursos dentro de cada una de las zonas propuestas, así como las acciones de conservación y restauración de las condiciones del área.

\subsection{RESULTADOS}




\subsubsection{Zonificación}

La CAG comprende una parte perteneciente al Parque Nacional Tierra del Fuego $(P N T d F)$, donde ya existe una zonificación establecida por el Decreto del PEN Nº 453/94, donde se determinaron tres áreas de Reserva Natural Estricta ( $R N E$ ) (norte, centro y sur) y se establece la categoría de Reserva Natural Silvestre (RNS) para un sector amplio del área central de la unidad de conservación. Existe una sola categoría de manejo (Reserva Natural Silvestre) dentro de la totalidad de la zona del PNTdF perteneciente a la CAG. Las definiciones y objetivos de las $R N E$ y las $R N S$ se fijan en los Decretos PEN N².148/90 y 453/94. La zonificación de manejo propuesta, imprescindible para ordenar el área y lograr los objetivos definidos, incluye las siguientes categorías:

Zona intangible (Reserva Natural Estricta):

Es el área de mayor protección de los recursos naturales y culturales y máximas restricciones al uso. Su finalidad es la preservación de determinados ambientes, sistemas o componentes naturales o culturales en condiciones intangibles. Las actividades están limitadas a la vigilancia, con medidas de manejo esenciales para la conservación de los recursos y el mantenimiento de los procesos naturales de los ecosistemas o de las condiciones que conforman una unidad cultural y su entorno. La investigación científica estará restringida a proyectos de bajo nivel de impacto, salvo raras excepciones debidamente justificadas. Como mínimo se corresponde con las 3 áreas de Reserva Natural Estricta creadas por Decreto 453/94 en el PNTdF, pero puede incluir algunas áreas adiciona les donde al menos a mediano plazo es necesario o prudente asegurar mínimos niveles de alteración y uso, como en algunas zonas de la $C A G$.

Zona de Uso Público Extensivo (Reserva Natural Silvestre):

Es el área que por sus características permite el acceso del público con restricciones, de forma tal que las actividades y usos aceptados causen un impacto mínimo a moderado sobre el ambiente, los sistemas o componentes naturales o culturales. Las actividades y usos permitidos son las contempladas en la zona intangible, a las que se agrega el uso científico y el uso educativo y turístico-recreativo de tipo extensivo, es decir no masivo ni concentrado. En materia de infraestructura sólo se admite la construcción de facilidades mínimas y de bajo impacto (Ejemplos: senderos, miradores, refugios tipo vivac, observatorios de fauna, campamentos de tipo 
agreste, refugios de montaña, etc.). En el decreto del PEN $N^{\circ} 453 / 94$ se presentan los objetivos de conservación del PNTdF, que se enuncian a continuación:

Objetivos de conservación generales:

1.- Conservar una muestra representativa de la porción más austral de los Bosques Andino Patagónicos correspondiente al Distrito Biogeográfico Magallánico, asegurando la continuidad de los procesos naturales.

2.- Conservar las altas cuencas hidrológicas, asegurando el mantenimiento de los procesos de regulación hídrica regional.

3.- Asegurar la protección del patrimonio cultural.

4.- Promover la investigación científica de los componentes naturales y culturales de la unidad.

5.- Preservar el patrimonio paisajístico natural y cultural, contribuyendo al desarrollo del potencial turístico de la región.

6.- Brindar oportunidades (áreas y facilidades) para el turismo y la recreación en contacto con la naturaleza.

7.- Propiciar el conocimiento público del área protegida y la comprensión de su importancia y funciones.

Objetivos de conservación específicos:

1.- Asegurar la conservación de comunidades vegetales de distribución restringida en nuestro país (bosque siempre verde de guindo, turberas de Sphagnum), especies de fauna amenazadas o vulnerables, endémicas o de distribución restringida: huillín, cauquén caranca, zorro colorado fueguino, pato de los torrentes.

2.- Conservar los ambientes y la fauna costeros que caracterizan el estuario del Río Lapataia, Bahía Lapataia y la costa del Canal Beagle.

3.- Proteger los yacimientos arqueológicos de las culturas de canoeros recolectores del Canal Beagle.

4.- Conservar componentes del paisaje de importancia geológica, geomorfológica, paleontológica: paleo fiordo Lago Roca - Bahía Lapataia, terrazas marinas holocenas.

De los objetivos de conservación específicos, el que tiene importancia en la $C A G$ es el primero ya que los objetivos 2, 3 y 4 abarcan la zona costera del PNTdF.

La zona que no pertenece al PNTdF se dividió en tres categorías de manejo: la categoría de Reserva Recreativa Natural $(R R M)$, de acuerdo a la Ley $N^{\circ} 272$ que rige el Sistema Provincial de Áreas Naturales Protegidas, la cual tiene como objetivo 
"conservar determinados rasgos escénicos naturales y artificiales asociados, asegurando y compatibilizando la perpetuación de sus características más sobresalientes con el aprovechamiento integral de sus posibilidades de uso", la categoría de Reserva de Usos Múltiples (RUM), cuyo objetivo es "conservar el equilibrio de sus ambientes, mediante el uso regulado de sus recursos naturales, respetuoso de sus características, estado ecológico, particularidades de la vida silvestre y potencialidades productivas" y la Zona de Uso Especial (ZUE), que comprende las zonas destinadas a usos diversos relacionados con el asentamiento de las poblaciones que residen en la CAG (Foto 9), cuyo objetivo es "brindar espacios para la convivencia armónica del hombre con la naturaleza, proporcionando oportunidades para las actividades productivas, turísticas y recreativas" (Planificación y ordenamiento de la vertiente sudoccidental del Valle de Andorra, Proyecto de Ordenanza Municipal Co.P.U. 40/2004).

Foto 9. Ocupación humana en el Valle del Arroyo Grande. Human settlement in Arroyo Grande Valley.

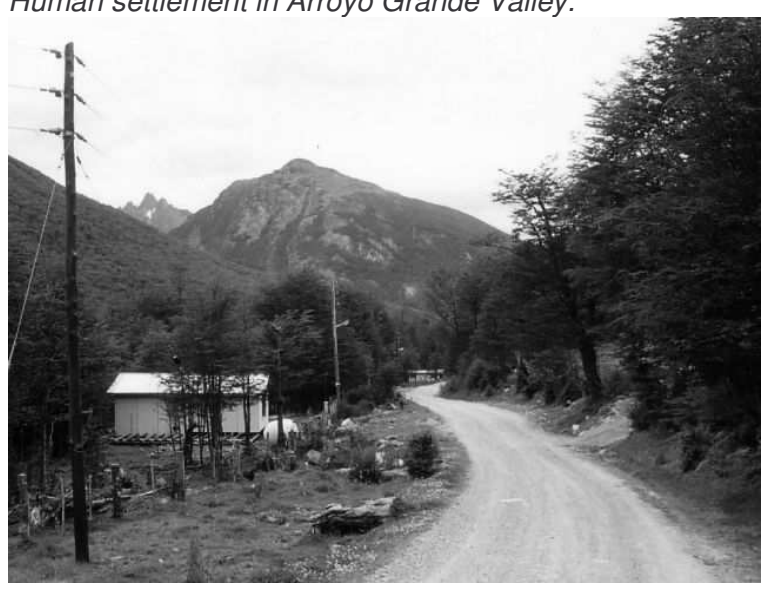

Los objetivos generales, de acuerdo al marco de la Ley $N^{\circ} 272$, adaptada a la CAG son:

Proteger la diversidad biológica de la $C A G$

Proteger áreas de interés para la conservación

Conservar la cuenca hídrica asegurando el mantenimiento de los procesos de regulación hídrica.

Promover el conocimiento público de las características naturales y culturales del área y la comprensión de su importancia y funciones.

Los objetivos específicos para cada categoría de manejo se enumeran a continuación: 
Reserva de Uso Múltiple (RUM)

Constituir un área de utilización de los recursos naturales, utilizando metodologías de bajo impacto.

Priorizar la conservación de la biodiversidad en el desarrollo de actividades extractivas y no extractivas.

Reserva Recreativa Natural ( $R R M)$

Desarrollar el uso turístico, manteniendo las condiciones naturales de los diferentes ambientes.

Zona de Uso Especial (ZUE) (extraído de Planificación y ordenamiento de la vertiente sudoccidental del Valle de Andorra, Proyecto de Ordenanza Municipal Co.P.U. 40/2004):

La preservación, conservación, defensa y mejoramiento del ambiente para lograr y mantener una óptima y mejor calidad de vida.

Brindar espacios para la convivencia armónica del hombre con la naturaleza, proporcionando oportunidades para las actividades productivas, turísticas y recreativas.

La implementación de los mecanismos legales, técnicos, administrativos y económicos que permitan a la autoridad de aplicación contar con los medios que posibiliten la eliminación de los abusos y excesos en la ocupación de las tierras fiscales suburbanas, a fin de asegurar que el proceso de ordenamiento y planificación se lleve a cabo salvaguardando los intereses generales de la comunidad en relación con los valores del ambiente. Propiciar y estimular la generación de una clara conciencia comunitaria sobre la necesidad vital de la preservación y recuperación de los valores ambientales, mediante una adecuada organización de las actividades en el espacio.

Se realizó la zonificación en la CAG teniendo en cuenta los objetivos de cada categoría de manejo. En el mapa 17 se presentan los límites de las distintas zonas. La superficie y la descripción de los usos permitidos de cada categoría de manejo se presentan a continuación:

Categoría de manejo: Reserva Recreativa Natural (Superficie: 4.151,40 ha).

Usos permitidos: Turístico; Investigación y Educación 
Como recomendación general del uso turístico se demarcó la $R R N$ en sectores que permitan el desarrollo de diferentes actividades recreativas y turísticas. Para esta categoría es necesario tener una infraestructura básica para control y fiscalización, construcción de un centro de visitantes, sanitarios para uso de los visitantes, delimitación de zonas de acampe y refugios.

Categoría de manejo: Reserva de Uso Múltiple (Superficie: 1.848,23 ha).

Usos permitidos: Extracción de turba; Manejo forestal; Turístico e Investigación y Educación

El principal uso de la tierra en referencia a este sector es la ganadería, básicamente de ganado bagual, sin marca y en baja cantidad. La delimitación de la superficie de la $R U M$ se realizó priorizando los sectores de manejo forestal, de extracción de turba y otros sectores para uso recreativo. La actividad forestal se realizará en unas $1.466,8$ ha de la $R U M$, intentando mantener una actividad permanente en el área. La superficie se delimitó teniendo en cuenta Esta zona cuenta, al menos en determinadas áreas, con caminos de acceso. Sobre las áreas ya aprovechadas se pueden estimar las actividades a realizar, ya que el inventario de las distintas UV sitúa a cada una de ellas en una de las etapas de manejo propuestas. Los procesos de transformación en bosques productivos llevan a cambios en la diversidad de especies, pero mitigados según el sistema empleado. La actividad de extracción de turba se realizará en las turberas dentro de la $R U M$.

Categoría de manejo: Zona de uso especial (Superficie: 729,95 ha).

Usos permitidos: Turístico, actividades pecuarias intensivas, gastronómicas y comerciales.

Esta categoría comprende zonas destinadas a usos diversos relacionados con el asentamiento de las poblaciones que residen en las áreas protegidas, o con distintos tipos de servicios, y que en general implican niveles altos de modificación ambiental. La propuesta de manejo de esta zona, presentada en el Proyecto de Ordenanza Municipal Co.P.U. 40/2004, Planificación y ordenamiento de la vertiente sudoccidental del Valle de Andorra, pone de manifiesto los problemas existentes. Uno de los puntos abordados es la necesidad de preservar y mejorar el ambiente que actualmente se encuentra degradado. Para ello se delimitarán zonas donde se prohibiran los asentamientos urbanos. La necesidad de brindar espacios para nuevas actividades productivas, turísticas y recreativas esta contemplada al definir zonas donde se podrán realizar las mismas. Asimismo el proyecto menciona la implementación de 
mecanismos legales para eliminar los abusos y excesos relacionados con la ocupación de tierras fiscales, siendo un problema importante en la zona. Como último punto se destaca la estimulación de generar una conciencia cumunitaria sobre la necesidad de preservar y recuperar valores ambientales.

Categoría de manejo: Zona intangible (Reserva Natural Estricta): (Superficie: 2.159,65 ha).

Usos permitidos: Investigación

Es un área donde se observan bajos niveles de alteración y de uso. Esta zona no presenta impactos debido a turismo ni ganadería.

Categoría de manejo: Zona de Uso Público Extensivo (Reserva Natural Silvestre): (Superficie: 4.062,05 ha).

Usos permitidos: Turístico e Investigación y Educación

Esta categoría de manejo es la ya existente en la zona del $P N T d F$, definida por el decreto del PEN N453/94.

\subsubsection{Producción Pecuaria}

El uso ganadero traería más perjuicios que beneficios dentro de los límites de la $R U M$, como ya se evidencia en la actualidad con el progresivo deterioro de los suelos, el impacto sobre la regeneración natural del bosque y la gran cantidad de especies exóticas concentradas en los sitios de pastoreo (ver 3. Uso de la tierra e impacto). Los ganaderos consideran a estos pastizales naturales mejores que las estepas, ya que el ambiente forestal mantiene la humedad y abriga al pasto y al ganado de los vientos fríos y desecantes. Sin embargo, el uso ganadero del bosque es muy destructor, como puede observarse en muchos lugares de la Isla (Vammiere \& Maurette, 1995). Existen en Tierra del Fuego alrededor de 15.000 hectáreas de bosque anillado o "capado", zonas que luego fueron quemadas y transformadas para su uso ganadero, ya que los criadores de ganado tuvieron antiguamente el concepto de que el bosque era inútil para el desarrollo de su actividad y era preferible eliminarlo o permitir el ramoneo de las áreas regeneradas, buscando así la ampliación de la superficie de tierras aprovechadas. La invasión del ganado en el bosque virgen o aprovechado ha comprometido seriamente su regeneración. Es debido a esto que el artículo 5 de la Ley Provincial $N^{\circ} 202 / 95$ prohibe el pastoreo en las áreas en regeneración y bosques degradados. 
El principal uso actual de la tierra dentro de los límites de la $R U M$ comprende el desarrollo de la actividad ganadera a través de la utilización del área como veranadas durante la temporada estival (noviembre a abril). Si bien es dificultoso conocer los números reales de animales en estos sectores el número de novillos rondaría los 20 animales en los pastizales de altura y 50 en los pastizales de las márgenes del Río Chico y Arroyo Grande. Al ser la actividad ganadera el uso actual de este sector, se hizo un análisis de la viabilidad de desarrollo de la misma utilizando las ecuaciones de Sala et al. (1988) para calcular la producción primaria neta aérea (PPNA) y el porcentaje que puede ser consumido (IC\%). Para determinar los equivalentes vacunos por ha se utilizó la metodología propuesta por Cocimano, el al. (1975).

Se tomó en cuenta la aptitud general del área para el desarrollo de la ganadería, siendo sólo un $9,41 \%$ de la $C A G$ correspondientes a pastizales de altura y vegas, sin discriminar la ubicación de estos sectores en la zona del PNTdF. La superficie de vegas (pastizales en los bordes de ríos) es de 87,57 ha dentro de la $R U M(4,7 \%$ de la superficie). La carga animal calculada para la superficie de vegas fue de 8,5 vacas y la producción de materia seca de $37.269,8 \mathrm{~kg} \cdot$ año ${ }^{-1}$ para las 87,57 ha. Al ser el uso limitado a los meses estivales, se desprende que la unidad de producción ganadera nunca se podrá constituir como una unidad económica en este sector ya que para realizar esta actividad de manera sustentable debería efectuarse una importante inversión económica a los fines del manejo. Si se habilita el bosque productivo para pastoreo, implicaría la degradación parcial del bosque (bases retorcidas, troncos bifurcados) y un aumento en el turno forestal debido a que aumenta el tiempo de instalación de la regeneración (Martínez Pastur et al., 2004). La ganarería ha sido objeto de un mal uso que ha ocasionado un alto deterioro en el ambiente natural, donde se observa un alto grado de degradación de las pasturas naturales tal como se expresa en 3.3.2.1. Ganadería. En base a lo expuesto no solo se considera que debe evitarse la actividad ganadera en el área sino que debe ejecutarse un programa de recuperación de los pastizales naturales, muchos de los cuales han sufrido un impacto tal que la degradación sería irreversible. En este sentido y en forma preliminar, se estimó que la recuperación de los pastizales, sin la presencia de ganado, demandaría como mínimo un plazo de diez años (CFI, 2001b).

Asimismo, la aplicación de sistemas silvícolas pueden ser muy peligrosos si no se controla el ganado, pues la apertura del dosel trae como consecuencia no sólo la regeneración de $N$. pumilio sino la implantación de herbáceas (Martinez Pastur et al., 2002b). La presencia del ganado se hace notar en función del número de renovales presentes por hectárea y de la distribución de los mismos (Martinez Pastur et al., 2004). No se encuentran diferencias importantes, en cambio, entre el crecimiento en 
altura y los grados de daño de los renovales. Martínez Pastur et al. (2004) citan que en un sitio de calidad alta (clase de sitio I) la presencia del ganado retrasa el turno en un $15 \%$, mientras que en un sitio de mala calidad (clase de sitio V) se amplía hasta un $61 \%$. También tiene otros efectos como la eliminación total de plantas pequeñas, la compactación del suelo y la degradación del sotobosque. La importancia del factor ganado en el establecimiento de los renovales lleva a la necesidad de excluir el mismo por un período de por lo menos 20 a 30 años en sectores de bosque en regeneración, por lo menos hasta que $N$. pumilio supere los $2 \mathrm{~m}$ de altura. Los guanacos también producen daño, aunque en menor magnitud que el ganado, sin embargo pueden producir severas alteraciones que impiden extensivamente el desarrollo de Nothofagus pumilio en altura (Carabelli, 1991). Skrt et al. (1997) establecen que los renovales que solo han sido ramoneadas en una ocasión no presentan alteraciones permanentes, siendo la presión de un ramoneo continuo a lo largo de un cierto número de años la que le confiere las características indeseables en forma permanente. Los árboles ramoneados en forma continua tuvieron menor altura que los renovales con desarrollo normal para la misma edad.

\subsubsection{Turismo}

Uno de los objetivos de las áreas protegidas es que las mismas sean conservadas para educación y goce de las presentes y futuras generaciones. El concepto recreativo de las áreas protegidas define la necesidad de perpetuar el recurso para futuras generaciones, por lo cual no existe la libre explotación del turismo, sino un planificado manejo del mismo. Un área natural a conservar puede tener manejo turístico, pero éste no puede ser su único objetivo, ni su actividad principal. El turismo en áreas naturales es conceptualmente diferente al criterio tradicional, se trata en términos generales de un turismo no masivo, de baja concentración de visitantes. Su actitud debe estar ordenada hacia la recreación contemplativa, que permita el conocimiento e interpretación de la naturaleza (APN, 1994). Es importante reordenar la actividad turística en la $C A G$, ya que existen sectores con un alto potencial turístico que no son aprovechados, mientras que los actualmente visitados poseen una elevada carga. Para ello se propone una serie de pautas de manejo acordes con los objetivos de conservación. El ordenamiento de la actividad permitirá mejorar el control sobre las áreas involucradas y la optimización del espacio. Se plantea mejorar la calidad de servicios al visitante, con la construcción de hosterías en sectores estratégicos, casillas de control y acceso, oficina de informes, 
sanitarios y playa de estacionamiento. Además se debería mejorar la señalización y cartelería informativa e interpretativa. Como se observó en el punto 3.2.4. Turismo, existen pocos senderos, parcialmente cerrados y en mal estado de mantenimiento, útiles para el control y vigilancia, así como para la lucha contra incendios forestales. Es importante reacondicionar los senderos de uso masivo, delimitando la traza mediante la colocación de troncos laterales y rellenando el piso del sendero con suelo mineral, así como en los sitios de mayor pendiente construir escalones de madera para mitigar los efectos erosivos.

La demarcación y habilitación de nuevos senderos permitirá diversificar la oferta y descomprimir el uso de algunas áreas. La puesta en valor y señalización de algunas de estas recorridas permitirá distribuir mejor a los visitantes interesados en realizar caminatas largas, disminuir en parte la presión de uso sobre las actuales sendas y aumentar el tiempo de estadía de los visitantes en general y los acampantes en particular. Estos circuitos deberán satisfacer las siguientes condiciones (APN, 2003b): a) los puntos de entrada y salida estarán ubicados en el área de uso público o cercanos a alguna instalación oficial permanente para asegurar el registro de los usuarios; b) el nivel de exigencia será conocido y advertido a los usuarios previamente; se impedirá el ingreso a las personas que carezcan de la preparación o equipo exigido, c) no se permitirá hacer fuego y tanto la traza como los sitios de pernocte estarán marcados y serán obligatorios, d) Deben ser vigilados regularmente y el quebrantamiento de las normas de uso serán severamente sancionadas con multas. Además de las excursiones existentes detalladas en el punto 3.2.4. Turismo, se definieron las ofertas potenciales de excursiones en las zonas propicias para ese fin (Mapa 17), como la RNS dentro de los límites del PNTdF y la RRN fuera de éste, las que se detallan a continuación.

\section{Zona de Reserva}

i) Recorrido desde las cabeceras del Río Chico hasta el Valle del Olivia. Éste recorrido incluye la visita de tres pequeñas lagunas de altura, la vista del valle del Río Chico desde el faldeo del cerro y la vista del Valle del Río Olivia. En el Valle del Olivia el recorrido termina en la ruta 3 en las cercanías del Monte Olivia.

ii) Recorrido desde las cabeceras del Río Chico hasta las Lagunas Encantadas Superior e Inferior. Esta excursión en las cabeceras del Río Chico, pasando por el Pequeño Horn, formación rocosa de singular belleza, y cruzando el filo entre el cerro Vinciguerra y el cerro La Esfinge. La excursión continúa pasando por las lagunas 
Encantadas Superior e Inferior y finaliza bajando por el río que desemboca de las lagunas hasta el Valle de Andorra.

iii) Tramo Valle Luis Martial pasando por Valle cañadón Negro y Valle de Andorra. Se trata de la unión del Valle Luis Martial con el cañadón Negro y el Valle de Andorra. Este circuito presenta algunas dificultades debido a la gran pendiente que existe alrededor del cañadón Negro, pero esta dificultad tiene la recompensa de la belleza que presenta la vista del Cañadón Negro hasta encontrar el sendero que de la Laguna del Caminante.

\section{Zona del PNTdF}

iv) Circuito Laguna Grande. El circuito Laguna Grande comienza en la separación del Arroyo Grande y la senda a la Laguna del Caminante. El recorrido mantiene al Arroyo Grande a la derecha, cruzando por una cadena de lagunas pequeñas de singular belleza. Existe un sector con posibilidades de instalar un campamento en la orilla de la Laguna Pruxo (Foto 12) ya que presenta un bosque alto, necesario como reparo de los fuertes vientos de la zona. A $600 \mathrm{~m}$ de la Laguna Pruxo se encuentra la Laguna Cil (Foto 13) y a $700 \mathrm{~m}$ de ésta, siempre teniendo al Arroyo Grande a la derecha, se llega a la Laguna Grande (Foto 14). La Laguna Grande presenta bosques propicios para la realización de un campamento en su margen sur. Siguiendo la margen derecha de la laguna se llega al arroyo que desemboca de la Laguna Calvario. Ésta laguna se encuentra inserta en un circo glaciar rodeada de altas cumbres. En las cercanías de la Laguna Calvario es posible la fabricación de un refugio para el pernocte de los montañistas.

Foto 12. Laguna Pruxo.

Pruxo Lagoon.

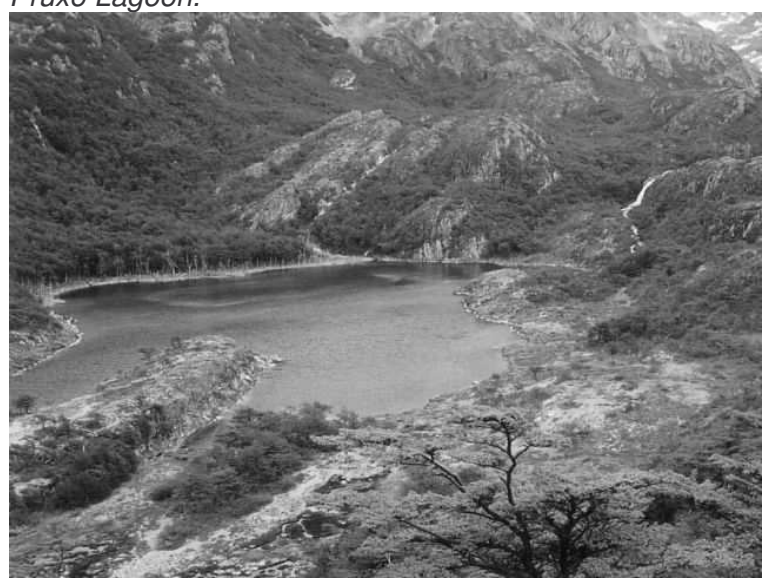


Foto 13. Laguna Cil.

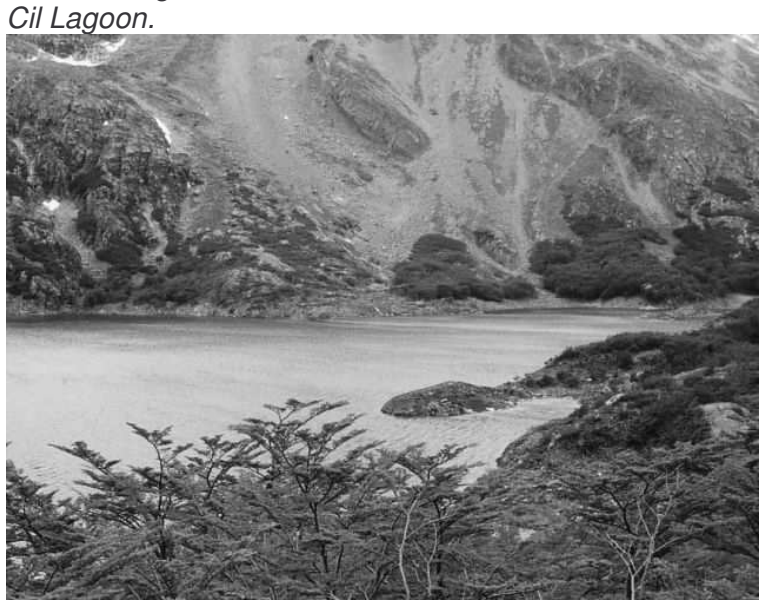

Foto 14. Laguna Grande.

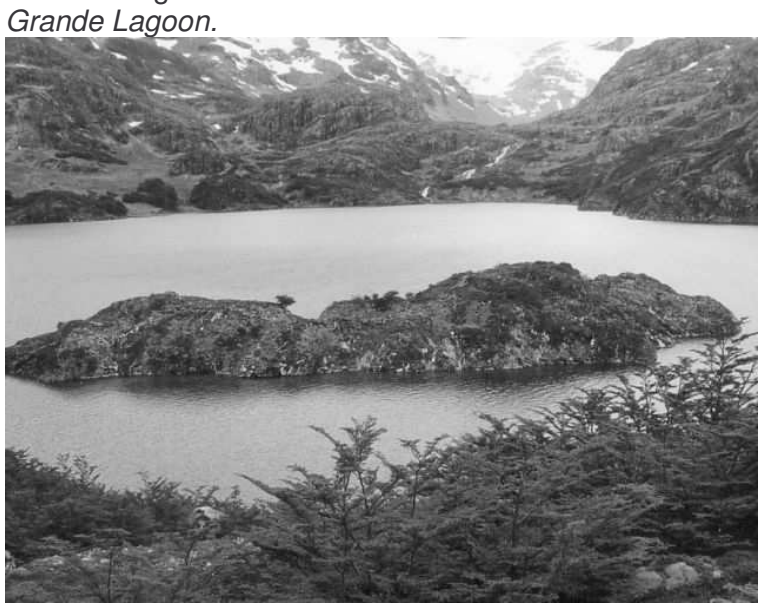

La propuesta del mejoramiento y establecimiento de nuevos circuitos, requiere la realización de inversiones para que de esta forma se pueda producir ingresos a la Provincia y a la población local, tanto por el desarrollo de actividades de turismo consumidoras del producto paisaje, como por la venta de otros productos también resultantes del manejo sustentable de la zona. Las mejoras propuestas constan de la senderización de los tramos cabeceras del Río Chico hasta el Valle del Olivia, cabeceras del Río Chico hasta las Lagunas encantadas Superior e Inferior y Valle Luis Martial pasando por Valle cañadón Negro y Valle de Andorra para tránsito peatonal. La senderización consiste en el mantenimiento de un sendero de 1,5m de ancho, retirando la vegetación leñosa anualmente y realizando la señalización en los sectores de sendero en que éste es confuso o en zonas abiertas como en pastizales de altura o roca desnuda. Es muy importante mantener en buen estado las sendas ya que pueden ocurrir extravíos de montañistas con la consecuente búsqueda. En los sectores pantanosos o en cruces de ríos es importante la realización de entablonadas, correcciones en el recorrido, para reducir la erosión producida por el pisoteo. Es 
importante la realización de obras básicas agrestes para facilitar el uso por parte de los excursionistas (puentes, barandas, escalones, etc.), que generan erosión. Asimismo la senderización de mini - circuitos opcionales que permitan visitas a sitios de atractivo por el tipo de flora o fauna que sustente. Se realizará también la señalización de todos los circuitos con criterio informativo, educativo e interpretativo de la flora.

Debido a la enorme importancia que tiene el uso turístico dentro de la RNS y la $R R N$, es necesario la realización de un control y vigilancia del área de los senderos habilitados. Los principales problemas que hacen necesario un control y vigilancia son: la operación de excursiones sin habilitación, el corte de árboles verdes para leña, el vandalismo, el ingreso de equinos, el acampe y fuego en sitios no habilitados, el ingreso de personas con mascotas, el ingreso de animales domésticos abandonados desde el ejido municipal, el ingreso de ganado, la pesca sin habilitación y la caza de animales silvestres. Por ello es necesario realizar un patrullaje regular de todos los sectores de las unidades para poder detectar, prevenir o reprimir estas actividades ilegales.

Para la planificación y fiscalización de los servicios turísticos y recreativos se proponen los siguientes objetivos (APN, 2003b): a) Promover el desarrollo de actividades recreativas en contacto con la naturaleza, b) Propiciar los proyectos de desarrollo de infraestructura y/o los servicios turísticos requeridos para una adecuada atención de los visitantes, c) Establecer las pautas que regularán el uso turístico de los distintos sectores, a efectos de asegurar su compatibilidad con los objetivos de conservación, d) Tomar los recaudos necesarios para minimizar los impactos negativos consecuentes del uso turístico, e) Fiscalizar la correcta prestación de los servicios turísticos y recreativos que se brindan en el área protegida. Se deberá tender a regular y ordenar los usos turísticos y recreativos en general, poniendo especial énfasis en aquellos usos no compatibles entre sí que se superpongan espacialmente. En líneas generales debería tenderse a una sectorización y ordenamiento de actividades, lo que plantea la necesidad de relocalizar o redefinir el uso de algunas áreas de acampe, ampliar la oferta para actividades de turismo no masivo y establecer ciertas condiciones de operación para el sector de uso intensivo.

La cartelería del área del PNTdF debe respetar las características de diseño y coloración de las normas de cartelería de la $A P N$. Se deberá realizar un inventario de la cartelería informativa y normativa existente en el área recreativa, con el objetivo de detectar los carteles necesarios y facilitar su mantenimiento y/o reposición; reemplazar paulatinamente la cartelería que no respete los diseños de las normas de cartelería de la APN y completar la cartelería normativa existente sobre: residuos, uso de leña, 
fogones, prohibición de alimentar a la fauna silvestre. En la zona no perteneciente al $P N T d F$, la cartelería puede tener un diseño propio de la reserva.

Se cree conveniente mantener áreas de acampe libres para utilizar el área con fines recreativos, muchas veces sin pernoctar. Deberá tenderse a reducir el uso de fogones en las áreas de acampe agreste, limitando como primera medida la extracción de leña en algunos sectores del Parque Nacional o incluso la prohibición total de realizar fuego si se considerara necesario. En las áreas dónde se autorice la realización de fogones pero no la extracción de leña deberá utilizarse leña comprada o traída por los acampantes desde afuera del área. A continuación se detallan las áreas sugeridas para la instalación de las áreas de acampe (Mapa 17).

Área de acampe Río Chico. Esta área de acampe se ubicará dentro del recorrido desde las cabeceras del Río Chico hasta el Valle del Olivia y desde las cabeceras del Río Chico hasta las Lagunas encantadas Superior e Inferior. Además ofrece una serie de ventajas como una amplia superficie disponible, terreno plano, posibilidades de ampliación, fuente de agua permanente y protección del viento.

Área de acampe Cañadón Negro. Esta área es de reducido tamaño y se debe prohibir la recolección de leña en sus alrededores y la realización de fogones. Se encuentra en el recorrido del Valle Luis Martial pasando por Valle cañadón Negro y Valle de Andorra.

Área de acampe Valle de Andorra. Se encuentra dentro del recorrido del Circuito Laguna Grande, Valle Luis Martial pasando por Valle cañadón Negro y Valle de Andorra, Valle de Andorra - Cañadón de la Oveja y Laguna de los Témpanos y el Glaciar Vinciguerra. Este sector ofrece una amplia superficie disponible, terreno plano, fuente de agua permanente y protección del viento.

Área de acampe Laguna Pruxo. Es un área de reducido tamaño y se debería prohibir la recolección de leña y la realización de fogones. El área de acampe se encuentra a mitad de camino del Circuito Laguna Grande.

Se propone para la habilitación de guías implementar anualmente los exámenes de habilitación para cada categoría previstos en la reglamentación vigente, preparar y mantener actualizado el material y/o referencias bibliográficas que se brinda a las personas interesadas en habilitarse como guía de turismo y/o guía especializado, para la preparación del examen de habilitación. Asimismo se propone analizar y promover mecanismos para la implementación conjunta de cursos y exámenes de actualización para todos los inscriptos en el registro de guías del PNTDF, conforme a lo establecido 
en el Reglamento de Guías de las Áreas Protegidas Nacionales, con el INFUETUR y la Asociación de Guías de Tierra del Fuego.

Con el propósito de registrar a los acampantes para disponer de información sobre el uso de las áreas de acampe se ha sugerido que se consignen los siguientes datos: procedencia, tamaño del grupo, edad, tiempo estimado de estadía, forma de arribo.

Deberían analizarse sendas alternativas para el uso de bicicletas, ya que las que se utilizan en el presente coinciden en parte con las pedestres. No se considera apropiada la realización de cabalgatas en el interior del área ya que no es posible desarrollar circuitos de baja o nula pendiente independientes de las sendas pedestres existentes ya que el tránsito de caballos por senderos de alta pendiente produce una elevada erosión.

El control de esta especie exótica se realiza mediante trampas. Hasta el presente no existen tareas de control siendo necesarias para mantener los senderos habilitados - los caminos interiores, minimizando el impacto en las áreas de uso público. El trampeo de animales se decide en base a un censado anual de castoreras activas.

La recolección y retiro del área de los residuos está a cargo de la APN y los concesionarios. Sería deseable disminuir los volúmenes de residuos que deben retirarse instando a los visitantes, especialmente los que arriban en vehículo propio a retirar sus residuos del área.

\subsubsection{Explotación de turberas}

A partir de 1800, el área global de turbales se ha visto reducido entre un $20 \%$ y $30 \%$, siendo la actividad humana la principal causa de la reducción (Joosten \& Clarke 2002). Las amenazas que afectan a los ecosistemas de turbales pueden ser de dos tipos: a) directas, como el drenaje y conversión de tierras, las excavaciones, las quemas, el exceso de pastoreo, la presión de los visitantes y la explotación comercial; y b) las indirectas, como la contaminación, la extracción excesiva de agua, la reducción de la extensión y el cambio climático (de la Balze et al., 2004). Se podría definir a los turbales como recursos renovables, considerando la escala temporal de renovación como geológica. Por lo tanto, el uso racional de los turbales es esencial para asegurar las funciones vitales del ecosistema, satisfaciendo los requerimientos de las comunidades locales. El uso racional de los turbales involucra la evaluación de sus funciones, usos, impactos y limitaciones (Josten \& Clarke 2002).

En el caso de las turberas en la CAG, se cuenta con 12 ha de superficie en explotación, donde no se están realizando tareas de recuperación del ecosistema 
degradado. Restablecer las funciones del ecosistema de turbales en donde se realizó la extracción es dificultoso, ya que en las turberas sin intervención, la presencia estrato activo superior (acrotelmo) asegura un nivel alto y estable de la napa freática el cual es crítico para el desarrollo del Sphagnum sp. (Ingram, 1992). En la extracción de turba se alteran las funciones que ayudan al normal crecimiento de la vegetación (Wheeler \& Shaw, 1995). Usualmente se realizan operaciones de drenaje mediante canales para disminuir el nivel freático; una vez que el agua es drenada, se remueve la vegetación superficial y se extrae la turba. Estas operaciones producen alteraciones de las propiedades hidrológicas de los perfiles expuestos, que constituyen un factor limitante a la restauración de la turbera al dificultar a las especies de Sphagnum en el establecimiento una vez abandonada la explotación, dejando un ecosistema con una baja cobertura de especies, con insuficiente sustrato para la colonización de especies típicas de turbales como Sphagnum (Schouwenaars, 1993). La creación de condiciones propicias de humedad es requerida para el reestablecimiento de la vegetación de la turbera para formar un ecosistema funcional. La forma de aumentar el nivel freático consiste en bloquear los drenajes existentes, resultando en un incremento del nivel freático existente (Egglsmann, 1988; Meade, 1992; Nick, 1984; Schouwenaars, 1992, Okruszko, 1995). La estructura porosa de la turba permite una gran capacidad de almacenamiento de agua, que permite regular las fluctuaciones de la napa freática (Wheeler \& Shaw, 1995; Price, 1996). En estudios realizados en Canadá por Rochefort et al. (1995) y Campeau \& Rochefort (1996), indican que la dispersión de fragmentos de Sphagnum sp., la instalación de barreras contra la desecación debido al viento o a la radiación solar (Sagot \& Rochefort, 1996; Quinty \& Rochefort, 1997) mediante barreras contra viento o la aplicación de mulch, ayudan a la recuperación de turberas explotadas mediante el sistema industrial de molienda y aspiración mediante maquinaria. Otro factor importante es la presencia de microtopografía, para crear una variedad de sitios en donde las esporas de Sphagnum sp. y otras especies tengan una mayor probabilidad de germinación. Quinty \& Rochefort (1997) demostraron que el establecimiento de Sphagnum esta favorecido en depresiones de un área con microtopografía en comparación con áreas planas.

En la única turbera en explotación de la $C A G$, la extracción se realiza formando dos canales espaciados en 1,5 m para favorecer el drenaje cada $20 \mathrm{~m}$. La capa superficial (musgo vivo) no se extrae para su comercialización, dejándola fuera del sector entre canales. Se cortan pequeños bloques de turba los que posteriormente se secan de manera natural mediante la exposición al aire (Figura 5). Los bloques de turba se apilan en estructuras de madera (caballetes, tarimas, secaderos) para una mejor ventilación y para no absorber la humedad del suelo, posibilitando el secado 
(Foto 11). Una vez que se extrae la turba entre los canales de drenaje, se sigue extrayendo hacia ambos lados de la zanja (Figura 6). La capa superficial de musgo vivo es extraída y volcada en el fondo de la zanja, dando lugar a la extracción de turba hasta alcanzar el nivel freático dado por el nuevo canal de drenaje. Los canales de las distintas zanjas drenan en el Arroyo Grande o algún afluente, habiendo previamente recorrido un sector de turba de Carex sp. que no es explotada, teniendo la zanja en este sector un ancho de $40 \mathrm{~cm}$ aproximadamente.

Figura 5. Método de extracción de turba que se utiliza en la Cuenca del Arroyo Grande, corte transversal. Peat bog extraction method in Arroyo Grande catchment, cross section.

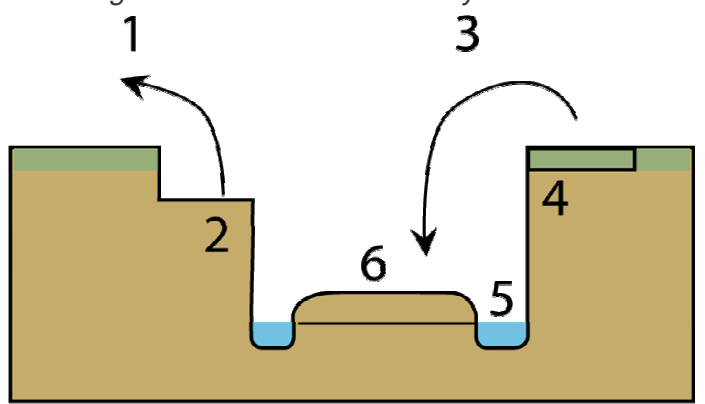

1. Turba extraída para su comercialización, 2. Turba para extraer, 3. Musgo vivo no comercial, retirado y depositado en la zanja, 4. Capa de musgo vivo, 5. Canal de drenaje, 6. Acumulación de musgo vivo.

Figura 6. Método de extracción de turba que se utiliza en la Cuenca del Arroyo Grande, vista superior. Peat bog extraction method in Arroyo Grande catchment, upper view.

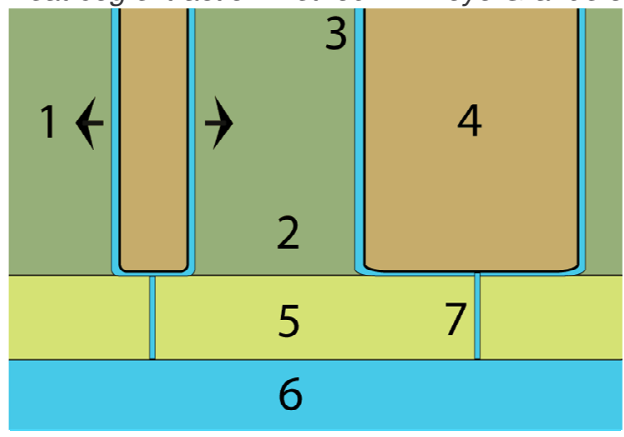

1. Crecimiento lateral de la explotación de turba, 2. Turba de Sphagnum sp. no explotada, 3. Canal de drenaje, 4. Acumulación de musgo vivo / Zona explotada, 5. Turbal de Carex sp. no comercial, 6. Río, 7. Canal de drenaje atravesando el turbal de Carex sp.

Foto 11: Turbera en explotación, mostrando los caballetes para el secado de la turba.

Peat bog exploitation, showing the easel for peat drying. 


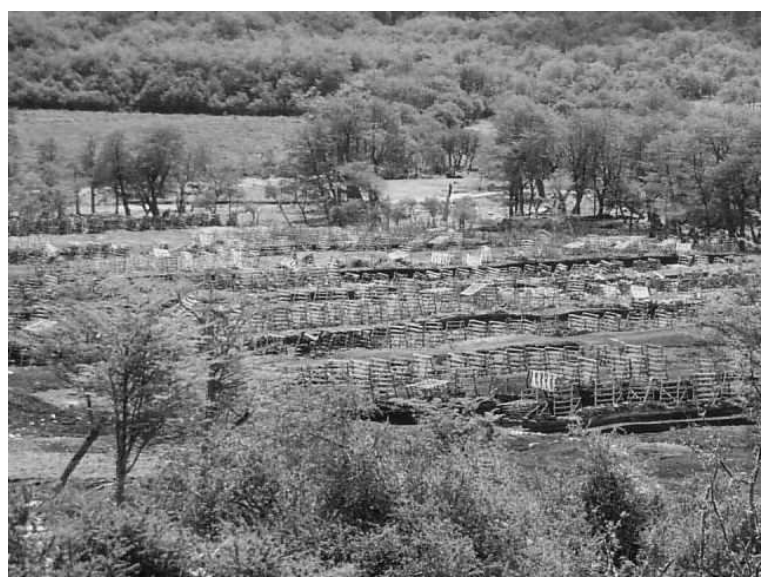

Para la recuperación del ecosistema es necesario realizar las obras de endicamiento en el sector de turba de Carex sp., cercano al desagüe de la zanja, obturando entre 20 y $40 \mathrm{~cm}$ de altura hasta cubrir con el embalse parte de la zona explotada. De esta forma, aprovechando la presencia de esporas ubicadas a lo largo del perfil de la turbera y de las existentes en la zona central de la zanja, el Sphagnum sp. comienza a colonizar el sector embalsado. Una vez que el embalse fue colonizado por vegetación, luego de aproximadamente 2 años, el nivel del embalse se tiene que elevar otros 20 a $40 \mathrm{~cm}$. El proceso se repite hasta llegar a niveles similares a los de la turbera antes de la explotación, recuperando las funciones del ecosistema original. Se recomienda realizar este tipo de obras en las zanjas en que ya ha sido extraída la turba. La recuperación del sistema en forma cualitativa y no cuantitativa, recuperándose las especies originales y parte de las funciones del turbal; y no del material extraído, ya que para lograr esa recuperación hacen falta esperar alrededor de 1.000 años por cada metro en profundidad extraído. Dentro de la RUM existen 112,01 ha de turbales factibles de ser explotadas, existiendo para conservación 12,28 ha en la zona perteneciente al PNTdF. La falta de ensayos de recuperación de turberas en la zona de estudio no permite determinar una superficie máxima de extracción anual, siendo esta una relación entre la superficie extraíble y el tiempo de recuperación cualitativo.

\subsubsection{Conservación de áreas protegidas}

Los bosques de Nothofagus no constituyen solamente un recurso maderero sino también una condición para la protección ambiental, la conservación de diversas formas de vida y la provisión de recursos hídricos de calidad. Para ello la planificación debe integrar estos otros objetivos de manejo como ser: regular el balance hídrico y la erosión de las cuencas, constituir un refugio para la flora y fauna silvestres, y proteger 
y mejorar la calidad de vida de las zonas urbanas. La planificación debe considerar la fragilidad de cada sistema pero además y fundamentalmente, tratar que las demandas que se pongan sobre los bosques sean compatibles con sus posibilidades de satisfacerlas sin perderlos. Los bosques son una parte importante pero parcial, ya que su mayor atractivo radica en los cerros, glaciares y aguas marinas o terrestres. La presencia de un entorno boscoso realza ese atractivo y aumenta la diversidad biológica (Vammiere \& Maurette, 1995). Debido al incremento de las presiones sobre áreas naturales derivadas de recreación y el turismo, es necesario implantar algún tipo de control o vigilancia en estas zonas, así es como se plantea la inclusión de un sector de 2159,65 ha (Mapa 17) como zona intangible con el objeto de preservar una zona poco impactada por el ganado y por el turismo ya que sólo un rodal de $N$. betuloides posee impacto bajo debido a la ganadería (ver 2. Morfometría y vegetación de la $C A G)$, y un aprovechamiento forestal viejo. Dentro de esta zona se encuentra el único pastizal de valle sin presencia de impacto ganadero. Es importante realizar la instalación de un alambrado en el límite de la zona intangible, ya que es necesario limitar el ingreso de ganado o intrusos a ésta zona. Asimismo se recomienda la ejecución de un control de Castor canadiensis. Esto es necesario para disminuir los impactos que la especie produce mediante la reducción de las poblaciones existentes.

\subsection{DISCUSIÓN}

Se desarrolló el proceso de zonificación dando como resultado 5 zonas de manejo, de las cuales la Zona intangible y la Zona de Uso Público Extensivo (Reserva Natural Silvestre) se encuentran dentro del PNTdF. La finalidad de la Zona intangible (dentro del PNTdF) es la preservación de determinados ambientes, sistemas o componentes naturales o culturales en condiciones intangibles, mientras que en la Zona de Uso Público Extensivo (Reserva Natural Silvestre) se permiten actividades y usos que causen un impacto mínimo a moderado sobre el ambiente, los sistemas o componentes naturales o culturales. La zona no perteneciente al PNTdF se dividió en 3 categorías de manejo: Reserva recreativa natural, con el objetivo desarrollar el uso turístico, manteniendo las condiciones naturales; Reserva de uso múltiple, siendo una zona de utilización de los recursos naturales, donde se prioriza la conservación de la biodiversidad en el desarrollo de actividades extractivas y no extractivas; y la Zona de uso especial, ubicada en los asentamientos cercanos a la desembocadura de la cuenca, destinada a usos diversos relacionados con el asentamiento de las poblaciones que residen en la $C A G$. 
Las actividades ganaderas deben evitarse dentro de la $C A G$, debido al alto impacto producido a los pastizales naturales, siendo necesario la aplicación de un plan de recuperación de ambientes degradados. Asimismo, tiene que tenerse en cuenta que la aplicación de sistemas silvícolas puede ser peligroso para la regeneración al existir ganado en la zona, disminuyendo por ramoneo el número de renovales y su distribución.

Se planteó la recuperación de los ecosistemas de turberas en explotación, mediante obras de endicamiento. La recuperación del sistema se basa en restaurar las condiciones de humedad para que las especies vegetales puedan colonizar las zonas explotadas.

Con respecto al turismo en la $C A G$, se propone demarcar y delimitar nuevos senderos en la RNS y en la RRN para diversificar la oferta, descomprimir y disminuir la presión sobre otras áreas y aumentar el tiempo de estadía de los acampantes. Asimismo se determinaron las necesidades de realizar una eficiente vigilancia de las distintas zonas, cartelería indicadora, localización de zonas de acampe agreste, habilitación de guías, registro de acampantes y manejo de residuos.

Carabelli et al. (2004) realizaron un estudio sobre los aspectos de carácter social que afectan o son afectados por el manejo actual de los bosques fueguinos. Los resultados indican que la participación ciudadana esta muy lejos de su estado deseable pero que a la vez es considerada como un factor poco importante para alcanzar el manejo sustentable de los bosques fueguinos. Un área percibida favorablemente son las inversiones en actividades turísticas y la integridad del ecosistema forestal. Sin embargo, la planificación, administración y utilización del recurso forestal han sido identificadas como áreas donde podrían introducirse cambios.

La mayoría de los problemas están relacionados con la administración gubernamental del uso del recurso y el cumplimiento de las normas, problema que a su vez esta relacionado con insuficiencias en el número de personal, la capacitación que los técnicos y funcionarios que reciben para cumplir con sus tareas, disponibilidad de vehículos y otros recursos para realizar las tareas de control.

Todas las personas con un interés en los bosques de Nothofagus de Tierra del Fuego tienen una oportunidad de contribuir con el objetivo de su manejo sustentable. Cada persona interesada, desde su lugar en la sociedad relacionada con los bosques (Gobierno, industria maderera, empresa de turismo, comunidad, organizaciones no gubernamentales, prensa, investigación o educación) debería buscar cuales son las acciones que pueden emprender para mejorar la situación actual. El punto de partida 
Juan Manuel Cellini - Manejo de los recursos naturales en la Cuenca del Arroyo Grande.

debería ser estar informado sobre lo que esta ocurriendo, para tomar parte en el análisis de los problemas y participar en los procesos de toma de decisión. 


\section{PROPUESTA DE MANEJO FORESTAL}

\subsection{INTRODUCCIÓN}

Es innegable la necesidad de una gestión humana integrada por medio de la ordenación forestal para garantizar la óptima salud de los bosques y lograr los objetivos que la sociedad humana demanda: protección, uso social y producción (Madrigal, 1992). En este sentido, se persigue la obtención de aprovechamientos sustentables, para los cuales se necesita una perfecta comprensión de la dinámica del bosque en relación con el hombre y sus actividades. Asimismo, es necesario mantener los ecosistemas forestales para conservar la diversidad que los integra (Spagarino et al., 2001; Deferrari et al., 2001), ya que un sistema que conserva su biodiversidad es más estable ante factores de riesgo. La combinación de las características de resistencia con su estructura anatómica homogénea, hacen de $N$. pumilio una madera que puede ser cepillada, perforada y tallada en todas direcciones casi sin esfuerzo, permitiendo excepcionales pulidos, superficies parejas y bordes perfectos. Hay que destacar, que además presenta buenos resultados tanto en el clavado, como en el atornillado y encolado (Tortorelli, 1956). A sus excelentes propiedades para ser trabajada, debemos agregar que, después del lijado fino, las superficies aceptan fácilmente todo tipo de pinturas, barnices y tinturas, proporcionando además, excelentes posibilidades para la aplicación de una gran variedad de lustres y semilustres finales. El artículo 3 de la ley provincial N²02/95 -llamada Ley Forestalprohibe destinar madera con aptitud para el aserrado a la producción de astillas. Este destino sería muy importante para los primeros raleos y los restos de cosecha que no pueden enviarse a aserrado por el grado de pudrición que presentan (CFI, 2001a). Además la eliminación de los restos de cosecha disminuiría los riesgos de producción de incendios. Los Tableros alistonados constituyen una posible solución frente a la baja calidad de la madera cosechada, ya que permite el empleo de calidades con las que actualmente no se obtiene ningún producto de valor agregado. La posibilidad de utilizar piezas de madera corta permitiría incorporar materia prima que actualmente no se emplea. Otros usos actuales de la madera de $N$. pumilio son los postes para redes de transmisión de energía y alambrados, varillas, puntales, carpintería rural y leña. La producción maderera es absorbida principalmente por el mercado interno como material para la construcción (encofrados y carpintería), en la forma de tablones, tablas y tirantes, siendo necesario para estos usos extraer del bosque trozas de 3 a 6 $\mathrm{m}$ de largo y con un diámetro mayor a $20 \mathrm{~cm}$ en punta fina. Es muy importante tener 
en cuenta las condiciones propias del rodal y los gradientes de calidades de sitio (Martínez Pastur et al., 1997a), referidas a la estabilidad del rodal (Peri et al., 2002) y a la regeneración (Martínez Pastur et al., 1999a). Estos bosques se adaptan fácilmente a la gran mayoría de los sistemas silvícolas, debido a que $N$. pumilio de desarrolla generalmente en rodales puros, con un banco de renovales permanente, regeneración abundante, y dado que responden a tratamientos intermedios (Costantino, 1950; Mutarelli \& Orfila, 1973; Schmidt \& Urzúa, 1982; Martínez Pastur et al., 2001).

Existen numerosos antecedentes silvícolas para Nothofagus, así como proposiciones de métodos clásicos de regeneración y modificaciones (i.e., Cozzo et al., 1969; Schmidt \& Caldentey, 1994; Bava, 1998; Martínez Pastur et al., 2000a; 2001; 2002a). Se puede afirmar que $N$. pumilio es la especie nativa mejor estudiada de Argentina y Chile, que implica la disponibilidad de un enorme caudal de información científico-técnica. Dentro de los métodos de regeneración, los más difundidos son la tala rasa y la corta de protección. La implementación de talas rasas fue rentable, la regeneración fue abundante, los árboles remanentes fueron sensibles a volteos de viento, fue negativo dejar individuos jóvenes aislados y fueron altamente sensibles al ramoneo, siendo este último el principal motivo del fracaso del método. La corta de protección fue propuesta originalmente para N. pumilio por Schmidt \& Urzúa (1982) como una alternativa sustentable a las prácticas habituales de entresaca selectiva, y rápidamente fue adoptado (Martínez Pastur et al., 2000a) cambiando metodologías habituales de trabajo, en productores y técnicos encargados de establecer las prescripciones silvícolas. El sistema de producción forestal de Cortas de Protección, propuesto por Schmidt \& Urzúa (1982) para Nothofagus pumilio, representa una intervención progresiva del bosque a lo largo de su ciclo. El método es rentable y regenera correctamente el rodal, aunque también es sensible al ramoneo. Los métodos silvícolas poseen aspectos culturales y económicos, que atienden a la conformación, conservación, desarrollo, mejora y regeneración de los rodales, así como a la conservación. En los últimos años hubo un cambio en los objetivos, desde valores económicos y empresariales, hacia parámetros biológicos, conservacionistas, sociales y de uso múltiple, que tienden a la protección del medio ambiente. Por ello las talas rasas fueron desestimadas, prefiriéndose la aplicación de cortas de protección como método de regeneración. El modelo silvícola teórico de la corta de protección y raleo por lo bajo implica una corta de regeneración que abre el dosel, la realización de una corta final, y la aplicación de tratamientos intermedios (raleos y podas). El aprovechamiento forestal modifica directamente la estructura forestal. Antes de la intervención el bosque presenta un dosel cerrado, con pocos individuos sobremaduros de grandes dimensiones, densidad completa y alto volumen comercial. La corta deja 
pocos individuos, de gran diámetro y dosel abierto, y algunos caen posteriormente por efecto del viento, reduciéndose el área basal y el volumen. Luego la regeneración crece formando un brinzal (comunidad densa de 1-2 m de altura) que cierra el dosel, con gran mortalidad debido al autorraleo. Posteriormente, a medida que crece el rodal, se van aplicando los tratamientos intermedios hasta la aplicación de la corta final. Las cortas afectan directa e indirectamente a los organismos del bosque. El impacto sobre el sotobosque puede considerarse intermedio, ya que la riqueza se modifica levemente incorporando especies exóticas y de otros ambientes (Martínez Pastur et al., 2002b). La riqueza de plantas aumenta respecto del bosque primario luego de la corta, porque la apertura del dosel modifica el microclima a nivel del suelo, aumentando la luz incidente, temperatura, precipitaciones y agua disponible. El máximo se alcanza cuando el dosel es mínimo luego del aprovechamiento; cuando el dosel se cierra en fase de crecimiento óptimo, la riqueza decae por debajo de los niveles iniciales, y se recupera lentamente a medida que la masa madura. Contrariamente, a las plantas vasculares, los musgos y hepáticas disminuyen su riqueza luego del aprovechamiento por la falta de protección del dosel contra la sequedad, y se benefician cuando la densidad y el cerramiento son altos, aumentando en cobertura y biomasa respecto del bosque primario. Una mejora en la calidad de sitio, implica mayor cantidad de recursos disponibles, y se manifiesta en bosques primarios con mayores coberturas y riquezas, manteniéndose luego del aprovechamiento. Sin embargo, cuando se alcanza la máxima apertura del dosel, tanto riqueza como cobertura permanecen constantes, independientemente de la calidad de sitio (Mariottini et al., 2002). Sobre los insectos el impacto es alto, perdiéndose numerosas especies al cabo de un turno (una cada 11 años), a la vez que se facilita el ingreso de otras desde ambientes cercanos no intervenidos, que colonizan los bosques impactados (Spagarino et al. 2001). Aunque el número de morfoespecies disminuye respecto del bosque primario a lo largo de todo el ciclo, la abundancia, que disminuye inicialmente al realizarse la corta, sufre una explosión en crecimiento óptimo, y luego decrece gradualmente en etapas posteriores. Dípteros e himenópteros son los órdenes más afectados, por poseer especies altamente especializadas, cuya alimentación o hábitat se modifican con la corta.

En los vertebrados (aves y guanacos) el impacto es bajo, ya que la riqueza no se modifica a lo largo del ciclo de manejo. La riqueza avícola aumenta luego de la intervención por el ingreso de especies de otros ambientes cercanos, y disminuye cuando la estructura se cierra, ya que el diámetro pequeño de los árboles no permite nidificar y dificulta la alimentación, caza, vuelos y actividades sociales. Finalmente se retoman los niveles del bosque primario cuando la masa forestal madura, ya que 
dichas especies no tienen elevados requerimientos específicos y se adaptan con relativa facilidad (Deferrari et al., 2001). En cuanto a los guanacos, los bosques aprovechados ofrecen mejores condiciones para su alimentación y protección, mientras que los bosques cerrados son desfavorables. Esto se corresponde altamente con la oferta alimenticia del sotobosque, y ocasiona daños en la regeneración (Martínez Pastur et al., 1999b). En los últimos años, el interés en la conservación de la biodiversidad ha propiciado la realización de estudios tendientes a la implementación de nuevos sistemas silvícolas que incorporen este tipo de indicadores. Es por ello que desde hace ocho años, la Universidad Nacional de la Patagonia Austral (UNPA), el Instituto Nacional de Tecnología Agropecuaria (INTA), el Centro Austral de Investigaciones Científicas (CADIC-CONICET), y más recientemente la Secretaría de Ambiente y Desarrollo Sustentable (Proyecto de Investigación Aplicada a los Recursos Forestales Nativos - PIARFON BIRF 4085 AR) están llevando a cabo investigaciones conjuntas a los fines de: (a) generar información de base sobre los componentes bióticos y abióticos de los bosques de Nothofagus pumilio sin intervención, (b) analizar el impacto que produce el manejo forestal sobre las variables bióticas y abióticas, y (c) desarrollar un nuevo método de regeneración que conjugue las variables económicas y de la conservación.

\subsection{MATERIALES Y MÉTODOS}

Se seleccionaron las UV forestales de la CAG para incorporarlos en el modelo de producción propuesto. Las UV seleccionadas debían presentar una pendiente menor a $25 \%$, poseer una calidad de sitio $V, I V$ O III y no pertenecer al régimen de la Administración de Parques Nacionales. Para el análisis de modelos de producción forestal en bosques de $N$. pumilio se utilizaron los modelos disponibles en la bibliografía (Cellini et al., 1998; Diaz et al., 1998; Martínez Pastur et al., 1997a; 1997b; 1999b; 2000a; Peri \& Martínez Pastur, 1996; Peri et al., 1997; Piriz Carrillo et al., 1996), aplicados a la zona de la CAG. Estos modelos fueron aplicados satisfactoriamente en otras zonas de la Isla de Tierra del Fuego ya que utilizan la variable calidad de sitio como predictiva, siendo así posible su uso en distintas zonas.

\subsubsection{Modelos incluidos en el Modelo de Producción de Nothofagus}

El modelo de producción utilizado consta de las siguientes ecuaciones y metodologías: (a) clasificación del sitio forestal y determinación del crecimiento en altura de individuos dominantes, se utilizaron las ecuaciones y clasificaciones 
propuestas por Martínez Pastur et al. (1997a); (b) cálculo del crecimiento diametral a partir de los trabajos de Peri \& Martínez Pastur (1996) y Díaz et al. (1998); (c) determinación del índice de densidad de rodales $(I D R)$ de acuerdo a ecuaciones y clasificaciones propuestas por Fernández et al. (1997); (d) diagramación de raleos mediante curvas de IDR de Martínez Pastur et al. (2002a); (e) cálculo del turno siguiendo la metodología planteada por Martínez Pastur et al. (2000c), en donde el turno se calcula considerando: una etapa de establecimiento, una etapa de crecimiento inicial y una etapa de crecimiento diamétrico para los renovales, y donde el tiempo que transcurre entre intervenciones silvícolas (raleos) y la definición de la corta final, se deducen de los anteriores modelos; (f) cálculo del volumen total con corteza utilizando el modelo propuesto por Peri et al. (1997); (g) cálculo del volumen de trozas sin corteza utilizando las proporciones, relaciones y modelos obtenidos por Martínez Pastur et al. (2001-2002)

\subsubsection{Supuestos del Modelo de Producción de Nothofagus}

Existen una serie de supuestos que deben tenerse en cuenta para conocer los alcances del modelo de producción utilizado: (a) los bosques se manejan mediante el criterio de maximización de la producción en madera aserrada. El sistema consta de raleos por lo bajo y una corta final (Schmidt \& Urzúa, 1982), manteniendo una estructura regular y se aprovecharán en la corta final los árboles dentro de la fase intermedia de crecimiento óptimo inicial - envejecimiento, de acuerdo a la clasificación propuesta por Schmidt \& Urzúa (1982) usando como criterio de corta un diámetro comercial mínimo; (b) el diámetro objetivo promedio es de $40-45 \mathrm{~cm}$ al DAP y un diámetro mínimo de extracción de $20 \mathrm{~cm}$, ya que se corresponde con los diámetros promedio de las trozas aprovechadas en la zona (Martínez Pastur et al., 2000a); (c) los crecimientos diamétricos se corresponden con árboles dominantes de rodales puros coetáneos de Nothofagus pumilio, desarrollándose bajo una dinámica natural; (d) los rendimientos obtenidos a lo largo de los diferentes raleos para cada clase de sitios son constantes y proporcionales a las tasas de extracción de trozas a lo largo del turno, basados en los resultados de Martínez Pastur et al. (2000c), desarrollados para bosques vírgenes; (e) los bosques bajo manejo silvícola no poseen presión por parte del ganado ni por otras poblaciones naturales de ramoneadores; (f) el total de la producción es absorbida localmente y los excedentes, comercializados en la región. (g) El modelo de producción se aplica a los rodales de $N$. betuloides con los resultados de $N$. pumilio, ya que en esta especie los crecimientos son similares a $N$. pumilio y es 
escasa la información generada para realizar un modelo de producción específico para la especie.

\subsubsection{Sistema silvícola seleccionado.}

Se seleccionó el sistema silvícola conocido como "método de retención dispersa y agregada" (Foto 10). Este sistema incorpora distintos grados de retención de los árboles remanentes, que permanecen por más de un turno forestal (Franklin \& Forman, 1987; Franklin, 1993). El objetivo principal de la retención es mantener la biodiversidad del bosque dentro de niveles aceptables, evitando la pérdida de especies y asegurando una eficiente recuperación del ecosistema después de la cosecha.

Foto 10. Estructura forestal remanente con un 30\% de retención agregada y dispersa. Remnant forest structure with $30 \%$ trees as aggregated and dispersed retention.

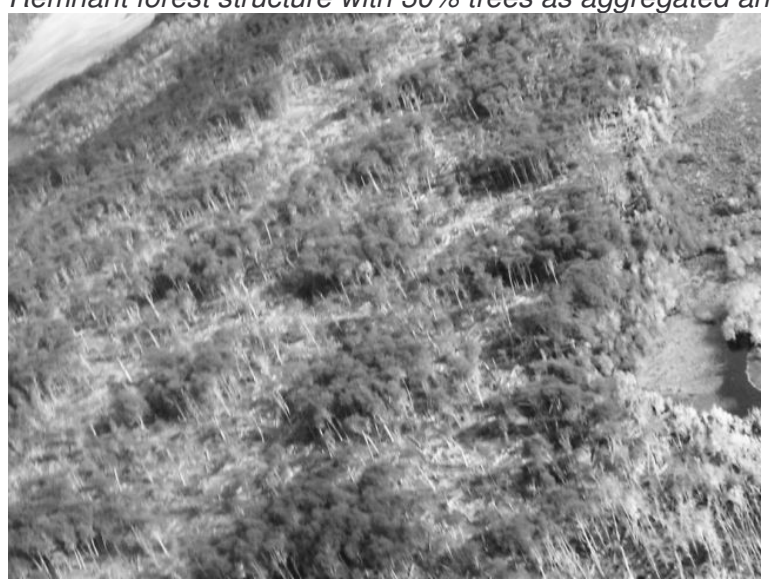

La propuesta incluye dejar un $30 \%$ del bosque productivo en forma de islas resguardando las características bióticas y abióticas del bosque primario (retención agregada), y un $10 \%$ más en forma de árboles aislados entre las islas de bosque (retención dispersa). El criterio de mayor importancia para seleccionar los árboles que quedan en pie es de orden biológico (árboles muy viejos, secos, árboles perchas o con huecos que sirven para la nidificación de varias especies de aves). Un aspecto secundario es de orden visual, ya que reduce la apariencia desagradable de vastas áreas sometidas a un aprovechamiento. Cabe destacar, que el desarrollo de este manejo forestal ha sido analizado desde un punto de vista económico para las empresas, habiéndose demostrado que se reducen significativamente los costos de marcación, fiscalización, volteo y rastreo, siendo el diseño de los caminos más ordenado y la ejecución de las tareas más eficiente.

A través del mismo, se dejan agregados de retención de $60 \mathrm{~m}$ de diámetro (uno por hectárea) y árboles dispersos no productivos en los sectores intermedios. La 
decisión del tamaño de los agregados y la separación entre ellos dependen de los objetivos del manejo, ya que si se pretende mantener en mayor medida las condiciones originales del bosque, se requerirá una mayor proporción de retención (Franklin et al., 1996). Para los bosques de Nothofagus sp. no existen análisis donde se comparen distintos tamaños de agregados ni distintos niveles de retención, de este modo se seleccionó el tamaño y la densidad de agregados utilizada actualmente en la provincia. Este sistema presenta grandes ventajas respecto de los antecesores por cuanto: (a) mejora la traza de caminos, (b) promueve el uso del volteo dirigido, (c) produce un menor impacto en el dosel remanente, (d) promueve la conservación de las especies (datos de los primeros cuatro años sobre plantas, insectos y aves), (e) mantiene características similares en la micrometeorología y en los ciclos de descomposición y mineralización dentro de los agregados de retención, (f) mantiene la heterogeneidad de la estructura forestal del bosque original, y (g) mantiene muchas de las características del paisaje. Debido a estas ventajas, se aconseja utilizar en las zonas de bosque productivo el "método de retención dispersa y agregada". En la zona de producción del sistema planteado se utilizará un modelo de producción basado en raleos y en una corta final.

\subsubsection{Estimación de la pérdida actual y potencial de suelos por erosión}

Se aplicó el modelo USLE (Universal Soil Loss Equation) para la estimación de la erosión hídrica actual y potencial debido a la aplicación del sistema silvícola. Su aplicación a nivel de cuencas hidrográficas implica la utilización de simplificaciones y suposiciones que deben tenerse presentes en la interpretación de los resultados (Mitasova et al., 1996; Eiumnoh, 2000; Wijesekera \& Samarakoon, 2001). La USLE permite cuantificar la pérdida anual de suelos a partir del producto de 6 factores (Ec. 8).

$$
A=R \cdot K \cdot L \cdot S \cdot C \cdot P
$$

Donde: $A$ = pérdida anual de suelo por hectárea $\left(\mathrm{t} \cdot \mathrm{año}^{-1} \cdot \mathrm{ha}^{-1}\right) ; R=$ erosividad de las lluvias $\left(\mathrm{J} \cdot \mathrm{mm} \cdot \mathrm{m}^{-2} \cdot \mathrm{h}^{-1}\right) ; K=$ erodabilidad del suelo $\left(\mathrm{t} \cdot \mathrm{J}^{-1} \cdot \mathrm{mm}^{-1}\right) ; L=$ longitud de una pendiente determinada; $S$ = pendiente en grados; $C$ = prácticas de manejo de la cobertura vegetal; y $P=$ prácticas de conservación. 
Para estimar un valor de pérdida anual de suelo por hectárea en las UV donde se aplicará el sistema silvícola propuesto, se utilizó una grilla de puntos espaciados 250 x 250 m. según los procedimientos detallados por Sun \& McNulty (1998) y Mati et al. (2000) para la aplicación del modelo a escala de cuenca. Cada uno de los puntos representa a una parcela de 6,25 ha. La modelización del factor $R$ no es una práctica común debido a la dificultad de la toma de datos para su cálculo (Vich, 1989). Se utilizó el índice modificado de Fournier (IMF) (Ec. 9) (Looijen et al., 1998; Sheridan \& Rosewell, 2003) como aproximación del factor $R$.

$$
I M F=\frac{\sum_{i=1}^{12} p_{x}^{2}}{P}
$$

Donde: $I M F=$ erosividad pluvial estimada mediante el Índice Modificado de Fournier; $p=$ precipitación mensual $(\mathrm{mm}) ; P=$ precipitación total anual en $\mathrm{mm}$.

Tabla 29. Rangos de valores aplicados a los distintos factores de la Ecuación Universal de Pérdida de Suelos (USLE) para la estimación de la erosión anual en la Cuenca del Arroyo Grande.

Ranks of values applied to the different parameters of the Universal Soil Loss Equation (USLE) for the estimation of annual erosion in the Arroyo Grande catchment.

\begin{tabular}{lll}
\hline Factor K & & \\
\hline Suelo & K mínimo & K máximo \\
\hline Franco - arenoso & 0,02 & 0,19 \\
Franco & 0,14 & 0,57 \\
Arenoso - franco & 0,03 & 0,09 \\
Arenoso & 0,00 & 0,01 \\
\hline Factores LS & & LS mínimo \\
\hline Pendiente & 0,0 & 4,1 \\
\hline$<10 \%$ & 4,1 & 12,4 \\
$10-20 \%$ & 12,4 & 21,3 \\
$20-30 \%$ & 21,3 & 30,2 \\
$30-40 \%$ & 30,2 & 38,6 \\
$40-50 \%$ & 38,6 & 56,1 \\
$>50 \%$ & & \\
\hline Factor C & C mínimo & C máximo \\
\hline Cobertura dominante & 0,006 & 0,061 \\
\hline Bosques de Nothofagus maduro con gran cobertura de dosel y de suelo & 0,046 & 0,185 \\
Bosques de Nothofagus con coberturas de dosel y de suelo variable & 0,007 & 0,420 \\
Bosques de Nothofagus abierto con baja cobertura de dosel / de suelo variable & 0,006 & 0,556 \\
Bosques de Nothofagus con manejo forestal & & \\
\hline
\end{tabular}

Para determinar el factor K (Renard et al., 1997 se utilizó la versión simplificada de su ecuación (Ec. 10), válida para aproximaciones preliminares (Mintegui \& Unzú, 1990), con información obtenida en 2. Morfometría y vegetación de la CAG. En Tabla 29 se resumen los rangos de valores utilizados. 


$$
K=0,000001 * 2,71 * M^{1,14} *(12-a)
$$

Donde: $K=$ factor de erodabilidad del suelo; $M=$ relación multiplicativa entre la fracción de partículas comprendidas entre 0,002-0,1 mm de diámetro y la fracción de arcillas; $a$ = fracción de materia orgánica presente.

La influencia de la topográfica en la erosión hídrica se calculó en el modelo mediante los factores $L$ y $S$. Se modelizaron valores para el factor topográfico $L \cdot S$ a partir de sus ecuaciones características (Ec. 11 y 12) y de parámetros de ajuste propuestos por Renard et al. (1997), Tragsa et al. (1998) y Mintegui \& Unzú (1990). En la Tabla 29 se resumen los rangos de valores aplicados.

$$
L * S=\left(\frac{\lambda}{22,1}\right)^{a} *\left(\frac{S}{c}\right)^{b}
$$

Donde: $L \cdot S=$ factor topográfico; $\lambda=$ longitud del declive en $\mathrm{m} ; s=$ factor de pendiente; $a, b$ y $c$ = parámetros de ajuste y constantes propuestas para el modelo, según diversos autores y situaciones de pendiente y longitud del declive.

$$
S=a^{*} \operatorname{seno}(\alpha)+b
$$

Donde: $a$ y $b=$ parámetros de ajuste del modelo, variables según los rangos de pendiente a que se apliquen; $\alpha$ = ángulo de pendiente.

El factor $C$ (efecto de las intervenciones antrópicas en la tasa de erosión) se estableció contemplando las características de la cobertura vegetal y de los residuos presentes, de la humedad del suelo y del poder erosivo de la lluvia y la escorrentía (Vich, 1989; Renard et al., 1997). Se obtuvieron los valores para el factor $C$ a partir de publicaciones de referencia para diversas situaciones de cobertura vegetal y de residuos, presentados por Mintegui \& Unzú (1990) y Tragsa et al. (1998). Se utilizó la información del sistema de información geográfico generado y del censo de vegetación realizado en la cuenca (ver 2.3.4. Vegetación). No se consideró en los cálculos el factor $P$ de prácticas de manejo dado que éste se orienta al impacto de actividades agrícolas. 


\subsection{RESULTADOS}

\subsubsection{Modelo silvícola}

El diagrama de raleos propuesto se presenta en la Figura 4. Cuando el rodal alcanza un $D A P$ promedio de $10 \mathrm{~cm}$ se realiza el primer raleo $(R 1)$, dejando 2.033 árb/ha de los 9.631 arb/ha que componen el rodal. Luego se realizan dos raleos fuertes cuando el rodal alcanza los $13 \mathrm{~cm}$ de $\operatorname{DAP}(R 2)$ y $17 \mathrm{~cm}(R 3)$ (Tabla 30 y Figura 4), donde se eliminan el $43 \%$ de los árboles remanentes en cada intervención. Con estos 3 primeros raleos se obtienen postes y varas, además de mejorar las características del rodal futuro. Posteriormente se realizan tres raleos por lo bajo a los 22, 28 y $36 \mathrm{~cm}$ de $D A P(M 1, M 2$ y M3), aportando volúmenes aserrables que varían de acuerdo al tipo de raleo y a la calidad de sitio, y una corta final (CF) al alcanzar un diámetro de $46 \mathrm{~cm}$, donde se regenera nuevamente el rodal por medio de las prácticas tradicionales.

Figura 4. Intervenciones silvícolas propuestas en el modelo de producción forestal para Nothofagus pumilio.

Forest interventions in the Nothofagus pumilio forest production model.

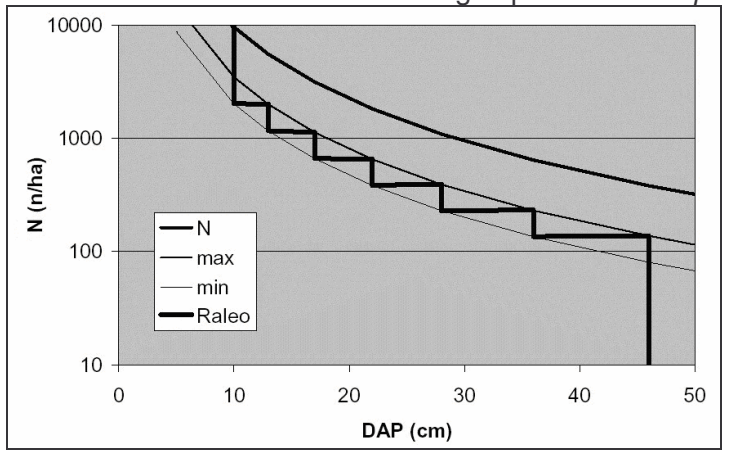

$\mathrm{N}$ (n/ha): número de árboles por hectárea; DAP: diámetro normal a 1,3 m.

Tabla 30. Variación del número de árboles para las intervenciones silvícolas propuestas en el Modelo de Producción para Nothofagus pumilio.

Variation of the number of trees for the forest interventions intended in the Production Model for Nothofagus pumilio.

\begin{tabular}{llll}
\hline Raleo & $D A P(\mathrm{~cm})$ & Antes del raleo $(\mathrm{n} / \mathrm{ha})$ & Después del raleo $(\mathrm{n} / \mathrm{ha})$ \\
\hline$P 1$ & 0 & 100.000 & 100.000 \\
$P 2$ & 5 & 41.623 & 41.623 \\
$R 1$ & 10 & 9.631 & 2.033 \\
$R 2$ & 13 & 2.033 & 1.168 \\
$R 3$ & 17 & 1.168 & 663 \\
M1 & 22 & 663 & 385 \\
M2 & 28 & 385 & 231 \\
M3 & 36 & 231 & 136 \\
$C F$ & 46 & 136 & 0
\end{tabular}

P1: Regeneración establecida; P2: Regeneración $5 \mathrm{~cm}$ de $D A P ; R 1$ : Primer raleo; R2: Segundo raleo; R3: Tercer raleo; M1: Primera corta maderable; M2: Segunda corta maderable; M3: Tercera corta maderable; $C F$ : Corta final.

Las diferencias volumétricas para las distintas clases de sitio hacen que el modelo de producción presente distintos resultados. En la Tabla 31 se muestran los 
resultados de VTCC y VMSC a lo largo del tiempo y el crecimiento potencial obtenido para las calidades de sitio III, IV y $V$. El año cero es el momento en que el rodal bajo alcanza una altura promedio de 1,3 m. (entre 13 y 15 años para los sitios $I V$ y $V$, respectivamente). El esquema de raleos plantea una densidad de ocupación que varía entre los 15 y los $25 \mathrm{~m}^{2} /$ ha constante para todas las clases de sitio. La aplicación de un modelo de producción permite estudiar la evolución de la oferta de distintos productos del bosque de Nothofagus pumilio. Conforme avanza el Plan de Ordenación es posible asegurar un abastecimiento continuo de postes, varas y un volumen continuo y creciente de material aserrable (Tabla 31). Esto se debe al progresivo mejoramiento de la sanidad del bosque resultante de la aplicación de raleos durante las etapas juveniles del bosque.

Tabla 31. Modelo de producción para un rango de calidades de sitio.

Production model for a site class interval.

\begin{tabular}{|c|c|c|c|c|c|c|}
\hline Sitio III & $T$ (años) & $V I\left(m^{3} / h a\right)$ & $V F\left(m^{3} / h a\right)$ & $V C\left(\mathrm{~m}^{3} / \mathrm{ha}\right)$ & Crec.(m³/ha.año) & $\operatorname{VMSC}\left(\mathrm{m}^{3} / \mathrm{ha}\right)$ \\
\hline$\overline{P 1}$ & 12 & 0 & 0 & 0 & 0 & 0 \\
\hline$P 2$ & 33 & 201 & 201 & 0 & 9,6 & 0 \\
\hline$R 1$ & 49 & 345 & 73 & 273 & 9 & Postes y Varas \\
\hline$R 2$ & 58 & 154 & 88 & 65 & 9 & Postes y Varas \\
\hline R3 & 70 & 187 & 106 & 81 & 8,2 & Postes y Varas \\
\hline M1 & 85 & 214 & 124 & 90 & 7,2 & 50 \\
\hline M2 & 105 & 236 & 142 & 94 & 5,6 & 53 \\
\hline M3 & 133 & 266 & 157 & 110 & 4,4 & 61 \\
\hline \multirow[t]{2}{*}{$C F$} & 176 & 279 & 0 & 279 & 0 & 156 \\
\hline & & & TOTAL & 992 & TOTAL & 320 \\
\hline Sitio IV & $T$ (años) & $V I\left(\mathrm{~m}^{3} / \mathrm{ha}\right)$ & $V F\left(m^{3} / h a\right)$ & $V C\left(\mathrm{~m}^{3} / \mathrm{ha}\right)$ & Crec.(m³/ha.año) & $\operatorname{VMSC}\left(\mathrm{m}^{3} / \mathrm{ha}\right)$ \\
\hline$P 1$ & 13 & 0 & 0 & 0 & 0 & 0 \\
\hline$P 2$ & 43 & 206 & 206 & 0 & 7,5 & 0 \\
\hline$R 1$ & 63 & 325 & 69 & 256 & 6,6 & Postes y Varas \\
\hline$R 2$ & 72 & 140 & 81 & 59 & 7,6 & Postes y Varas \\
\hline$R 3$ & 85 & 166 & 95 & 71 & 6,5 & Postes y Varas \\
\hline M1 & 103 & 187 & 109 & 78 & 5,6 & 32 \\
\hline M2 & 123 & 203 & 122 & 81 & 4,6 & 33 \\
\hline M3 & 153 & 227 & 134 & 93 & 3,6 & 38 \\
\hline \multirow[t]{2}{*}{$C F$} & 195 & 238 & 0 & 238 & 0 & 98 \\
\hline & & & TOTAL & 876 & TOTAL & 201 \\
\hline Sitio V & $T$ (años) & $V I\left(m^{3} / h a\right)$ & $V F\left(m^{3} / h a\right)$ & $V C\left(\mathrm{~m}^{3} / \mathrm{ha}\right)$ & Crec.(m³/ha.año) & $\operatorname{VMSC}\left(\mathrm{m}^{3} / \mathrm{ha}\right)$ \\
\hline$P 1$ & 15 & 0 & 0 & 0 & 0 & 0 \\
\hline$P 2$ & 54 & 210 & 210 & 0 & 5,4 & 0 \\
\hline$R 1$ & 76 & 303 & 64 & 239 & 4,2 & Postes y Varas \\
\hline$R 2$ & 86 & 125 & 72 & 53 & 6,1 & Postes y Varas \\
\hline$R 3$ & 101 & 144 & 82 & 62 & 4,8 & Postes y Varas \\
\hline M1 & 120 & 159 & 92 & 67 & 4 & 13 \\
\hline M2 & 142 & 168 & 101 & 67 & 3,5 & 13 \\
\hline M3 & 172 & 187 & 110 & 77 & 2,8 & 15 \\
\hline \multirow[t]{2}{*}{$C F$} & 213 & 196 & 0 & 196 & 0 & 39 \\
\hline & & & TOTAL & 761 & TOTAL & 80 \\
\hline
\end{tabular}

Sitio: clase de sitio, T: Tiempo, VI: Volumen inicial, VF: Volumen final, VC: Volumen de corta, Crec.: Crecimiento, VMSC: Volumen de trozas sin corteza extraído. Los valores están referidos a una hectárea efectiva, sin la inclusión del agregado de retención.

La presión ejercida sobre el bosque produce un empeoramiento de las condiciones de la cuenca hidrográfica, el cual puede representar el comienzo de un proceso progresivo de degradación (Cárdenas de Llano, 1971). El modelo de 
producción planteado, al simular la dinámica natural de los bosques, hace que el empeoramiento de las condiciones de las cortas sea mínimo.

Los parámetros estructurales del bosque productivo de Nothofagus pumilio muestran un bosque irregular (Tabla 32). En número de árboles por ha no se observan diferencias entre calidades de sitio, encontrándose una gran variación, lo que indica un amplio gradiente de densidades en las unidades productivas y que cada rodal presenta una situación particular de raleos. En las variables de $A B, D C M$ y $V T C C$ no se observaron diferencias, encontrándose valores similares en las distintas calidades de sitio. Se encontraron diferencias en el VVSC dadas por la calidad de sitio, indicando un gradiente que disminuye a medida que empeora la calidad de sitio. La posibilidad anual para Nothofagus pumilio en el bosque ordenado asciende a unos $1509,446 \mathrm{~m}^{3}$ de trozas sin corteza (Tabla 33), valor que permitiría sustentar a un aserradero pequeñomediano operando en la zona. La superficie forestal susceptible de ser manejada se redujo a un $31 \%$ al ser descartadas las superficies con una pendiente mayor al $40 \%$, áreas protegidas y bosque no productivo.

Tabla 32. Superficie y estructura de los bosques de producción de Nothofagus. Area and structure of the Nothofagus productive forests.

\begin{tabular}{lllllll}
\hline Sitio & Densidad (árb/ha) & $A B A P$ & $A B T$ & $D C M$ & VTCC & VVSC \\
\hline III & $388,5 \mathrm{a}$ & $14,0 \mathrm{a}$ & $48,3 \mathrm{a}$ & $53,1 \mathrm{a}$ & $583,0 \mathrm{a}$ & $144,3 \mathrm{a}$ \\
$\mathrm{VI}$ & $4063,2 \mathrm{a}$ & $14,9 \mathrm{a}$ & $56,3 \mathrm{a}$ & $32,6 \mathrm{a}$ & $555,2 \mathrm{a}$ & $122,4 \mathrm{a}$ \\
$\mathrm{V}$ & $994,8 \mathrm{a}$ & $17,7 \mathrm{a}$ & $60,1 \mathrm{a}$ & $37,7 \mathrm{a}$ & $437,6 \mathrm{a}$ & $80,9 \mathrm{~b}$ \\
\hline $\mathrm{P}(95 \%)$ & 0,1913 & 0,7405 & 0,4529 & 0,1149 & 0,0771 & 0,0006 \\
$\mathrm{~F}$ & 1,73 & 0,30 & 0,81 & 2,29 & 2,74 & 9,08 \\
\hline
\end{tabular}

Sitio: Calidad de sitio según Martínez Pastur et al. (1997b); árb/ha: número de árboles por hectárea; $A B$ $A P$ : área basal aprovechable en $\mathrm{m}^{2} ; A B T$ : área basal total en $\mathrm{m}^{2} ; D C M$ : diámetro cuadrático medio en $\mathrm{cm}$; VTCC: Volumen total con corteza en $\mathrm{m}^{3}$; VVSC: Volumen maderable sin corteza en $\mathrm{m}^{3}$, letras diferentes indican diferencias significativas a $\mathrm{P}<0,05$ según prueba de Tukey, $\mathrm{n}$ : número de observaciones, $\mathrm{F}$ : Test de Fisher, $\mathrm{P}(95 \%)$ : nivel de probabilidad, valores expresados en medias.

Tabla 33. Posibilidad de la cuenca de estudio.

Possibility of the river basin under study.

\begin{tabular}{|c|c|c|c|c|c|}
\hline Sitio & Área (ha) & Área Ef. (ha) & VVSC/ha & Años & Posibilidad \\
\hline $\bar{V}$ & 919,59 & 659,58 & 80 & 213 & 247,73 \\
\hline VI & 378,65 & 271,59 & 201 & 195 & 279,95 \\
\hline III & 168,51 & 120,86 & 320 & 176 & 219,74 \\
\hline Total & 1466,75 & 1052,03 & $200,3^{*}$ & $194,7^{*}$ & 1082,29 \\
\hline
\end{tabular}

Posibilidad: $\mathrm{m}^{3}$ ha/año, *: valor promedio, Área: Superficie de los rodales; Área ef: Área de los rodales productivos descontándoles la superficie de retención agregada.

\subsubsection{Posibilidad}

La cobertura forestal se halla representada por bosques de Nothofagus pumilio y Nothofagus betuloides, con 4722,88 hectáreas. El bosque representa un $36,46 \%$ de la superficie total del área (Tabla 34). Los rodales productivos de Nothofagus presentan una calidad promedio de sitio baja (Tabla 33), siendo la media ponderada de un valor de 4,51. En general presentan una subocupación del sitio en términos de área basal y volumen total con corteza por hectárea según los valores esperados para la 
mencionada calidad de sitio y en rodales sin intervención silvícola de ningún tipo (Martínez Pastur et al., 2002a). Una vez descontadas las superficies de protección por pendientes $\left(>40^{\circ}\right.$ ) así como las pertenecientes al régimen de la Administración de Parques Nacionales y bosque no productivo, la superficie total aprovechable de Nothofagus alcanza las 1466,75 ha, representando un $31.06 \%$ del total de bosques de Nothofagus. Si descontáramos la superficie ocupada por los agregados de retención, la superficie efectiva del bosque se reduce a 1052,03 ha, un 22,27\% del bosque de Nothofagus de la CAG distribuidas en 18 rodales o Unidades de Corta (UC).

Tabla 34. Superficies de las distintas unidades de la Cuenca del Arroyo Grande. Catchment area of the different units in Arroyo Grande.

\begin{tabular}{lllllllll}
\hline & Roca & Glaciar & Lagos & $G$ & $L$ & $P$ & $T$ & Total \\
\hline ha & 5587,45 & 1152,58 & 132,63 & 570,22 & 4152,66 & 1219,46 & 136,29 & 12951,29 \\
$\%$ & $43,14 \%$ & $8,90 \%$ & $1,02 \%$ & $4,40 \%$ & $32,06 \%$ & $9,42 \%$ & $1,05 \%$ & $100 \%$ \\
\hline L: tipo de unidad de vegetación N. pumilio, G: tipo de unidad de vegetación N. betuloides, T: tipo de \\
unidad de vegetación Turbera, P: tipo de unidad de vegetación Pastizal
\end{tabular}

La alta variabilidad encontrada en el bosque está explicada por las intervenciones forestales del pasado (ver 3. Uso de la tierra e impacto), el 76,3\% de la superficie del sitio III esta en condiciones de realizar la CF, mientras que en el sitio IV es el $18,7 \%$ y en el sitio $V$ el $22,7 \%$, siendo necesario aplicar el resto de la superficie los tratamientos intermedios (raleos).

El cálculo de la posibilidad aporta datos sumamente interesantes, ya que en el supuesto de tener el total de la superficie ordenada, los rendimientos en madera aserrable son importantes y rentables. Se observa también que en el caso de la mejor calidad de sitio (III) se cuenta con una superficie de 168,51 ha. El valor del total de la posibilidad $\left(1082,29 \mathrm{~m}^{3}\right)$ indica que este volumen de madera es suficiente para abastecer un aserradero pequeño a mediano en la zona (Tabla 33).

\subsubsection{Alternativas de turno}

Se planteó agregar al modelo silvícola propuesto, 3 opciones que se basan en la modificación del turno de corta, realizando la corta final en las intervenciones $M 1, M 2$, M3 o CF. De esto se desprende que se obtendrá, a medida que se reduce el turno, un menor volumen maderable (Tabla 35). La diferencia entre las distintas opciones tiene incidencia en los productos obtenidos, ya que cuando la CF se realiza en el raleo $M 1$, el diámetro promedio de los árboles a cosechar es de $22 \mathrm{~cm}$, logrando de esta manera productos de bajas escuadrías, obteniendo una baja diversidad en la producción. A medida que la $C F$ se pospone, los diámetros de corta se modifican siendo 28, 36 y 46 cm para M2, M3 y CF respectivamente, teniendo de este modo un mayor espectro de productos. Las modificaciones en la producción de madera van de $31 \mathrm{~m}^{3} / \mathrm{ha}$ en el sitio 
$V$ con un turno de 140 años, realizando la $C F$ en el primer raleo maderable, hasta 320 $\mathrm{m}^{3} / \mathrm{ha}$ en el sitio III con un turno de 160 años cumpliendo con el modelo de producción teórico.

Tabla 35. Períodos, crecimientos y rendimientos de las distintas alternativas de turno. Period, growth and yield of the different alternatives.

\begin{tabular}{|c|c|c|c|c|c|c|}
\hline Sitio III & $\mathrm{T}$ & Crec.(m³/ha.año) & $\operatorname{VMSC}\left(\mathrm{m}^{3} / \mathrm{ha}\right)$ & Opc 1 & Opc 2 & Opc 3 \\
\hline$\overline{R 1}$ & 40 & 9 & Postes y Varas & Postes y Varas & Postes y Varas & Postes y Varas \\
\hline$R 2$ & 60 & 9 & Postes y Varas & Postes y Varas & Postes y Varas & Postes y Varas \\
\hline R3 & 80 & 8,2 & Postes y Varas & Postes y Varas & Postes y Varas & Postes y Varas \\
\hline M1 & 100 & 7,2 & 50 & 50 & 50 & 119 \\
\hline M2 & 120 & 5,6 & 53 & 53 & 133 & \\
\hline M3 & 140 & 4,4 & 61 & 148 & & \\
\hline$C F$ & 160 & 0 & 156 & & & \\
\hline TOTAL & & & 320 & 251 & 183 & 119 \\
\hline Sitio IV & $\mathrm{T}$ & Crec.(m³/ha.año) & $\operatorname{VMSC}\left(\mathrm{m}^{3} / \mathrm{ha}\right)$ & Opc 1 & Opc 2 & Opc 3 \\
\hline$R 1$ & 60 & 6,6 & Postes y Varas & Postes y Varas & Postes y Varas & Postes y Varas \\
\hline$R 2$ & 80 & 7,6 & Postes y Varas & Postes y Varas & Postes y Varas & Postes y Varas \\
\hline$R 3$ & 100 & 6,5 & Postes y Varas & Postes y Varas & Postes y Varas & Postes y Varas \\
\hline M1 & 120 & 5,6 & 32 & 32 & 32 & 77 \\
\hline M2 & 140 & 4,6 & 33 & 33 & 83 & \\
\hline M3 & 160 & 3,6 & 38 & 93 & & \\
\hline$C F$ & 180 & 0 & 98 & & & \\
\hline TOTAL & & & 201 & 158 & 115 & 77 \\
\hline Sitio V & $\mathrm{T}$ & Crec.(m³/ha.año) & $\operatorname{VMSC}\left(\mathrm{m}^{3} / \mathrm{ha}\right)$ & Opc 1 & Opc 2 & Opc 3 \\
\hline$\overline{R 1}$ & 80 & 4,2 & Postes y Varas & Postes y Varas & Postes y Varas & Postes y Varas \\
\hline$R 2$ & 100 & 6,1 & Postes y Varas & Postes y Varas & Postes y Varas & Postes y Varas \\
\hline$R 3$ & 120 & 4,8 & Postes y Varas & Postes y Varas & Postes y Varas & Postes y Varas \\
\hline M1 & 140 & 4 & 13 & 13 & 13 & 31 \\
\hline M2 & 160 & 3,5 & 13 & 13 & 33 & \\
\hline M3 & 180 & 2,8 & 15 & 36 & & \\
\hline$C F$ & 200 & 0 & 39 & & & \\
\hline TOTAL & & & 80 & 62 & 46 & 31 \\
\hline
\end{tabular}

Sitio: clase de sitio, T: Tiempo, Crec.: Crecimiento, VMSC: Volumen de trozas sin corteza extraído; Opc: opción de modificación del modelo de producción teórico. Los valores están referidos a una hectárea efectiva, sin la inclusión del agregado de retención. R1: Primer raleo; R2: Segundo raleo; R3: Tercer raleo; M1: Primera corta maderable; M2: Segunda corta maderable; M3: Tercera corta maderable; CF: Corta final.

Para la selección de la mejor alternativa de corta, se desarrolló un modelo matemático cuya solución óptima puede ser obtenida mediante algoritmos de uso corriente en la programación lineal. La condición inicial de la unidad de manejo se describe mediante unidades de corta $(U C)$ que se definen por la situación inicial del tipo de rodal y por su calidad de sitio. La función objetivo busca la maximización de la producción volumétrica de madera sujeta a las restricciones del área disponible en cada una de las unidades de corta y al requerimiento de una producción mínima de $4.000 \mathrm{~m}^{3}$ para cada período de 20 años. El horizonte temporal se fijó arbitrariamente en 340 años siguiendo la práctica de planificar las cortas para un período de tiempo de 1,5 a 2 veces la rotación de la especie cuando se elaboran planes estratégicos. En este caso, el período de 340 años se corresponde con dos turnos para la opción de corta de mayor duración (sitio $\mathrm{V}$, corta final en $\mathrm{CF}$ ).

El modelo matemático resultante puede ser considerado como de Tipo I (Clutter et al., 1983) que se caracteriza porque la identidad de las unidades de corta que 
describen inicialmente a la unidad de manejo se preserva durante todo el horizonte de planificación. La otra característica distintiva de los modelos Tipo I es que requiere el planteo de varias alternativas de manejo para cada unidad de corta, denominadas regímenes de manejo, para que el problema resulte significativo. En el modelo desarrollado, para cada una de las 18 UC se plantearon todas las opciones de turno (cuatro) en todas las combinaciones posibles durante los 17 períodos de 20 años cada uno tiempo definidos. Aplicando estas reglas para plantearlos, los regímenes de manejo resultantes fueron 431 para el total de unidades de corta.

En la Tabla 36 se puede observar el resumen de los resultados, indicando para el período evaluado el orden y los tipos de alternativas de turno aplicadas a cada una de las UC, El resultado de este análisis es básicamente el ordenamiento temporal de los rodales para satisfacer las reglas planteadas. En algunas $U C(1,2,5,6,9,12,13$ y 14) se plantean varias opciones de manejo, ya que la solución óptima del problema implica la subdivisión de la superficie aplicando distintos regímenes de manejo en cada una de ellas. Finalmente, en la Tabla 37 se presentan los volúmenes discriminados por calidad de sitio, observándose que la producción maderera es máxima en el primer período de corta (de 0 a 20 años) con un mínimo en el período comprendido entre los 80 a 100 años.

Tabla 36. Opciones de corta resultantes de la optimización para cada unidad de corta. Cut alternatives resulting from optimization of each unit

\begin{tabular}{|c|c|c|c|c|c|c|c|}
\hline$U C$ & Sitio & Área (ha) & Sit. Inic & & Opcior & s de corta & \\
\hline 1 & III & 28,61 & R3 & O1-MT-O3 & O2-MT-O2 & $\mathrm{O} 2-01-02$ & \\
\hline 2 & III & 92,24 & $C F$ & MT-MT-MT & MT-MT-O1 & MT-O1-O2 & MT-O1-MT \\
\hline 3 & IV & 11,36 & $P 1$ & MT-O1 & & & \\
\hline 4 & IV & 10,74 & $P 2$ & MT-O1 & & & \\
\hline 5 & IV & 54,57 & $R 1$ & MT-O1 & 01-01 & O3-O1 & O3-MT \\
\hline 6 & IV & 16,86 & $R 2$ & MT-O1 & O3-MT & & \\
\hline 7 & IV & 6,24 & $R 3$ & O3-MT-O3 & & & \\
\hline 8 & IV & 4,80 & M1 & O3-MT-O2 & & & \\
\hline 9 & IV & 116,18 & M2 & MT-MT & O1-MT-O3 & O2-MT-O2 & \\
\hline 10 & IV & 50,84 & $C F$ & MT-MT-O2 & & & \\
\hline 11 & $V$ & 12,96 & $P 2$ & MT-O1 & & & \\
\hline 12 & V & 123,53 & $R 1$ & MT-O2 & MT-MT & & \\
\hline 13 & V & 40,98 & $R 2$ & MT-O2 & O1-01 & & \\
\hline 14 & V & 110,90 & $R 3$ & MT-O2 & MT-MT & & \\
\hline 15 & V & 117,37 & M1 & MT-MT & & & \\
\hline 16 & V & 23,99 & M2 & O2-MT & & & \\
\hline 17 & V & 79,80 & M3 & O1-MT & & & \\
\hline 18 & $V$ & 150,05 & $C F$ & MT-MT & & & \\
\hline
\end{tabular}


A partir de los 140 años la producción maderera se estabiliza en aproximadamente $20.000 \mathrm{~m}^{3}$ por período.

Tabla 37. Volúmenes maderables obtenidos por períodos de 20 años discriminados por calidad de sitio. Harvest volumes for 20-year periods by site class

\begin{tabular}{|c|c|c|c|c|c|c|c|c|c|}
\hline tio & Per 0-20 & Per 20-4 & Per & Per & er 8 & $100-12$ & 12 & 14 & 1 \\
\hline III & $14.389,4$ & $1.430,5$ & $3.065,6$ & $1.365,9$ & 0,0 & 4.6 & $4.888,7$ & 10.6 & 8.6 \\
\hline IV & $9.911,2$ & $7.959,1$ & 4.4 & 5 & $1.462,7$ & 3. & 3.4 & & 2,4 \\
\hline V & $1.066,8$ & $2.967,5$ & $3.735,0$ & $8.379,6$ & $6.927,2$ & 3.2 & 5.0 & 5,4 & 3.2 \\
\hline tal & $35.367,4$ & $12.357,1$ & $11.286,0$ & $12.950,5$ & $8.389,9$ & $11.405,0$ & $13.372,9$ & $20.535,0$ & 19.575 \\
\hline
\end{tabular}

Per: período en años; datos volumétricos en $\mathrm{m}^{3}$

\subsubsection{Riesgo erosivo}

La pérdida de suelos por erosión hídrica es uno de los principales condicionantes para el aprovechamiento de un territorio (Gil, 1986). La estimación de la erosión mediante modelos matemáticos permite una aproximación al conocimiento del estado de conservación y riesgo de diferentes suelos sometidos a condiciones diversas de uso e intensidad. Sin embargo, la utilización del modelo USLE para la estimación de la pérdida anual de suelos a escala de cuenca presenta una serie de limitantes que deben tenerse presentes durante la interpretación de sus resultados (Wijesekera \& Samarakoon, 2001). El cálculo de la erosión hídrica actual presentó valores medios y bajos de erosión (Tabla 29), con aproximadamente un $12 \%$ de la superficie con niveles bajos de erosión, con valores de hasta 1,0 t/ha/año. La mayor superficie $(87,5$ $\%$, se encuentra sometida a procesos moderados de erosión, entre 1,0 y 10,0 t/ha/año. Los valores más elevados de erosión, por encima de las 10 t/ha/año, se presentan en un $0,5 \%$ de la superficie. El cálculo de pérdida anual de suelo por hectárea potencial $\left(\mathrm{t} \cdot \mathrm{año} \mathrm{-}^{-1} \cdot \mathrm{ha}^{-1}\right.$ ) debido a la aplicación del sistema silvícola arrojó valores similares de erosión para los rodales estudiados. Se observó que los valores de $A$ aumentan con la aplicación del sistema silvícola, presentando un $96,5 \%$ de la superficie erosión moderada, y un 3,5\% erosión alta (Tabla 38 ).

Tabla 38. Modelización de la erosión actual y por la aplicación de silvicultura en bosques productivos de Nothofagus sp. en la Cuenca del Arroyo Grande.

Modelization of present erosion and of erosion due to the application of silviculture in productive forests of Nothofagus in Arroyo Grande catchment.

\begin{tabular}{lrr}
\hline Pérdida de suelo $\left(\mathrm{t} \cdot \mathrm{anno}^{-1} \cdot \mathrm{ha}^{-1}\right)$ & SA & \multicolumn{1}{c}{ SMS } \\
\hline $0-0,09$ & 175 & 0 \\
$0,1-0,49$ & 31 & 219 \\
$0,5-0,99$ & 594 & 118 \\
$1,0-4,99$ & 525 & 806 \\
$5,0-9,99$ & 119 & 256 \\
$10,0-49,99$ & 6 & 51
\end{tabular}

SA: Superficie de bosques sin manejo silvícola en ha, SMS: Superficie de bosques con manejo silvícola en ha. 


\subsection{DISCUSIÓN}

El bosque de Nothofagus de la CAG presentó un potencial en volúmenes maderables dependiendo de las calidades de sitio involucradas a través de la aplicación de un sistema silvícola. La duración de las rotaciones en el manejo del bosque fue variable debido a la aplicación de análisis de programación lineal cuyo objetivo fue la maximización de la producción de madera y una producción mínima de $4000 \mathrm{~m}^{3}$. Se seleccionó como sistema silvícola a emplear el "método de retención dispersa y agregada", método que mantiene la biodiversidad del bosque dentro de niveles aceptables. El sistema elegido no solo presenta ventajas del punto de vista de la conservación, sino que también presenta facilidades en la planificación y ejecución de las tareas forestales. Se seleccionaron los rodales productivos del bosque dando una superficie aprovechable de Nothofagus de 1.466,75 ha, dando un valor de posibilidad de 1.082,29 m³/año; suficiente para abastecer un aserradero en la zona.

La producción de madera proveniente del bosque nativo es absorbida en la actualidad principalmente por el mercado interno como material para la construcción (encofrados y carpintería), en la forma de tablones, tablas y tirantes. La fuerte expansión urbana en Tierra del Fuego, sumada a las importantes inversiones en infraestructura turística privada representa un mercado local para el abastecimiento de madera para la construcción y para otros usos a menor escala, como la mueblería rústica. Los riesgos de erosión hídrica que determina la aplicación del sistema silvícola propuesto no son importantes, debiéndose realizar monitoreos en las zonas que presentan alto riesgo erosivo (3,5\% de los rodales). 


\section{CONCLUSIONES}

Se determinaron en la cuenca zonas con distintos grados de uso, dados por los efectos negativos que producen las actividades humanas en la naturaleza. Para cada zona se plantearon las condiciones y limitaciones para el manejo y aprovechamiento de los recursos naturales, así como las acciones de conservación y restauración. El estado actual de conservación de la cuenca hace necesaria la eliminación de la producción pecuaria, debido al progresivo deterioro de los suelos, el impacto sobre la regeneración natural del bosque, comprometido seriamente su regeneración y la gran cantidad de especies exóticas concentradas en los sitios de pastoreo. Se considera que debe evitarse la actividad ganadera en el área, siendo necesaria la ejecución de un programa de recuperación de los pastizales naturales. La presencia del ganado en el bosque hace disminuir el número de renovales, la distribución de los mismos, la eliminación total de plantas pequeñas, la compactación del suelo y la degradación del sotobosque.

La superficie los bosques de Nothofagus factibles de ser manejada es de 1466,7

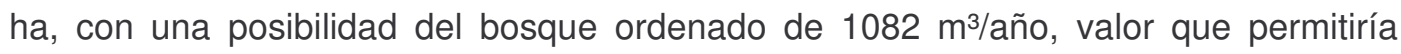
sustentar un aserradero pequeño en la zona. Los volúmenes aserrables no alcanzan para satisfacer las demandas de la ciudad de Ushuaia, pero sí para las demandas del asentamiento dentro de la cuenca. Los parámetros dasométricos muestran variaciones a lo largo del gradiente de calidades de sitio, siendo mayormente baja calidad forestal. El modelo de producción propuesto permite estudiar la evolución de la oferta de distintos productos del bosque, ya que es posible asegurar un continuo abastecimiento de postes, varas y material aserrable. El método de retención dispersa y agregada propuesto mejoraría la capacidad de conservación de la biodiversidad del bosque, con la obtención de volúmenes económicos de cosecha, evitándose la pérdida de especies y asegurando la recuperación del ecosistema después del impacto producido por el aprovechamiento.

El emprendimiento de extracción de turba altera del hábitat natural al producir el desecamiento del turbal mediante un sistema de drenaje y la posterior extracción. Una vez concluidas las actividades extractivas, se plantea restablecer las funciones del ecosistema en donde se realizó la explotación, requiriendo lograr las condiciones de humedad originales mediante técnicas de endicamiento, bloqueando los drenajes existentes, con el consiguiente incremento del nivel freático existente.

Es necesario efectuar un control de Castor canadensis a lo largo del Arroyo Grande y el Río Chico, siendo esta especie responsable de causar la degradación de ecosistemas ribereños, al producir embalses, modificación del paisaje y corte de 
árboles. Se recomienda la utilización de trampas que permitan capturar a los animales sin destruir el embalse, produciendo su lento drenaje una vez asegurada la captura de todos los individuos de la colonia, minimizando la pérdida de sedimentos y nutrientes y favoreciendo la recolonización vegetal.

El turismo impacta significativamente en la vegetación, principalmente en la Laguna de los Témpanos y el Glaciar Vinciguerra, así como en el Circuito Valle de Andorra - Cañadón de la Oveja. Los senderos se hallan en mal estado de mantenimiento, con signos de erosión y con muerte de la vegetación arbustiva y herbácea. Se observa la acumulación de basura en áreas de campamento agreste y la perdida de la cubierta vegetal y daños en los árboles. Es por ello que se hace necesario reordenar la actividad turística en la cuenca, debido a la importancia de aprovechar los sectores de alto potencial turístico mientras que los actualmente visitados poseen una elevada carga. El ordenamiento mejorará el control de las áreas involucradas y la optimización del espacio. Se plantea la construcción de hosterías en sectores estratégicos, casillas de control y acceso, oficina de informes, sanitarios y playa de estacionamiento. Se propone demarcar nuevos para diversificar la oferta, aumentar el tiempo de estadía de los acampantes y disminuir la presión sobre otras áreas. Con el aumento del número de turistas, es necesario aumentar la vigilancia de las distintas zonas, así como la colocación de cartelería indicadora, demarcación de zonas de acampe agreste, habilitación de guías, registro de acampantes y manejo de residuos.

Es necesario realizar un ordenamiento territorial de la Cuenca del Valle de Andorra, para mitigar la acción de los agentes de impacto y poder llevar a cabo alternativas de manejo de las actividades productivas tradicionales en un marco de sustentabilidad económica y ambiental, mejorando la capacidad de conservación de la cuenca. 


\section{AGRADECIMIENTOS}

Durante estos años son muchas las personas e instituciones que han participado en este trabajo, a quienes quiero expresar mi gratitud por el apoyo y la confianza que me han prestado de forma desinteresada, muy especialmente a mis directores, Gerardo Denegri y Guillermo José Martínez Pastur, por su confianza en mí, sus contribuciones y su plena colaboración en el desarrollo de este trabajo, a Boris Gastón Díaz, por su ayuda en el relevamiento de campo, sus respuestas a mis continuas preguntas e incentivo constante para finalizar este trabajo. A María Vanessa Lencinas, por su ayuda en la determinación de las especies, por su atención y sus continuos consejos, a Gustavo Gabriel Archuby por sus siempre acertadas opiniones y comentarios sobre el trabajo en marcha, a Pablo Víctor Musa, Julián Cellini y Karina Alejandra Presta por las observaciones al manuscrito final y la ayuda en los gráficos, a Pablo Yapura, Julio Arce y Jorge Bozzi por su ayuda en programación lineal, a Adriana Adaglio, Ricardo Fabián Vukasovic, Mónica Adriana Murace, Mariel Oyhamburu, Sarah Lilian Burns, Emilce Andrea Gallo, Guillermina Leticia Massaccesi, Andrea Coronato, Julio Escobar, Ignacio Alfredo Mundo y Claudio Roig por su cooperación y apoyo, a Ignacio Capiel por sus oportunas observaciones que siempre han hecho surgir nuevas preguntas, reflexiones e ideas, y a Carolina Isabel Llavallol por su compañía y por su continuo apoyo y ayuda. 


\section{BIBLIOGRAFÍA}

Alfonso J. 1942. Los bosques de Tierra del Fuego. Revista Suelo Argentino 1: 47-51.

Aparicio Mijares F.J. 1994. Fundamentos de la hidrología de superficie. En: La cuenca hidrológica. Aparicio Mijares F.J., Ed. Limusa, México. pp.19-27.

APN. 1994. El sistema nacional de áreas naturales protegidas de la Argentina. Diagnóstico de su patrimonio natural y su desarrollo institucional. Administración de Parques Nacionales, Buenos Aires, Argentina. 95 pp.

APN. 2003a. Plan de Manejo PNTdF Parte I: Documento preliminar del Plan de Manejo del Parque Nacional Tierra del Fuego. Administración de Parques Nacionales, Buenos Aires. Parte 1. 48 pp.

APN. 2003b. Plan de Manejo Parque nacional Tierra del Fuego Parte II: Objetivos, zonificación y programas de manejo. Administración de Parques Nacionales, Buenos Aires. 24p.

Ardura F. 1994. El sistema nacional de áreas protegidas de la Argentina, diagnóstico de su patrimonio natural y su desarrollo institucional. Capítulo 4 Desarrollo sustentable del turismo en las áreas protegidas de la Argentina. Administración de Parques Nacionales, Buenos Aires. Argentina. pp. 83-86.

Asancaic J. \& J. Frkovic. 1962. Plan de ordenación del Cuartel lote 80. Territorio Nacional de Tierra del Fuego. Secretaría de Estado de Agricultura y Ganadería de la Nación - Administración Nacional de Bosques. 42 pp.

Assman E. 1970. The principles of forest yield study. Pergamon Press. Oxford. New York. 506 pp.

Barrera M., J. Frangi, L. Richter, M. Perdomo \& L. Pinedo. 2000. Structural and functional changes in Nothofagus pumilio forest along an altitudinal gradient in Tierra del Fuego, Argentina. Journal of Vegetation Science 11:179-188.

Bava J. 1998. Aportes ecológicos y silviculturales a la transformación de bosques vírgenes de Lenga (Nothofagus pumilio) en bosques manejados en el sector argentino de Tierra del Fuego. Centro de Investigación y Extensión Forestal Andino Patagónico. Publicación Técnica $n^{\circ} 29.138$ pp.

Bava J. \& C. Puig. 1992. Regeneración natural de lenga. Análisis de algunos factores involucrados. Centro de Investigación y Extensión Forestal Andino Patagónico. Publicación Técnica 8: 85-110.

Bay R. \& J. Blydenstein 1971. Comportamiento de la cuenca hidrográfica. Informe sobre el Seminario Latinoamericano de Ordenación de Cuencas Hidrográficas. Food and Agriculture Organization, La Plata, 22 de noviembre - 16 de Diciembre: 7-9. 
Benitez Chunga C.A. 1978. Estudio de los parámetros geomorfológicos de una cuenca. Ministerio de Agricultura y Alimentación, Dirección General de Aguas, Perú. Boletín Técnico Número 2. 32 pp.

Bessera E.M., I.V. Irrazabal \& D.O. Alcalde. 1996. Parque Nacional Tierra del Fuego, Plan Operativo Preliminar, Presidencia de la Nación. 22 pp.

Bitterlich W. 1984. The relascope idea. Relative measurements in forestry. Commonwealth Agricultural Bureaux. Londres, Inglaterra. 242 pp.

Bonino N. \& A. Sbriller. 1991a. Composición botánica de la dieta del guanaco (Lama guanicoe) en dos ambientes contrastantes de Tierra del fuego, Argentina. Ecología Austral 1(2): 87-96.

Bonino N. \& A. Sbriller. 1991b. Comparación de las dietas del guanaco, ovino y bovino en Tierra del fuego, Argentina. Turrialba 41(4): 452-457.

Borla M. \& M. Vereda. 2001. Explorando Tierra del Fuego. Zaguier \& Urruty. Ushuaia. 416 pp.

Bravo O., C. Busso, M.V. Lencinas \& G. Martínez Pastur. 2002. Caracterización de suelos en bosques de Nothofagus y sus ambientes asociados en Tierra del Fuego. Actas del XVIII Congreso Argentino de la Ciencia del Suelo. Puerto Madryn. pp. 110.

Brooks K.N., P.F. Ffolliott, H.M. Gregersen \& J.L. Thames. 1991. Hydrology and the management of watersheds. lowa State University Press, lowa (USA). 392p.

Bruno J.E. 1973. La ordenación de cuencas como método de planificación regional. Ex Escuela Superior de Bosques, Universidad Nacional de La Plata. 28 pp.

Calderón G. 1993. La explotación de Nothofagus al tapete. Chile forestal 11(1): 32-33.

Caminos R. 1980. Cordillera fueguina. Geología Regional Argentina, Academia Nacional de Ciencias. Córdoba. Argentina. 2:1463-1501.

Campeau S. \& L. Rochefort. 1996 Sphagnum regeneration on the bare peat surfaces field and greenhouse results. Journal of Applied Ecology 33: 599-608

Cao Q.C. 1993. Estimating coefficients of base-age-invariant site index equations. Canadian Journal of Forest Research 23: 2343-2347.

Carabelli C., P. Peri \& G. Martínez Pastur. 2004. Aspectos sociales de la evaluación del estado de sustentabilidad del manejo actual del bosque fueguino. Secretaría de Ambiente y Desarrollo Sustentable de la Nación, Proyecto PNUD ARG/99/011. $21 \mathrm{pp}$.

Carabelli F. 1991. Estudio bibliográfico sobre lenga (Nothofagus pumilio) con énfasis en aspectos de dinámica y manejo del bosque. Universidad Nacional de la Patagonia - Centro de Investigaciones Forestales. 32 pp. 
Cárdenas de Llano F. L. 1971. Rehabilitación de cuencas. Seminario Latinoamericano de Ordenación de Cuencas Hidrográficas. La Plata, 22 de Noviembre - 16 de Diciembre. Food and Agriculture Organization, Roma. pp. 134-156.

Casaza J \& Crosio H. 1999. Programa de gestión participativa para el desarrollo sustentable: bosques modelo. Seminario Taller Internacional sobre Desarrollo Sostenible en Zonas de Montaña de América Latina, Food and Agriculture Organization - Red Latinoamericana de Cooperación Técnica en Manejo de Cuencas Hidrográficas, Querétaro, México. Actas: 5-16.

Cellini J.M., C.R. Spagarino, G. Martínez Pastur, P. Peri, R. Vukasovic. 1998. Rendimiento de distintos sistemas de aprovechamiento en la corta de protección de un bosque de Nothofagus pumilio. Actas Primer Congreso Latinoamericano de International Union of Forest Research Organizations. Valdivia, Chile. pp. 22-28.

Cellini J.M., G. Martínez Pastur, E. Wabö \& M.V. Lencinas. 2000. Modelos de perfiles de tronco en Nothofagus pumilio y su utilización para el cálculo del volumen total. Actas I Jornadas de Investigación y Extensión de la Facultad de Ciencias Agrarias y Forestales. Universidad Nacional de La Plata. La Plata. pp. 25.

CFI. 1961. Recursos hidráulicos superficiales. Serie: Evaluación de los Recursos Naturales de la Argentina. Primera Etapa, Tomo IV, Vol.2. Buenos Aires. 879p.

CFI 2001a. Elaboración del diagnostico ambiental y las cuentas patrimoniales de la reserva Corazón de la Isla, Provincia de Tierra del Fuego, Antártida e Islas del Atlántico Sur. Contrato de Locación de Obra, Expediente №4.601. Consejo Federal de Inversiones, Buenos Aires, Argentina. $600 \mathrm{pp}$.

CFI 2001b. Plan de Manejo de Reservas Naturales: Inventario y zonificación de la Reserva Corazón de la Isla. informe final. Consejo Federal de Inversiones. 212 pp.

Chapman A. 1987. La Isla de los Estados en la prehistoria; primeros datos arqueológicos. Ed. Eudeba, 123 pp.

Christensen M. \& J. Emborg. 1996. Biodiversity in natural versus managed forest in Danemark. Forest Ecology and Management 85: 47-51.

Ciccacci S., L. D’Alessandro, P. Fredi \& E. Lupia Palmieri. 1992. Relations between morphometric characteristics and denudational processes in some drainage basins of Italy. Z. Geomorph. N.F. 36(1): 53-67.

Clutter J., J. Fortson, L. Pienaar, G. Brister \& R Bailey. 1983. Timber management: a quantitative approach. John Wiley \& Sons, Inc. EE.UU. 333 pp.

Cocimano M., A. Lange \& E. Menvielle. 1975 Estudio sobre equivalencias ganaderas. Producción Animal, Buenos Aires, Argentina. 4: 161-190. 
Coronato A. 1995. Geomorfología glacial de valles de los Andes Fueguinos y condicionantes físicos para la ocupación humana. Tesis Doctoral. Departamento de Geografía, Facultad de Filosofía y Letras, Universidad de Buenos Aires. pp. 318 pp.

Costantino I. 1950. Nothofagus pumilio: estudio forestal y método de tratamiento. Revista de la Facultad de Agronomía de La Plata 27(2): 197-220.

Cozzo D., E. Mutarelli \& E. Orfila. 1969. Plan de investigaciones silvodasocráticas en las etapas de ordenación, recuperación y reproducción económica de los bosques Andino-patagónicos. Plan $n^{\circ}$ 129. Universidad de Buenos Aires y Comisión Administradora del Fondo de Promoción de Tecnología Agropecuaria. 150 pp.

Cuevas J.G. \& M.T.K. Arroyo. 1999. Ausencia de banco de semillas persistente en Nothofagus pumilio (Fagaceae) en Tierra del Fuego, Chile. Revista Chilena de Historia Natural 72: 73-82.

Daniel T.W., J.A. Helms \& F.S. Backer. 1982. Principios de silvicultura. Ed. McGraw-Hill, S. A. de C. V. México. 492 pp.

de la Balze V.M., D.E. Blanco \& N. Loekemeyer. 2004. Aspectos sobre usos y conservación de los turbales patagónicos. pp. 129-140. En: Blanco D. E. \& V. M. de la Balze (Editores). Los turbales de la Patagonia: Bases para su inventario y la conservación de su biodiversidad. Publicación No. 19. Weatlands International. Buenos Aires. Argentina. 150 pp.

Deferrari G., C. Camilión, G. Martínez Pastur \& P. Peri. 2001. Changes in Nothofagus pumilio forest biodiversity during the forest management cycle: Birds. Biodiversity and Conservation 10(12): 2093-2108.

Diaz B.G., P. Peri \& G. Martínez Pastur. 1998. Crecimiento diamétrico en bosques de Nothofagus pumilio en sitios de calidad IV de Patagonia Sur. Actas Primer Congreso Latinoamericano de International Union of Forest Research Organizations. Valdivia, Chile.

Donoso C. 1990. Ecología Forestal: el bosque y su medio ambiente. Ed. Universitaria. Universidad Austral de Chile. Segunda edición. Santiago, Chile. 369 pp.

Eggelsman R. 1988. Rewetting for protection and restauration/regeneration of peatlands after or without peat winning. 8th International Peat Congress, Leningrad, Rusia. pp. 251-260.

Endlicher W. \& A. Santana. 1988. El clima sur de la Patagonia y sus aspectos ecológicos. Un siglo de mediciones climatológicas en Punta Arenas. Anales del Instituto de la Patagonia. Serie Ciencias Naturales. 8: 57-86. 
Espinoza G., P. Pisani, F. Jaksic, P. Inojosa \& C. Soto. 1993. Seminario-Taller sobre Evaluación de Impacto Ambiental. Secretaría Técnica y Administrativa, Comisión Nacional del Medio Ambiente, Santiago. 179 pp.

ESRI. 1998. ArcView version 3.1. Environmental Systems Research Institute Inc., EE.UU.

Etchevere P. 1981. Normas de reconocimiento de suelos. Publicación № 152. Instituto Nacional de Tecnología Agropecuaria, Departamento de suelos. Argentina. $211 \mathrm{pp}$.

Etchevere P. \& C. Miaczynski. 1963. Los suelos de Tierra del Fuego. Instituto Nacional de Tecnología Agropecuaria - Departamento de Suelos y Agrotecnia. Argentina. $142 \mathrm{pp}$.

FAO. 1993. Memorias del Taller Latinoamericano de Extensión en Cuencas Hidrográficas. Acarigua, Venezuela 21-27 Marzo. Documento RLAC/93/34-FOR-44, Santiago, Chile. 58p.

FAO. 1996. Planificación y manejo integrado de cuencas hidrográficas en zonas áridas y semiáridas de América Latina. Publicación Food and Agriculture Organization, Serie: Zonas Áridas y Semiáridas N7. Santiago, Chile. 321p.

Fernández M.C. 1993. Estimación de la erosión hídrica y la torrencialidad de un sistema de cuancas de la Bahía de Ushuaia. Informe de avance, Programa de Recursos Vegetales, CADIC. 49 pp.

Fernández M.C., G. Martínez Pastur, P. Peri \& R. Vukasovic. 1997. Thinning schedules for Nothofagus pumilio forest in Patagonia, Argentina. Actas del XI Congreso Forestal Mundial. Natalia, Turquía. 3: 13-22.

Fernández, M.C., G. Staffieri, G. Martínez Pastur \& P. Peri. 1999. Instituto Nacional de Tecnología Agropecuaria - Universidad Nacional de La Plata - Centro austral de Investigaciones Científicas - Universidad Nacional de la Patagonia Austral. Impacto del manejo forestal en Nothofagus pumilio: 1. Plantas vasculares. XIX Reunión de la Asociación Argentina de Ecología. Horco Molle. pp. 21-23

Ferrando T.M. 1994. Estructura de un bosque de lenga de la XI Región, y rendimiento volumétrico en la corta de protección. Tesis de grado. Facultad de Ciencias Agrarias y Forestales - Universidad de Chile. 57 pp.

Ferrando F.J. 1996: Cuenca Andina del Río Mapocho: Metodología y resultados de la determinación del Factor de Energía de Posición, componente de la Erosividad, a nivel de Microcuencas, Santiago, Chile. Meridiano, Revista de Geografía 3:20-25,

Fitzgerald L.W., H.F. Scharenberg, R. Carranza, J. Menz \& E. Talat. 1972. Planificación y formulación de proyectos. Informe sobre el Seminario Latinoamericano 
de Ordenación de Cuencas Hidrográficas, FAO-AT3112. La Plata, Buenos Aires. Pp. 22-24.

Fournier F. 1960. Debit des cours d'eau, Essai d'estimation de la Perte en Terre subie par l'ensamble du globe terrestre. Internacional Association de Hydrologique Scientifique, 53: 19-22 pp.

Frangi J.L. \& L.L. Richter. 1992. Los ecosistemas forestales de la Tierra del Fuego. Vida Silvestre, Instituto Nacional para la Conservación de la Naturaleza, España. 72(2): 36-43.

Frangi J.L. \& L.L. Richter 1994. Balances hidrológicos de bosques de Nothofagus de Tierra del Fuego, Argentina. Revista de la Facultad de Agronomía (La Plata) 70: 6579.

Franklin, J. 1993. Preserving biodiversity: Species, ecosystems or landscapes?. Ecological Applications 3: 202-205.

Franklin, J. y R. Forman. 1987. Creating landscape patterns by forest cutting: Ecological consequences and principles. Landscape Ecology 1: 5-18.

Eiumnoh A. 2000. Integration of geographic information systems (GIS) and satellite remote sensing (SRS) for watershed management. Food \& Fertilizer Technology Center, Thailand. 11p. http://www.fftc.agnet.org/library/abstract/tb150.html

Franklin, J.F., D.R. Berg, D.A. Thornburgh \& J.C. Tappeiner. 1996. Alternative silvicultural approaches to timber harvesting: variable retention harvest systems p. 111 - 139. En: Creating a forestry for the 21st century. K. Kohm and J. F. Franklin (Eds.). Washington, D.C., Island Press.

Frederiksen P. 1988. Soils of Tierra del Fuego: a satellite-based land survey approach. Folia Geographica Danica. Tomo XVIII. 159 pp.

Gebhard J. 1978. Nociones generales sobre fotografías aéreas, sus características, fotogrametría y sensores remotos. Dirección de Explotación, Dto. Geología Terrestre. 82 pp.

Gil N. 1986. Desarrollo de cuencas hidrográficas y conservación de suelos y aguas. Boletín de Suelos, FAO 44. Roma. 229p.

Godagnone R. \& J. Irisarri. 1990. Mapa de suelos del Territorio Nacional de Tierra del Fuego. En: G. Moscatelli. Atlas de suelos de la República Argentina. SAGyP- Instituto Nacional de Tecnología Agropecuaria -Proyecto PNUD ARG 85/019. Instituto Nacional de Tecnología Agropecuaria. Centro de Investigación en Recursos Naturales (Argentina). 2: 615-641

González L.A. \& R.M. Sepúlveda Manzor. 2003. Hidrología forestal. Universidad de Chile, Facultad de Ciencias Forestales, Departamento de Manejo de Recursos Forestales. $31 \mathrm{pp}$. 
Gutiérrez E. \& M.T. Sebastiá. 1985. On some ecological characteristics of the Nothofagus forests in Tierra del Fuego (Argentina). Informe Técnico - Centro Austral de Investigaciones Científicas. 44 pp.

Gutiérrez E., R.V. Vallejo, J. Romana \& J. Fons. 1991. The subantartic Nothofagus forests of Tierra del Fuego: distribution, structure and production. Oecologia Aquatica 10:353-366.

Henao J.E.S. 1988. Introducción al manejo de cuencas hidrográficas. Publicación de la Universidad Santo Tomás. Bogotá, Colombia. 396p.

Heras R. 1976. Hidrología y recursos hidráulicos. Dirección General de Obras Hidráulicas, Centro de Estudios Hidrográficos. España. 1: 639-793.

Hildebrand-Vogel R., R. Godoy \& A. Vogel. 1990. Subantarctic-Andean Nothofagus pumilio forests. Vegetatio 89: 55-68.

Horton R. 1945. Erosional development of streams and their drainage basins: hydro-physical approach to quantitative geomorphology. Geological Society of America Bulletin. 56: 275-370

INDEC. 2001. Censo Nacional de Población y Vivienda. Censo 2001 Resultados provinciales, Tierra del Fuego, Antártida e Islas del Atlántico Sur. Disponible en http://www.indec.mecon.ar/censo2001s2_2/Datos/94000LC121.xls Ultimo acceso: Marzo de 2005.

Ingram H.A.P. 1992 Introduction to the ecohydrology of mires in the context of cultural perturbation. En: Bragg O.M., P.D. Hulme, H.A.P. Ingram, \& R.A. Robertson (Eds.). Peatland ecosystem and man: an impact assessment. Dundee, U.K. pp. 67-93

INTA. 1991. Grupo de estudios de los suelos con aluminio activo. Tierra del Fuego, Santa Cruz y Magallanes. Informe Técnico. 156 pp.

Iturraspe R., R. Sottini, C. Schröder \& J. Escobar. 1989. Hidrología y variables climáticas del Territorio de Tierra del Fuego. Información básica. Consejo de Investigaciones Científicas y Técnicas - CADIC. Ushuaia, Tierra del Fuego (Argentina). Contribución № 7. pp. 123.

Jaksic F.M., J.A. Iriarte, J.E. Jiménez \& D.R. Martínez. 2002. Invaders without frontiers: cross-border invasions of exotic mammals. Biological Invasions 4: 157-173.

Joosten H. \& D. Clarke. 2002. Wise use of mires and peatlands. Background and principles including a framework for decision making. International Mire Conservation Group and International Peat Society. Finland. 304 pp.

Köppen W. 1936. Das geographische System der Klimate. En: Köppen, W. and Geiger, R. (Eds.) Handbuch der Klimatologie, Gebrüder Borntraeger, Berlin. pp. 1-46.

Lemmon P. 1957. A new instrument for measuring forest overstory density. Journal of Forestry 55(9): 667-668. 
Lencinas M.V., J. Escobar, G. Martínez Pastur, P. Quiroga \& L. Malmierca. 2001a. Dinámica de la vegetación de bosques de Nothofagus en áreas impactadas por Castor canadensis en Tierra del Fuego. XXVIII Jornadas Argentinas de Botánica, Boletín de la Sociedad Argentina de Botánica Santa Rosa 36: 94.

Lencinas M.V., G. Martínez Pastur, C. Busso \& O. Bravo. 2001b. Relaciones entre bosques asociados y productivos en Tierra del Fuego mediante análisis de especies del sotobosque. XXVIII Jornadas Argentinas de Botánica, Santa Rosa, Boletín de la Sociedad Argentina de Botánica 36: 95.

Lencinas M.V., G. Martínez Pastur, C. Busso \& P. Rivero. 2001c. Frecuencia de ocurrencia de especies del sotobosque en bosques de Nothofagus pumilio de Tierra del Fuego (Argentina). Actas XX Reunión de la Asociación Argentina de Ecología. Bariloche (Argentina). pp. 145.

Lencinas M.V., G. Martínez Pastur, E. Gallo \& C. Busso. 2001d. Riqueza y cobertura del sotobosque en un rango de calidades de sitio en bosques de Nothofagus pumilio. XXVIII Jornadas Argentinas de Botánica, Santa Rosa. En: Boletín de la Sociedad Argentina de Botánica 36: 95.

Liu Q.J., A. Kondoh, N. Takeuchi. 1998. The forest vegetation and its differentiation under disturbance in a temperate mountain, China. Journal of Forest Research 3: 111-117.

Lizarraide M. 1993. Current status of the introduced beaver (Castor canadensis) population in Tierra del Fuego. Ambio 22(6):351-358.

Lizarralde M., G.A. Deferrari, S.E. Álvarez \& J.M. Escobar. 1996. Effects of beaver (Castor canadensis) on the nutrient dynamics of the Southern Beech forest of Tierra del Fuego (Argentina). Ecología Austral 6:101-105

Lizarralde M., J.M. Escobar \& O. Bianciotto. 1989. El castor (Castor canadensis) en Tierra del Fuego: efectos de alteración ambiental y su aprovechamiento como recurso natural. En: Libro del Proyecto Extremo Oriental del Archipiélago Fueguino, Ed. Haniss. Museo del Fin del Mundo. 21 pp.

Lizarralde M. \& J.M. Escobar. 2000. Mamíferos exóticos en la Tierra del Fuego. Ciencia Hoy. 10(56): 56.

Lizarralde M., J.M. Escobar \& G.A. Deferrari. 2004. Invader species in Argentina: a review about the beaver (Castor canadensis) population situation on Tierra del Fuego ecosystem. Interciencia. 29 (7): 352-356.

Loguercio G.A. 1995. Crecimiento de la regeneración natural de la Lenga (Nothofagus pumilio [Poepp. et Endl.] Krasser) y su dependencia de las condiciones dominantes de radiación. Publ. Técn. N²1 CIEFAP: Regeneración natural de la Lenga: factores ecológicos. Esquel, Chubut. 1-47. 
Looijen H., A. Boom, J. Abreu, U. Kosir \& O. Stan. 1998. A soil erosion risk analysis on a big scale in a small area near Lammi, Southern Finland. Proc. 10th EGEA Congress, 19-27 September, Finland. 6pp.

Llamas J. 1993. Hidrología general, principios y aplicaciones. Características físicas de una cuenca hidrográfica. Servicios edit. Universidad del País Vasco, España. 59-85.

Maderey L.E.R. 1973. Obtención de los elementos que influyen en el régimen hidrológico. Instituto de Geografía, Universidad Nacional Autónoma de México. 2: 166176.

Madrigal A. 1992. Selvicultura de hayedos. Actas del Congreso Internacional del Haya. Pamplona-Navarra.1: 33-60.

Marcolín A., J. Ayesa, C. López, D. Bran \& M. Faria. 1996. Zonificación del potencial Forestal de las Tierras del Centro y Sur del Depto. Minas (Pcia. del Neuquén). Informe Técnico Instituto Nacional de Tecnología Agropecuaria Estación Experimental Agraria Bariloche. 29pp

Mariottini Y., M.V. Lencinas, G. Massaccesi, E. Gallo, I. Gamondès, L. Larralde \& G. Martínez Pastur. 2002. Cambios en la diversidad del sotobosque de Nothofagus pumilio debido a la aplicación de una corta de protección a lo largo del gradiente de calidades de sitio. Primer Congreso Chileno de Ciencias Forestales. Santiago, Chile.

MARNR-CIDIAT. 1984. Diagnóstico Físico Conservacionista en Cuencas Hidrográficas. Centro Interamericano de Desarollo e Investigacion Ambiental y Territorial. Mérida. 63 pp.

Martín C. 1994. Guía para la elaboración de planes de manejo. Ministerio de Desarrollo Sostenible y Medio Ambiente. Proyecto de conservación de la Biodiversidad. La Paz, Bolivia. 38 pp.

Martínez Pastur G. 1999. Biometría del inventario forestal de la provincia de Tierra del Fuego. Campaña 1996-1997. Informe Técnico. Dirección de Bosques Subsecretaría de Recursos Naturales y Ambiente Humano - Secretaría de Desarrollo y Planeamiento - Gobierno de la Provincia de Tierra del Fuego, Antártida e Islas del Atlántico Sur, Argentina. 25 pp.

Martínez Pastur G., C. Fernández \& P. Peri. 1994. Variación de parámetros estructurales y de composición del sotobosque para bosques de Nothofagus pumilio en relación a gradientes ambientales indirectos. Ciencias Forestales 9 (1-2): 11-22.

Martínez Pastur G., P. Peri, R. Vukasovic, J.M. Cellini, C. Spagarino \& D. Sharpe. 1997a. Funciones de rendimiento volumétrico para un bosque de Nothofagus pumilio de calidad III y un aserradero mediano en Tierra del Fuego. $I^{\circ}$ Congreso Forestal 
Argentino y Latinoamericano. Tomo Industria y Comercio. Posadas, 13-15 Agosto. 123-132.

Martínez Pastur G., P. Peri, R. Vukasovic, S. Vaccaro \& V. Piriz Carrillo. 1997b. Site index equation for Nothofagus pumilio Patagonian forest. Phyton 6(1/2): 55-60.

Martínez Pastur G., P. Peri, C. Fernández, G. Staffieri. 1999a. Desarrollo de la regeneración a lo largo del ciclo del manejo forestal de un bosque de Nothofagus pumilio: 1. Incidencia de la cobertura y el aprovechamiento o cosecha. Bosque 20(2): 39-46.

Martinez Pastur G., P. Peri, C. Fernández, G. Staffieri \& D. Rodriguez. 1999b. Desarrollo de la regeneración a lo largo del ciclo del manejo forestal de un bosque de Nothofagus pumilio: 2. Incidencia del ramoneo de Lama guanicoe. Bosque 20(2): 4753.

Martínez Pastur G., J.M. Cellini, P. Peri, R. Vukasovic \& M.C. Fernández. $2000 a$. Timber production of Nothofagus pumilio forests by a shelterwood system in Tierra del Fuego (Argentina). Forest Ecology and Management 134(1-3): 153-162.

Martínez Pastur G., M.V. Lencinas, R. Vukasovic, P. Peri \& C. Fernández. 2000 b. Incorporación de la altura dominante y de la clase de sitio en la construcción de ecuaciones estándar de volumen total y de fuste en Nothofagus. Actas Reunión Internacional: Modelos y Métodos Estadísticos Aplicados a Bosques Naturales. Valdivia, Chile. pp. 18-19.

Martínez Pastur G., P. Peri, R. Vukasovic, M.V. Lencinas, B.G. Diaz \& J.M. Cellini. 2000c. Modelo de producción y rendimiento para bosques de Lenga bajo manejo a lo largo de un gradiente de calidad de sitio. Actas Reunión Internacional: Modelos y Métodos Estadísticos Aplicados a Bosques Naturales. Valdivia, Chile. pp. 22-23.

Martínez Pastur G., J.M. Cellini, M.V. Lencinas, R. Vukasovic, R. Vicente, F. Bertolami \& J. Giunchi. 2001. Modificación del crecimiento y de la calidad de fustes en un raleo fuerte de un rodal en fase de crecimiento óptimo inicial de Nothofagus pumilio. Ecología Austral 11: 95-104.

Martinez Pastur G., J.M. Cellini, M.V. Lencinas, B.G. Diaz, P. Peri \& R. Vukasovic. 2001-2002. Funciones de rendimiento volumétrico en pie y en aserradero la lenga (Nothofagus pumilio). Ciencias Forestales 15(1-2): 32-45.

Martínez Pastur G., M.V. Lencinas, J.M. Cellini, B.G. Diaz, P. Peri \& R. Vukasovic. 2002a. Herramientas disponibles para la construcción de un modelo para la lenga (Nothofagus pumilio) bajo manejo en un gradiente de calidades de sitio. Bosque 23(2):69-80. 
Martínez Pastur G., P. Peri, M.C. Fernández, G. Staffieri \& M.V. Lencinas. 2002b. Changes in understory species diversity during the Nothofagus pumilio forest management cycle. Journal of Forest Research. 7(3): 165-174.

Martínez Pastur G., M.V. Lencinas, R. Vukasovic, P. Peri, B. Diaz \& J.M. Cellini. 2004. Turno de corta y posibilidad de los bosques de lenga (Nothofagus pumilio) el Tierra del Fuego (Argentina). Bosque 25(1):29-42.

Mati B.M., R.P. Morgan, F.N. Gichuki, J.N. Quinton, T.R. Brewer \& H.P. Liniger. 2000. Assessment of erosion hazard with USLE and GIS: A case of study of the Upper Ewaso Ng'iro North basin of Kenya. JAG 2(1): 1-9.

Matteri C.M. \& M.M. Schiavone. 1988. Comunidades muscinales del suelo de los bosques de Nothofagus fueguinos. Monografías de la Academia Nacional de Ciencias Exactas, Físicas y Naturales. Sección de Ciencias Químicas, de la Tierra y Biológicas. 4: 25-36.

McDill M. \& R. Amateis. 1992. Measuring forest site quality using the parameters of a dimensionally compatible height growth function. Forest Science 38(2): 409-429.

Mcnulty G. \& G. Sun. 1998. The development and use of best practices in forest watersheds using GIS and simulation models. Int. Symposium on Comprehensive Watershed Management, 7-10 September, Beijing, China. Proceedings, 391-398.

Meade R. 1992. Some early changes following the reweting of a vegetated cutover peatland surface at Danes Moss, Cheshire, UK, and their relevance to conservation management, Biological Conservation 61:31-40

Méndez V. 1978. Reconocimiento geológico preliminar del territorio de Tierra del Fuego. Dirección de Fabricaciones Militares. Subdirección de Desarrollo Minero. Departamento de Geología y Minería. 35 pp.

Ministère De L'education Nationale. 1995. Titus v1.03a, France.

Mintegui J.A. \& Unzu F.L. 1990. La ordenación agrohidrológica en la planificación. Depto. Agricultura y Pesca, Gobierno Vasco, España. 306p.

Mitasova H., J. Hofierka, M. Zlocha \& R.L. Iverson. 1996. Modeling topographic potential for erosion and deposition using GIS. Int. Journal of Geographical Information Science, 10(5): 629-641.

Molchanov A.A. 1963. Hidrologia florestal. Fundação Calouste Gulbenkian, Lisboa, Portugal. 419p. Trad. de The hydrological role of forests. Jerusalem, Israel Program of Scientific Translations.

Moore, D.M. 1983. Flora of Tierra del Fuego. Anthony Nelson, Inglaterra Missouri Botanical Garden, EE.UU. 396 pp. 
Mosqueda C. 1995. Rendimientos volumétricos en el raleo de un bosque de lenga (Nothofagus pumilio) en la XII Región. Tesis de grado. Universidad de Chile, Santiago, Chile. 68 pp.

Mutarelli E.J. \& E. Orfila. 1971. Observaciones sobre la regeneración de Lenga, Nothofagus pumilio (Poepp. et Endl.) Oerst., en parcelas experimentales del Lago Mascardi, Argentina. Revista Forestal Argentina 15(4): 109-115.

Mutarelli E. \& E. Orfila, 1973. Algunos resultados de las investigaciones de manejo silvicultural que se realizan en los bosques andino-patagónicos de Argentina. Revista Forestal Argentina 17(3): 69-75.

Nick K.J. 1984. Measures and chances of success for the regeneration of bogs after the complete industrial cutting of peat. 7th International Peat Congress. The Irish National Peat Committee and The International Peat Society, Dublín, Ireland. pp. 331338.

Norton D.A. \& W. Schönenberger, 1984. The growth froms and ecology of Nothofagus solandri at the alpine timberline, Craigieburn range, New Zeland, Arctic Alpine Research 16:361-370.

Okruszko H. 1995. Influence of hydrologic differentiation of fens on their transformation after dehydration and on possibilities for restoration. En: Wheeler B.D., S.C. Shaw, W. Fojt \& R.A. Robertson (Eds.). Restoration of temperate wetlands. John Wiley \& Sons. Chichester, U.K. pp. 113-119.

Orquera L.A. \& E.L. Piana. 1999. La vida material y social de los Yámana. Ed. Eudeba. Inst. Fueguino de Inv. Científicas. 567 pp.

Otero A.M. 1997. Gestión estratégica de las áreas protegidas. I Congreso Latinoamericano de Parques Nacionales y otras Áreas Protegidas. Documento de discusión. Santa Marta, Colombia. Disponible en http://investigadores.uncoma.edu.ar/plan_desarr_turistico/Colomdoc.html Ultimo acceso: Marzo de 2005.

Peri P. \& G. Martínez Pastur. 1996. Crecimiento diamétrico de Nothofagus pumilio para dos condiciones de copa en un sitio de calidad media en Santa Cruz, Argentina. Investigación Agraria: Sistemas y Recursos Forestales 5(2): 201-212.

Peri P., G. Martínez Pastur, B. Díaz \& F. Fucaraccio. 1997. Uso del Índice de Sitio para la construcción de ecuaciones estándar de volumen total de fuste para lenga (Nothofagus pumilio) en Patagonia Austral. Actas II Congreso Forestal Argentino y Latinoamericano. Tomo Bosques Nativos y Protección Ambiental. Posadas, Misiones (Argentina). 309-316. 
Peri P., G. Martínez Pastur, R. Vukasovic, B. Díaz, M.V. Lencinas \& J.M. Cellini. 2002. Thinning schedules to reduce risk of windthrow in Nothofagus pumilio forests of Patagonia, Argentina. Bosque 23(2): 19-28.

Piriz Carrillo V., S. Vaccaro \& G. Martínez Pastur. 1996. Informe Técnico: Funciones de volumen total y crecimiento diamétrico para bosques de segundo crecimiento de Nothofagus pumilio en Tierra del Fuego. Laboratorio de Propagación y Producción Vegetal - Centro Austral de Investigaciones Científicas. 13 pp.

Pisano E. 1997. Los bosques de Patagonia Austral y Tierra del Fuego chilenas. Anales del Instituto de la Patagonia, Serie Ciencias Naturales 25: 9-19.

Price J. S. 1996. Hydrology and micro climate of a partly restored cutover bog, Québec. Hydrologic Proceses 10:1263-1272

Prodan M., R. Peters, F. Cox \& P. Real. 1997. Mensura Forestal. GTZ/IICA. Serie Investigación y Educación en Desarrollo Sostenible. San José, Costa Rica. 586 pp.

Pulido F., B.G. Diaz \& G. Martínez Pastur. 2000. Incidencia del ramoneo del guanaco (Lama guanicoe) sobre la regeneración de Lenga (Nothofagus pumilio) en bosques de Tierra del Fuego, Argentina. Investigación Agraria: Sistemas y Recursos Forestales 9(2): 381-394.

Quinty F. \& L. Rochefort. 1997. Plant reintroduction on a Harvested peat bog. En: Trettin C.C., M.R. Gale, D.R. Grigal, J.K. Jeglum \& M.G. Jurgense. Ecology and management: Forested wetlands. Lewis publishers. Boca Raton, Florida. pp: 137-150

Rabassa J., C.J. Heusser \& N. Rutter. 1990. Late-glacial and Holocene of Tierra del Fuego. Quaternary of South America and Antarctic Peninsula 7, 327-351

Rabassa J., A. Coronato, G. Bujalesky, M. Salemme, C. Roig, A. Meglioli, C. Heusser, S. Gordillo, F. Roig, A. Borromei \& M. Quattrocchio. 2000. Quaternary of Tierra del Fuego, Southernmost South America: an updated review. Quaternary International, 68-71: 217-240

Rebertus A. \& T. Veblen. 1993. Structure and tree-fall gap dynamics of oldgrowth Nothofagus forests in Tierra del Fuego, Argentina. Journal of Vegetation Science 4: 641-654.

Rebertus A., T. Kitzberger, T. Veblen \& L. Roovers. 1997. Blowdown history and landscape patterns in the Andes of Tierra del Fuego, Argentina. Ecology 78(3): 678692.

Rechene C. 1995. Establecimiento y desarrollo de renovales de Lenga en situaciones de baja cobertura. Publ. Técn. N²1. Centro de Investigación y Extensión Forestal Andino. Regeneración natural de la Lenga: factores ecológicos. Esquel, Chubut. 75-114. 
Reineke L.1933. Perfecting a stand-density index for even-aged forests. Journal of Agricultural Research 16(7): 627-638.

Renard K.G., G.R. Foster, G.A. Weesies, D.K. McCool \& D.C. Yoder. 1997. Predicting soil erosion by water: A guide to conservation planning with the Revised Universal Soil Loss Equation (RUSLE). US Dept. of Agriculture, Agriculture Handbook No703: 404p.

Rice R. J. 1983. Fundamentos de Geomorfología. Ed. Paraninfo, Madrid, España. 96-212 pp.

Richter L.L. \& J.L. Frangi. 1992. Bases ecológicas para el manejo del bosque de Nothofagus pumilio de Tierra del Fuego. Revista de la Facultad de Agronomía, La Plata. Tomo 68: 32-52.

Rivero P., M.V. Lencinas, S. Medina, F. Rojas Molina, R. Sottini, G. Martínez Pastur, M.C. Marozzi \& C. Busso. 2000a. Variación en el sotobosque de los ambientes asociados al bosque productivo de Nothofagus pumilio en Tierra del Fuego: 1. Riqueza de especies. Actas VII Jornadas de Ciencias Naturales del Litoral. Santa Fe, Argentina. pp. 75.

Rivero P., M.V. Lencinas, S. Medina, F. Rojas Molina, R. Sottini, G. Martínez Pastur, M.C. Marozzi \& C. Busso. 2000b. Variación en el sotobosque de los ambientes asociados al bosque productivo de Nothofagus pumilio en Tierra del Fuego: 2. Abundancia y biomasa. Actas VII Jornadas de Ciencias Naturales del Litoral. Santa Fe, Argentina. Pp. 76.

Rochefort L., R. Gauthier \& D. Lequéré. 1995. Sphagnum regeneration - Toward an optimization of bog restoration. En: Wheeler B. C., S.C. Shaw, W.J. Fojt \& R.A. Robertson. Restoration of temperate wetlands. John Wiley \& Sons. Chichester, U.K. pp: $423-434$

Roig F. 1998. La vegetación de la Patagonia. En: Correa, M. Flora Patagónica. Instituto Nacional de Tecnología Agropecuaria, Colección Científica. Tomo VIII, 1: 48174.

Rothkugel M. 1916. Los Bosques Andino Patagónicos. Ministerio de Agricultura. Dirección General de AGricultura y Defensa Agrícola. Buenos Aires. 207 pp.

Rusch V.E. 1987. Estudio sobre la regeneración de la Lenga (Nothofagus pumilio) en la cuenca del Río Manso Superior, Pcia. de Río Negro. Consejo de Investigaciones Científicas y Técnicas: Informe final de Beca de Iniciación. Buenos Aires, Argentina. $113 \mathrm{pp}$.

Rusch V.E. 1989. Determinación de las transiciones de estado en bosques de lenga (Nothofagus pumilio). Consejo de Investigaciones Científicas y Técnicas. Informe final Beca de Perfeccionamiento, $75 \mathrm{pp}$. 
Sabins F. 1987. Remote sensing, principles \& interpretation. $2^{\circ}$ Ed. W.H. Freeman \& Co. New York, EE.UU. 449 pp.

Sagot C. \& L. Rochefort. 1996 Tolérance des Sphagnes à la dessiccation. Cryptogamie Bryol. Lichenol. 17:171-183

SAGyP - INTA 1990. Atlas de Suelos de la República Argentina. United Nations Population Division project. Arg-85/019, Buenos Aires. 1600 pp.

Sala O.E., M.E. Biondini \& W.K. Lauenroth. 1988. Bias in estimates of primary production: an analytical solution. Ecological Modelling 44, 43-55.

Schlatter J.E. 1994. Aspectos de regeneración de Haya y Lenga - una comparación. Actas del Seminario de Manejo Forestal de la lenga y Aspectos Ecológicos relacionados. Esquel, Argentina. pp. 74-84.

Schlitcher T.M. 1988. Impacto del pastoreo del ganado bovino y ovino sobre el bosque de Nothofagus sp. en Santa Cruz. Informe Parcial Consejo Federal de Inversiones, Buenos Aires. 16 pp.

Schmidt H. 1997. Aprovechamiento y sustentabilidad productiva en el bosque de Lenga en Magallanes. Conferencia Internacional. Sistemas de producción forestal: Análisis, cuantificación y sustentabilidad. Talca, Chile. 7 pp.

Schmidt H. \& A. Urzúa. 1982. Transformación y Manejo de los Bosques de Lenga en Magallanes. Universidad de Chile. Ciencias Agrícolas $n^{\circ} 11.62$ pp.

Schmidt H., J. Caldentey \& T.P. Gaertig. 1992. Informe Lenga 1992: Análisis silvicultural de los ensayos. Universidad de Chile - Corporación Nacional Forestal. 37 pp.

Schmidt H. \& J. Caldentey. 1994. Apuntes 3er. Curso de Silvicultura de los Bosques de Nothofagus pumilio. Corporación Nacional Forestal- Corporación Chilena de Madera - Universidad de Chile, 12-22 enero. 108 pp.

Schmidt H., J. Caldentey \& S. Donoso. 1994. Investigación aplicada sobre el manejo de la Lenga en la XII ${ }^{\circ}$ Región. Informe Técnico U. de Chile - Corporación Nacional Forestal, Chile. 35 pp.

Schouwenaars J.M. 1993. Hydrologic differences between bogs and bog-relicts and consequences for bog restoration. Hidrobiología 265:217-224

Secretaría de Turismo de la Municipalidad de Ushuaia, 2005a. Informe Estadístico 2004-2005, Características de la Demanda Turística. http:// www.eushuaia.com/estadisticas/cap3.pdf [Consulta: Noviembre 2005].

Secretaría de Turismo Municipalidad de Ushuaia, 2005b. Temporada de turismo 2004 - 2005. http://www.e-ushuaia.com/estadisticas/sintesis20042005_1.pdf [Consulta: Noviembre 2005]. 
Sheridan G.J. \& C.J. Rosewell. 2003. An improved Victorian erosivity map. Australian Journal of Soil Research 41: 141-149.

Silva M.F.F. 1987. Estudos botânicos em Carajás. In: SEMA/IWRB/CVRD, Desenvolvimento econômico e impacto ambiental em áreas de trópico úmido brasileiro: a experiência da CVRD. Rio d Janeiro, pp. 93-99.

Skrt M.V., G. Staffieri, P. Ferrere, G. Martinez Pastur \& P. Peri. 1997. Incidencia de la cobertura, el aprovechamiento y el ramoneo de Lama guanicoe sobre la regeneración de un bosque de Nothofagus pumilio. Actas II Congreso Forestal Argentino y Latinoamericano. Tomo Bosques Nativos y Protección Ambiental. Posadas, Misiones, Argentina. 13-15 Agosto. 149-162.

Smith R.A. \& M.V. Vélez. 1997 Hidrología de Antioquia. Medellín, Colombia. Secretaría de Obras Públicas de Antioquia. pp. 28-46.

Soil Survey Staff. 1999. Soil Taxonomy. Agriculture Handbook Number 436. United States Department of Agriculture - National Spatial Reference System. Second Edition, EE.UU. 869 pp.

Spagarino C., G. Martínez Pastur \& P. Peri. 2001. Changes in Nothofagus pumilio forest biodiversity during the forest management cycle: Insects. Biodiversity and Conservation 10(12): 2077-2092.

Strahler A.N. 1979. Geografía Física. Editorial Omega. Barcelona. 521-538 pp.

Sun G. \& S.G. Mcnulty. 1998. Modeling soil erosion and transport on forest landscape. Proc. of IECA - International Erosion Control Association, Nevada, EE.UU. pp. 187-198.

Thorbury W. D. 1960. Principios de geomorfología. Editorial Kapeluz. Buenos Aires, Argentina. 36-70: 104-185 pp.

Tortorelli L. 1956. Maderas y Bosques Argentinos. ACME, Buenos Aires. 920 pp.

TRAGSA, TRAGSATEC \& Ministerio de Medio Ambiente. 1998. Restauración hidrológico-forestal de cuencas y control de la erosión. Ed. Mundi-Prensa, Madrid, España. 945p.

Tuhkanen S., I. Kuokka, J. Hyvonen, S. Stenroos \& J. Niemela. 1989-1990. Tierra del Fuego as a target for biogeographical research in the past and present. Anales del Instituto de la Patagonia 19(2): 107.

UNESCO. 1998. Bilko for Windows v2.0. Pharos Scientific Ltd., EE.UU.

Vammiere B. \& A. Maurette. 1995. Auditoría Ambiental a los Bosques Nativos de Lenga de la Patagonia. Office National des Forêts (ONF). París, Francia. pp. 58

Vázquez D.P. 2002. Multiple effects of introduced mammalian herbivores in a temperate forest. Biological Invasions 4: 175-191. 
Veblen T., M. Mermoz, C. Martín \& E. Ramilo. 1989. Effects of exotic deer on forest regeneration and composition in northern Patagonia. Journal of Applied Ecology 26: 711-724.

Veblen T., M. Mermoz, C. Martín \& T. Kitzberger. 1992. Ecological impacts of introduced animals in Nahuel Huapi National Park, Argentina. Conservation Biology 6(1): 71-83.

Veblen T.T., C. Donoso, T. Kitzberger \& A.J. Rebertus. 1996. Ecology of Southern Chilean and Argentinean Nothofagus Forests. En: The ecology and biogeography of Nothofagus forests. Veblen T.T., R.S. Hill \& J. Read. Yale University Press, New Heaven, London. pp. 292-353.

Vergara J.D.U. 1992. Uso múltiple de los recursos naturales de la Cuenca Binacional del Puelo (Río Negro, Chubut - X`Región). Publicación Centro de Investigación y Extensión Forestal Andino. Esquel, Chubut. 152p.

Vich A.J. 1989. Erosión hídrica: estimación y medición de pérdidas de suelo. Curso Latinoamericano sobre Detección y Control de la Desertización. Fidel A. Roig (Ed.) CRICYT, Mendoza. pp. 118-130.

Wheeler B.D. \& S.C. Shaw. 1995. Restoration of damaged peatlands. HMSO, London, UK. pp. 211.

Wigley T.B. \& T.H. Roberts. 1997. Landscape-level effects of forest management on faunal diversity in bottomland hardwoods. Forest Ecology and Management 90: 141-154.

Wijesekera S. \& L. Samarakoon. 2001. Extraction of parameters and modelling soil erosion using GIS in a grid environment. 22nd Asian Conf. Remote Sensing, 5-9 November, Singapore. $6 \mathrm{pp}$.

Yorio P., A. Tagliorete, G. Harris \& M. Giaccardi. 1998. Áreas Protegidas costeras de la Patagonia: Síntesis de información, diagnosis sobre su estado actual de protección y recomendaciones preliminares. Informes Técnicos del Plan de manejo Integrado de la Zona Costera Patagónica. Fundación Patagonia Natural, Puerto Madryn, Argentina 39: 1-70. 


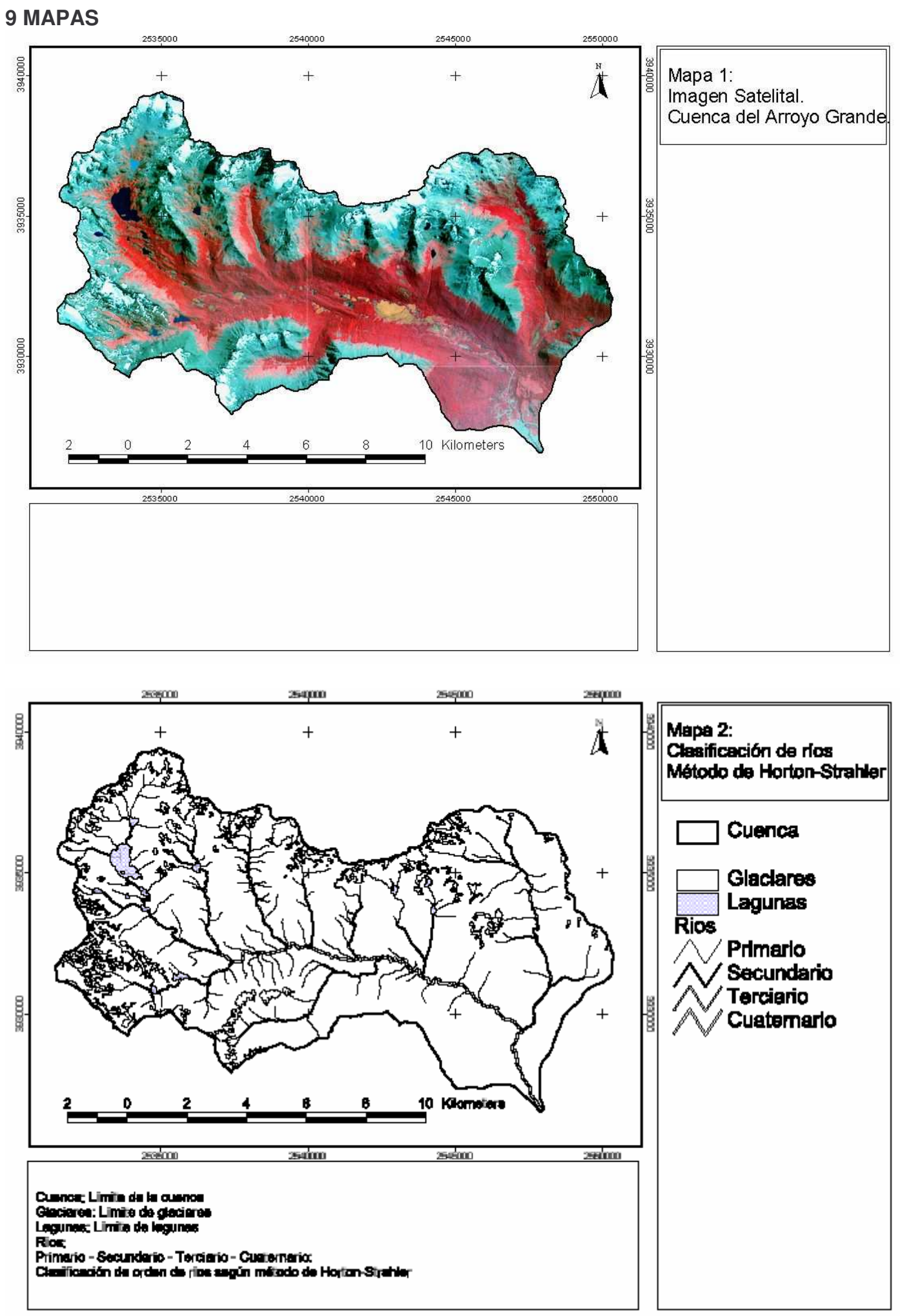




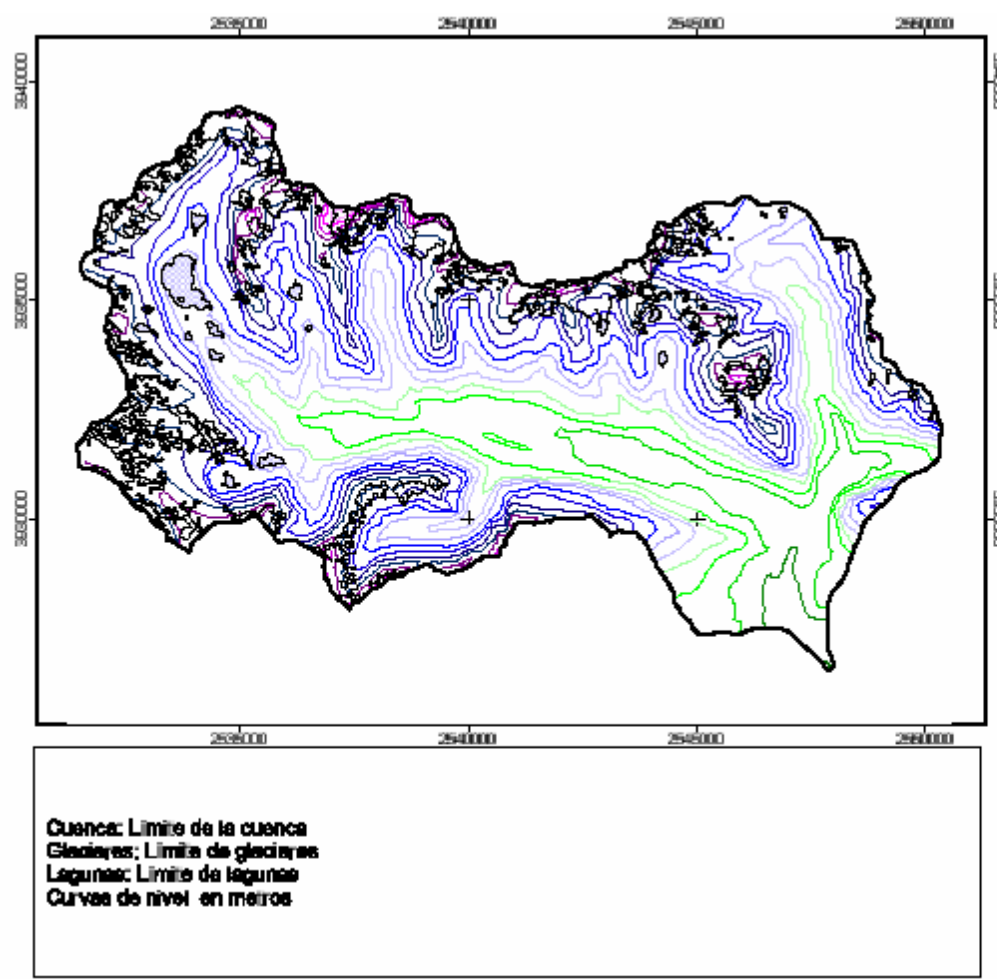

Mape 3

Curvas de nivel

(Equidistancia $100 \mathrm{~m}$ )

$\square$ Cuence

\begin{tabular}{l}
$\square$ Claciares \\
\hline Curvas de Nivel
\end{tabular}

$\triangle 0$

$\widehat{\triangle}_{100}^{0}$

200

300

400

500

600

700

$\checkmark 800$

900

1000

1100

1200

1300

1400

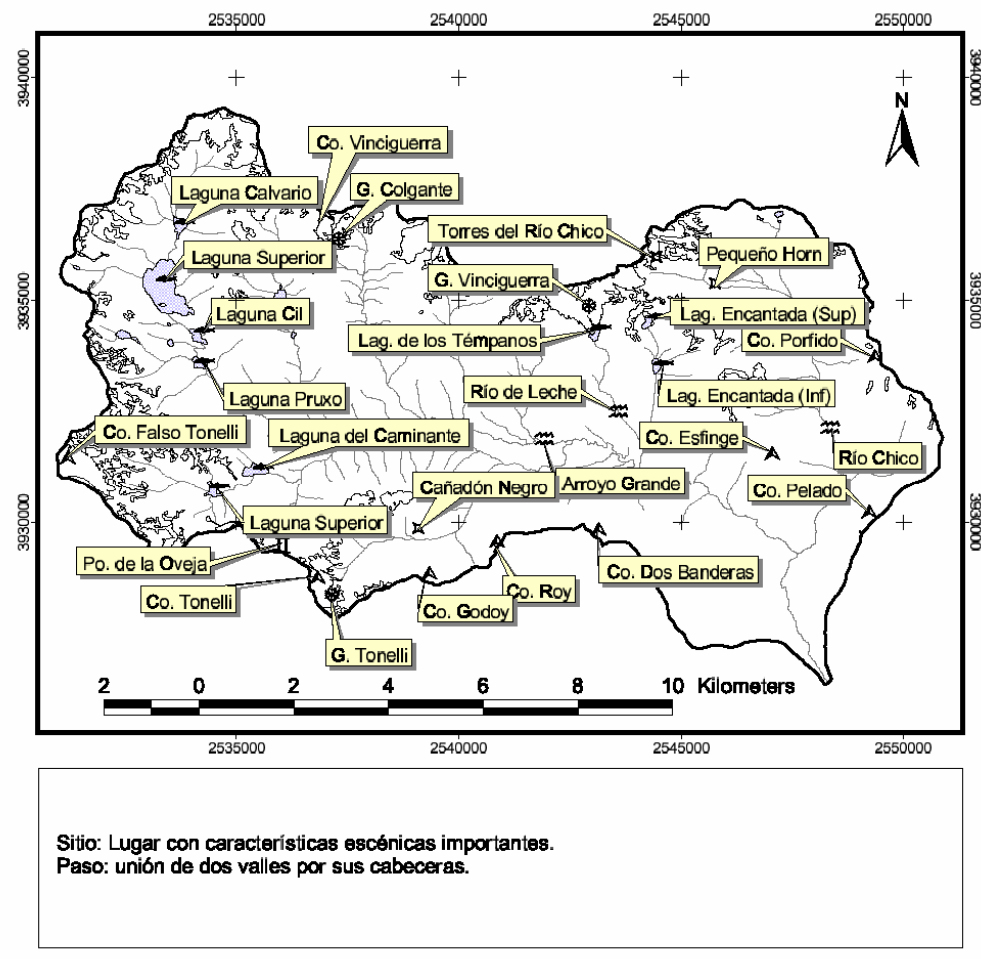

Mapa 4

Nombres de

accidentes geográficos

- Laguna

a Sitio

II Paso

A Cerro

- Glaciar

* Curso de agua

Cuenca

Glaciares

Lagunas

Rios 


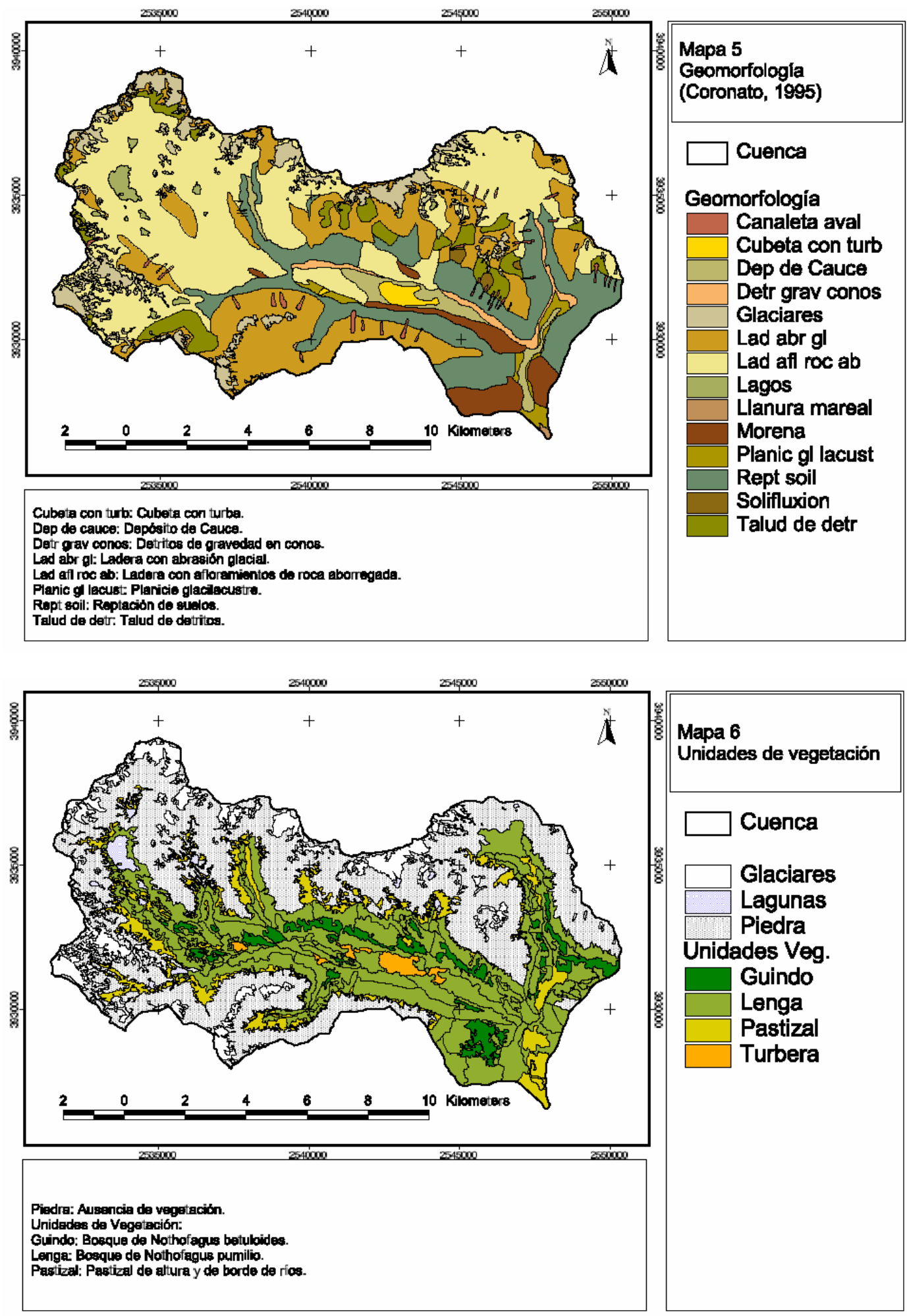




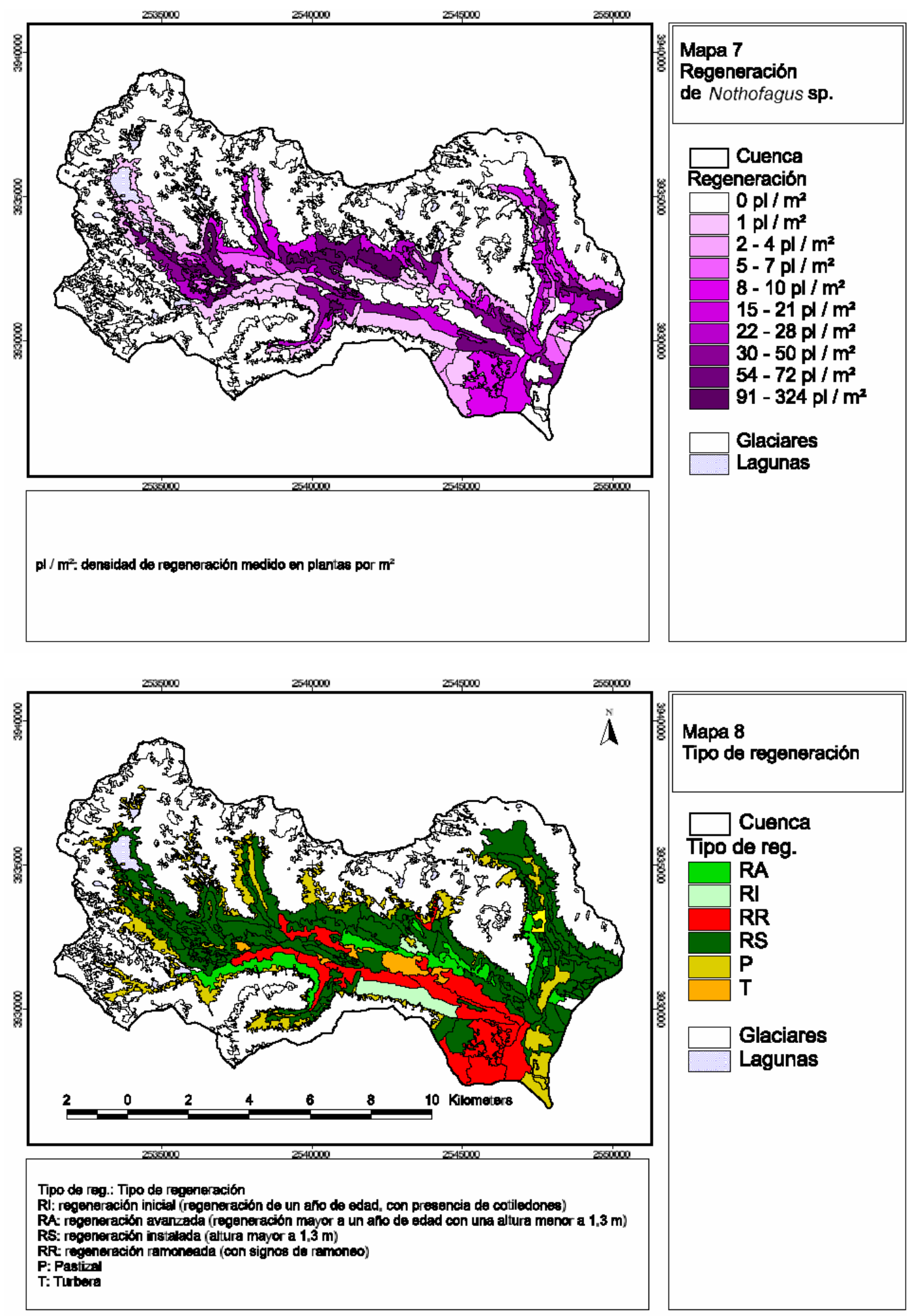




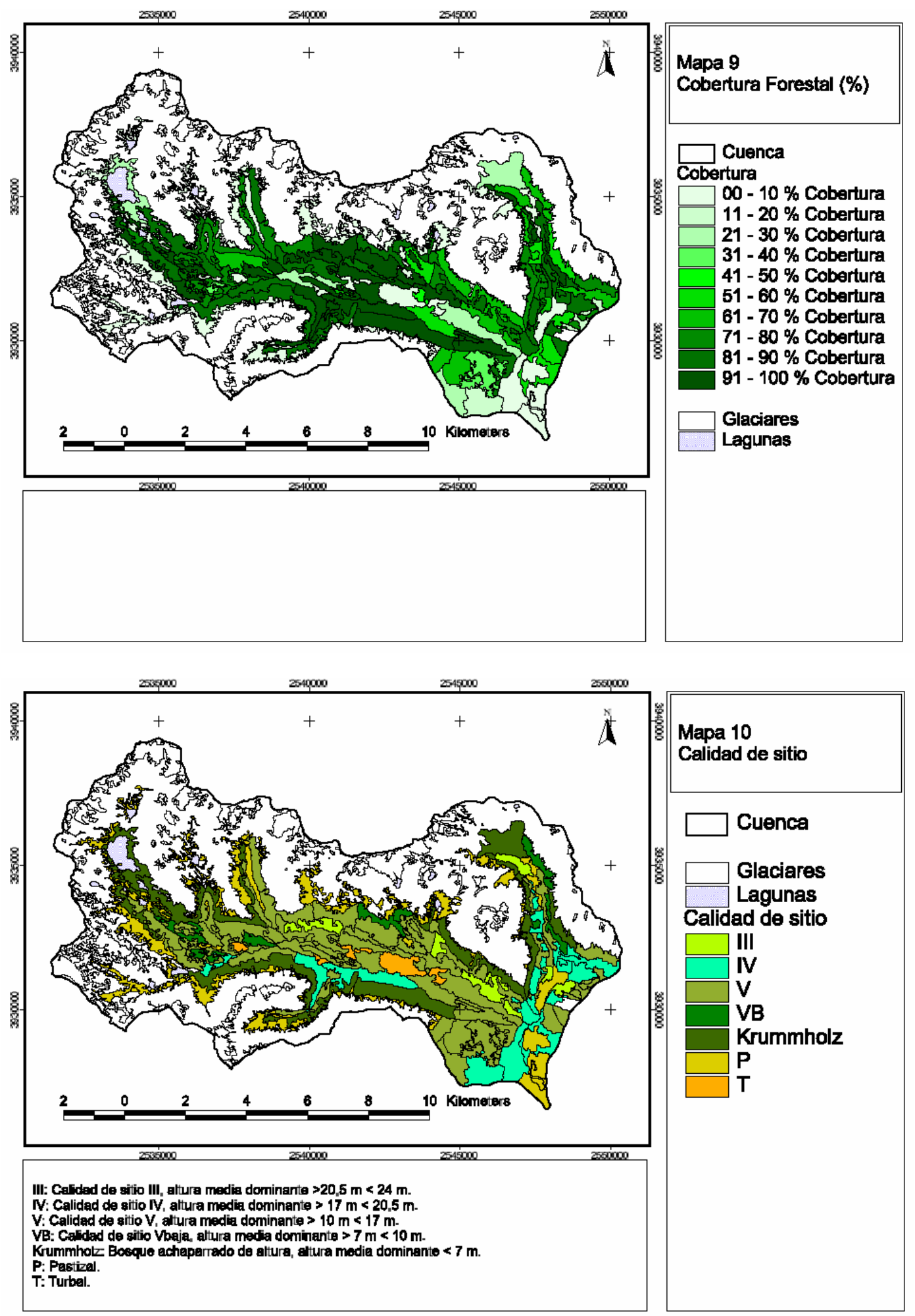




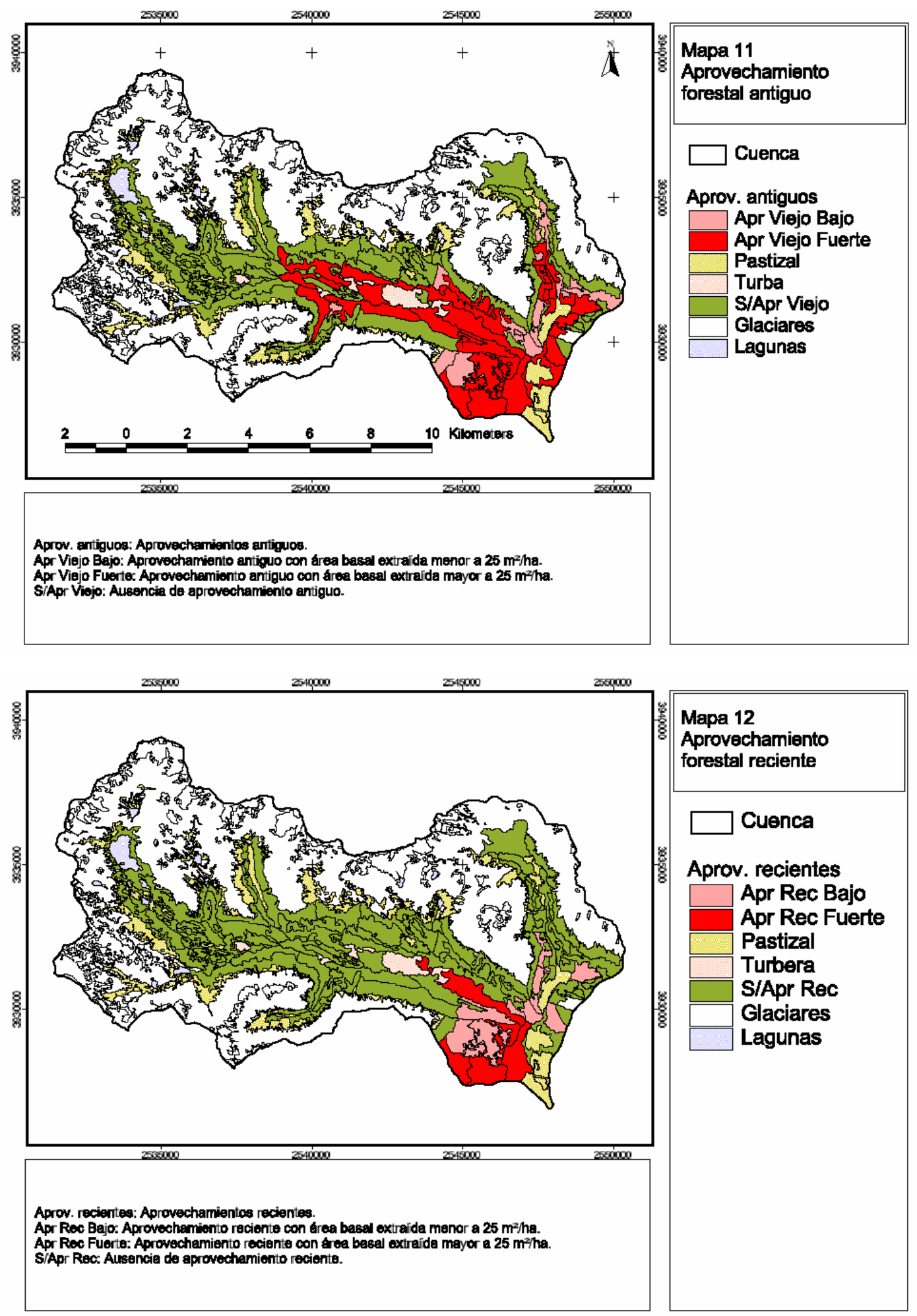




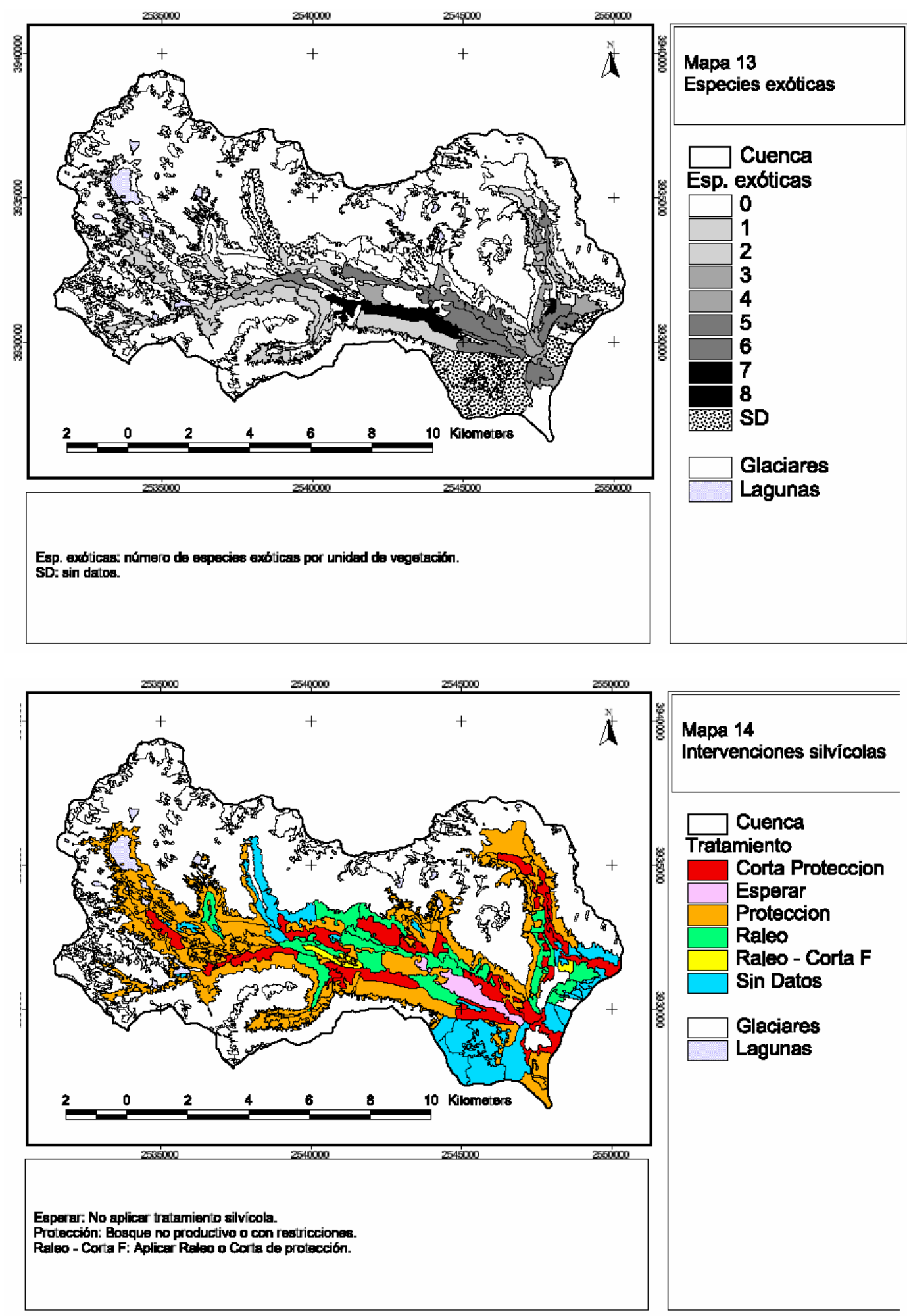




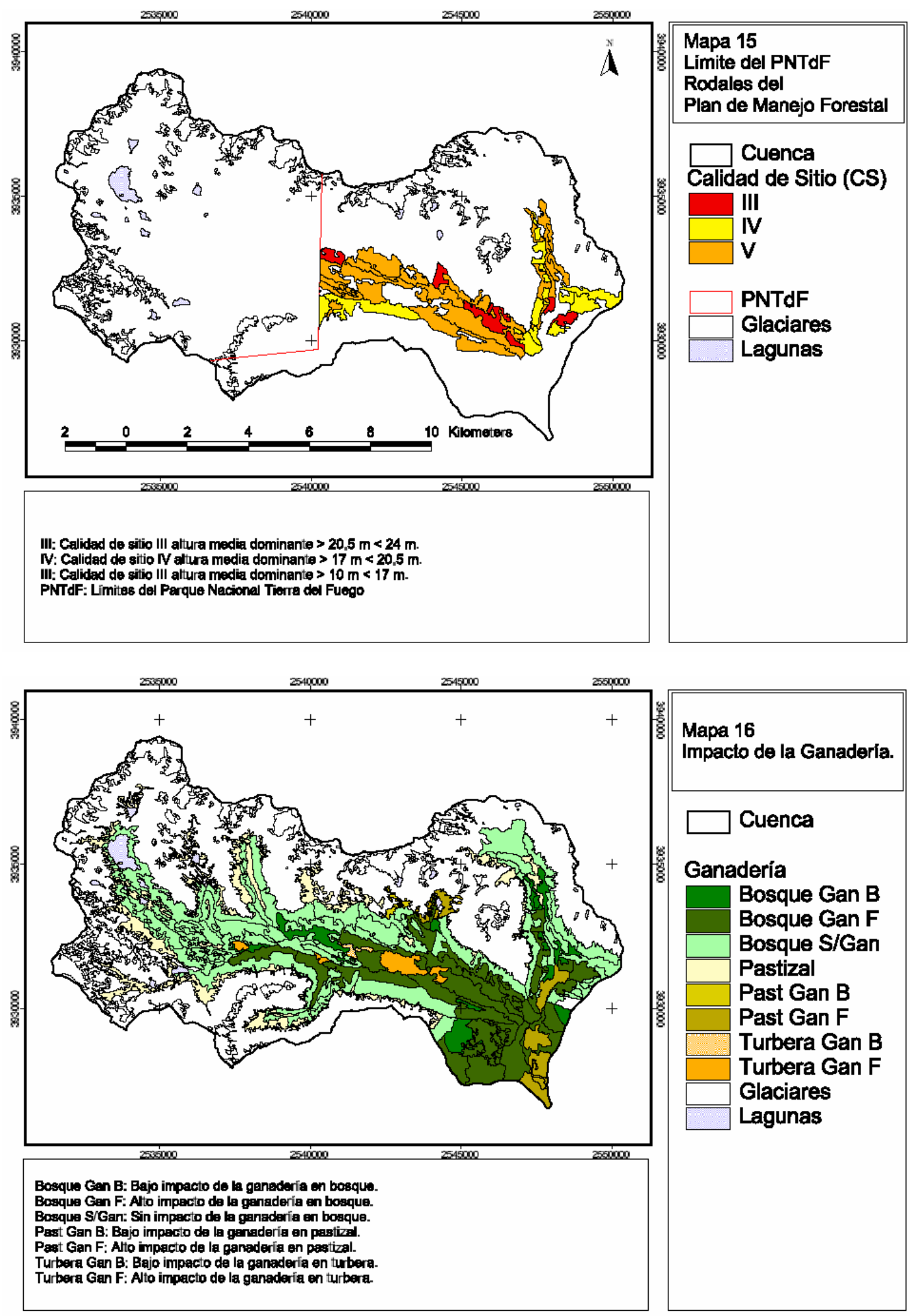




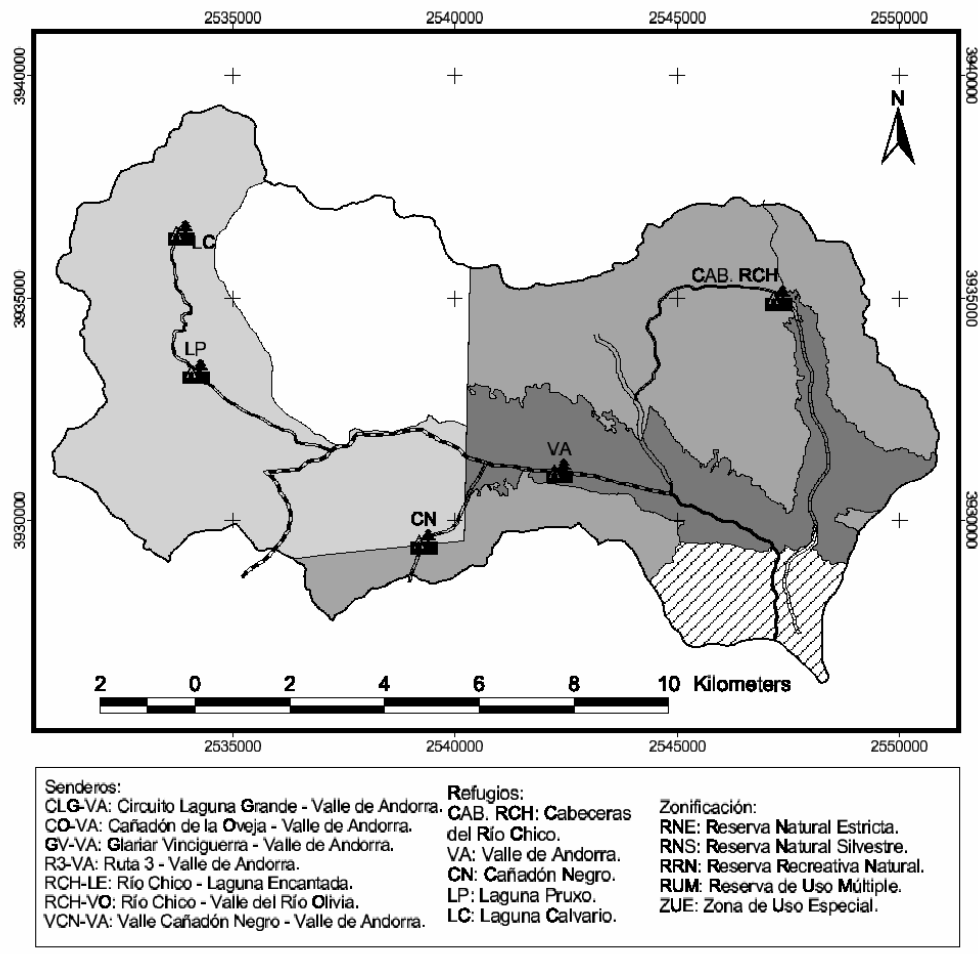

Mapa 17

Zonificación

Senderos y Refugios

Senderos

CLG-VA

A CO-VA

GV-VA

R3-RCH

RB-VA

RCH-LE

RCH-VO

N VCN-VA

Refugios

Zonificacion

RNE

RNS

RRN

RUM

ZUE

Cuenca

Glaciares

Lagunas

Rios 
Cita:

Magister Scientiae en Manejo Integral de Cuencas Hidrograficas, orientación Manejo sustentable de los recursos naturales en cuencas de montaña. Tesis: Estado y propuesta de manejo de los recursos naturales de la cuenca del Arroyo Grande, Tierra del Fuego 160 pp + 17 mapas Expediente 200-4295. Facultad de Ciencias Agrarias y Forestales UNLP. 2001-2006. Director: Gerardo Denegri, Co-Director: Guillermo Martínez Pastur. Expediente. 200-4295. Nota: 9. Categorizada "Bn" (Resol. CONEAU No: 491/05). 